SCHOOL OF CIVIL ENGINEERING

JOINT HIGHWAY
RESEARCH PROJECT JHRP-76-25

BLOW-UPS ON RESURFACED CONCRETE PAVEMENTS

D. L. Gress 
Digitized by the Internet Archive in 2011 with funding from

LYRASIS members and Sloan Foundation; Indiana Department of Transportation 


\section{BLOW-UPS ON RESURFACED CONCRETE PAVEMENTS}

T0: J. F. McLaughlin, Director Joint Highway Research Project

FROM: H. L. Michael, Associate Director Joint Highway Research Project
August 3,1976 Revised August 1977 Project: $\quad C-36-460$ File: $5-11-15$

The attached Final Report is submitted on the JHRP research study entitled "Pavement Blow-ups and Resurfacing". The Report is titied "Blow-ups for Resurfaced Concrete Pavements" and has been authored by D. L. Gress. An Executive Summary report covering the entire project is included. An Interim Report by P. T. Foxworthy, "Statewide Survey of Blowups in Resurfaced Concrete Pavements" was made as JHRP Report No. 3, February 1973. All the reports were prepared under the direction of the principal investigators, Professors W. L. Dolch, C. F. Scholer arid E. J. Yoder.

One result of overlaying a concrete paverifent ihat was concluded by the research is that such action increases its probability of having blow-ups distress. The causes are not due to greater temperature or to increase in the coefficient of thermal expansion but due to a general increase in the moisture content and its accompanying expansion combined with the thermal expansion characterization of concrete.

The cooperation of the Indiana State Highway Commission in many phases of this research investigation is acknowledged with sincere appreciation to the many individuals involved.

The report is submitted for approval.

Respectfuliy submitted,

$H L M: m s$

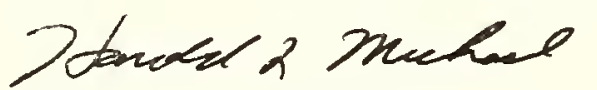

Harold L. Michael

Associate Director
CC: W. L. Dolch
K. R. Hoover
C. F. Scholer
R. L. Eskew
G. A. Leonards
M. B. Scott
G. D. Gibson
R. F. Marsh
K. C. Sinha
W. H. Goetz
R. D. Miles
C. A. Venable
M. J. Gutzwiller
P. L. Owens
G. K. Hallock
G. T. Satterly
L. E. Wood
E. J. Yoder
D. E. Hancher
S. R. Yoder 


\section{Final Report \\ BLOW-UPS ON RESURFACED CONCRETE PAVEMENTS}

by

David L. Gress

Graduate Instructor in Research

Joint Highway Research Project

Project No.: C-36-460

File No.: $5-11-5$

Prepared as Part of an Investigation

Conducted by

Joint Highway Research Project

Engineering Experiment Station

Purdue University

in cooperation with the

U.S. Department of Transportation

Federal Highway Administration

The contents of this report reflect the views of the author who is responsible for the facts and the accuracy of the data presented herein. The contents do not necessarily reflect the official views or policies of the Federal Highway Administration. This report does not constitute a standard, specification, or regulation.

Purdue University

West Lafayette, Indiana

August 3, 1976

Revised August 1977 
TECHNICAL REPORT STANOARO TITLE PAGE

\begin{tabular}{|c|c|c|}
\hline $\begin{array}{l}\text { 1. Roport No. } \\
\text { JHRP }-76-25\end{array}$ & 2. Govornment Accession No. & 3. Recipient' = Catolog No. \\
\hline \multirow{2}{*}{\multicolumn{2}{|c|}{$\begin{array}{l}\text { 4. Tirlo and Subtifle } \\
\text { BLOW-UPS ON RESURFACED CONCRETE PAVEMENTS }\end{array}$}} & \multirow{2}{*}{$\begin{array}{l}\text { 5. Roport Dolo Aug. } 1976 \\
\text { Revised Aug: } 1977 \\
\text { 6. Performing Orgonizotion Codo }\end{array}$} \\
\hline & & \\
\hline \multicolumn{2}{|l|}{$\begin{array}{l}\text { 7. Author(s) } \\
\text { David L. Gress }\end{array}$} & $\begin{array}{l}\text { 8. Porforming Orgonizofion Roport No. } \\
\text { JHRP }-76-25\end{array}$ \\
\hline \multirow{3}{*}{\multicolumn{2}{|c|}{$\begin{array}{l}\text { 9. Peeforming Organization Nome ond Addras } \\
\text { Joint Highway Research Project } \\
\text { Civil Engineering Building } \\
\text { Purdue University }\end{array}$}} & \multirow{2}{*}{$\begin{array}{l}\text { 10. Work Unir No. } \\
\text { 11. Controet or Gront No. } \\
\text { HPR-1 (13) Part II }\end{array}$} \\
\hline & & \\
\hline & & \multirow{2}{*}{$\begin{array}{l}\text { 13. Typo of Report ond Poriod Covered } \\
\text { Final Report }\end{array}$} \\
\hline \multirow{2}{*}{\multicolumn{2}{|c|}{$\begin{array}{l}\text { 12. Sponsoring Agency Nome ond Addres: } \\
\text { Indiana State Highway Commission } \\
\text { State Office Building } \\
\text { loo North Senate Avenue } \\
\text { Indianapolis, Indiana } 46204\end{array}$}} & \\
\hline & & 14. Sponsoring Ageney Code \\
\hline
\end{tabular}

15. Supplomontory Nores cooperation with the U.S. Department of Transportation,

Federal Highway Administration.

From the Study "Pavement Blow-ups and Resurfacing".

16. Abstroct

The objective of this study was to determine if overlaying a concrete pavement significantly influences blow-up performance and to isolate those variables that affect blow-up distress.

The conclusions of this study were based upon the results of a statewide survey of overlaid pavement blow-ups and related factors of the field testing of a bare pavement and an overlayed pavement and laboratory testing of pavement cores taken from various Indiana pavements.

The field testing of the bare pavement and overlayed pavement consisted of monitoring deformation, temperature and moisture as a function of time. Moisture contents were determined by utilizing newly developed moisture gauges imbedded within the concrete pavements.

The laboratory testing consisted of a microscopic anaiysis, and the determination of thermal and moisture properties of selected pavement field cores. The microscopic testing included compositional analysis, general physical condition investigation, and the detection and measurement of infiltration of polished sections taken from the field pavement cores. Coefficients of thermal expansion for the oven dry and twentyfour hour saturation moisture states and the effect of moisture on expansion were determined on selected field pavement cores using a special heating chamber in conjunction with a sensitive deformation measuring system.

17. Koy Wards 18 . Distribution Stotement

Pavement, portland cement concrete, No restrictions. This document overlays, blow-up, maintenance, is available to the public through moisture content, coef. of the National Technical Information thermal expansion Service, Springfield, Virginia 22161

\begin{tabular}{|l|c|c|c|}
\hline $\begin{array}{l}\text { 19. Security Cloasif. (of this report) } \\
\text { Unciassified }\end{array}$ & $\begin{array}{c}\text { 20. Socurity Clossif. (of thio pogo) } \\
\text { Unclassified }\end{array}$ & $\begin{array}{c}\text { 21. No. of Pogoe } \\
128\end{array}$ & 22. Price \\
\hline
\end{tabular}




\section{BLOWUPS ON RESURFACED CONCRETE PAVEMENTS}

The pavement blow-up, be it large or small, results in a bump which is at the very best, uncomfortable and possibly dangerous to vehicular traffic. The term is applied to all bumps caused by compressive stresses resulting from heat, water or other causes and generally occur at a joint or crack. The bump itself occurs when the compressive stress within the pavement causes buckling and/or faulting of the pavement, or when they cause crushing and the broken material is extruded vertically causing a bump in the riding surface. More refined classifications of blow-ups were made in this project's interim report, by Foxworthy.* Blow-ups occur on both bare and on resurfaced pavements. This project primarily concerned itself with resurfaced pavements.

Foxworthy's survey (1) identified the major factors that contribute to blow-ups of resurfaced pavements. These were listed in the summary of that interim report and were as follows:

1. Insofar as influencing blow-ups on resurfaced. concrete pavements is concerned, the factors of pavement design, base, and age of the original pavement are all interrelated. The data suggest that present design and construction practices are superior to those of the past in preventing blow-ups.

*Foxworthy, Paul T., Statewide Survey of.Blowups in Resurfaced Concrete Pavements", JHRP Report No. 3, February 1973. (An interim report on this project). 
(a) All other factors being equal, the data indicate that original pavement design is a major factor as a contributor to blow-ups. For example, pavements built between 1941 and 1944 with short joint spacing and no steel depart from the previously established trend of improving performance as design changes were made. These pavements have the highest mean number of blow-ups per mile and the lowest per cent of miles of road with no blow-ups.

(b) The addition of a granular base beneath concrete pavements in 1946 has substantially improved their performance. This is due, at least in past, to the increased drainage capability provided by the base, thus reducing the moisture present beneath the pavement.

(c) Blow-up activity increased as the age of the original pavement increased. This trend continued for pavements up to 40 years old with older pavements showing no preference for high or low blow-up occurrence.

2. Crushed stone as a coarse aggregate in concrete pavements has shown slightly better performance overall as compared to gravel. However, both types have shown variable performance. The actual source of the material should be given primary consideration when choosing materials.

3. Pavements built on subgrades of residual soils showed fewer blow-ups than those on other soil types, and those built through terminal morraines had the highest 


\section{blow-up occurrences. Other soil types showed little differences in performance.}

4. Weather, winter maintenance (salting and sanding), and soils seem to interact in the district factor, with blow-ups occurring at higher frequencies in the northern portion of the state than in the southern part.

5. Paved shoulders are significant in reducing blow-ups.

6. Blow-up activity starts very soon after the pavement is overlaid, and the percentage of roads with more than four blow-ups per mile increased with age of the overlay.

A factor which appeared to have little effect on blow-up occurrence was overlay thickness.

Accompanying this project summary is a report by D. L. Gress, "Pavement Blow-ups and Resurfacing", in which similar portions of a concrete pavement were instrumented and measured both with and without an overlay. Cores were taken from additional pavements selected from the comprehensive survey compiled by Foxworthy and careful laboratory measurements made of their coefficient of linear expansion and an analysis made of the concrete's composition.

Temperature and moisture data was obtained and is shown with the measured weather data and with expansion measurements made on the instrumented pavements. These measurements extend thru the total climatic variation experience in Indiana. Gress's work made use of a simple hence a highly effective and efficient method of measuring dimensional changes of the slab. He also further developed a moisture measuring device 
and successfully applied it to enable the concrete's degree of saturation to be internally measured. No existing method was satisfactory. Although his gauges may not be ideal they did give valuable information not otherwise obtainable. Specifically they measured the distribution of moisture within slabs of concrete, both bare and overlaid.

Moisture was shown by Gress's work to be an important factor in the blow-ups behavior of concrete. This contributes some understanding to findings of Foxworthy's field survey and by the observations of others in the field. Gress shows the moisture distribution under an overlay and relates its changes to dimensional changes. This was also established by laboratory measurements.

Temperatures were also measured but similar data has been obtained by other investigators.

In obtaining cores of selected pavements around the state a number of joints were cored, but by no means all of the joints were cored. The findings showed that considerable infiltration had occurred in some joints. No statistical correlation could be found between blow-ups and the infiltration of joints. It should be pointed out that Gress's last conclusion, "Infiltration cannot be demonstrated to be significantly related to blow-up distress", should be taken as it is stated and not construed to mean that such a relationship does not sometimes exist. A much more extensive coring program would be required to clarify this question.

The total effect of overlaying a concrete pavement is to increase its probability of having blow-ups distress. The causes 
as developed by Gress are not due io greater temperature or to increase in the coef. of thermal expansion. The principal cause appears to be a general increase in the moisture content and its accompanying expansion combined with the thermal expansion characterization of the concrete.

The overlaid pavements became critically saturated for a considerable time in the winter. The consequence of this on cement paste and aggregate as it undergoes the freeze-thaw cycles of a winter are obvious. A concrete may have been resistant in the lower degree of saturation, yet may fail at the larger degree saturation. D-cracking coarse aggregates would especially be subject to this acceleration of deterioration due to overlaying.

It is believed, by the principal investigators, that a substantial number of the small blow-ups, such as are called high joints in overlaid pavements, are caused by the deterioration of the concrete under the combination of compressive stresses, and aggravated freeze-thaw exposure due to the increased moisture resulting from overlaying the pavement.

A goal of this project was to make recommendations for corrective procedures as well as diagnostic methods to indicate the likelihood of blow-ups occurring.

The results are not definitive enough to allow quantitative measurements to be judged as an accept or reject system for evaluating a potential pavement for overlay. Instead the common nemesis of pavements, moisture, must be considered. Everything that will reduce moisture will tend to reduce the likelihood 
of blow-ups. This was shown by Foxworthy's survey of Indiana pavements. A further aid in reducing blow-ups is the survey itself which should be kept up and will identify material which are more prone to blow-ups. This is commonly done by experience but the documentation should help make it more generally acceptable and understood. 


\section{ACKNOWLEDGEMENTS}

The author wishes to express his appreciation to Dr. W1lliam L. Dolch and Dr. Charles F. Scholer for their invaluable guidance and support during the conduct of this research. The statistical consultation form Dr. Virgil Anderson is very much appreciated.

The assistance in field site preparation, field testing, sample preparation and laboratory testing from Mr. Max Anthis and Mr. Chip Locke 1 s greatly appreciated.

The author extends special thanks to his wife, whom without her this study would not have been possible, for her assistance in testing, data reduction, typing and for her endiess patience throughout the course of the study. 
TABLE OF CONTENTS

Page

LIST OF TABLES . . . . . . . . . . . . . v

LIST OF FIGURES. • . . . . . . . . . . . . . . . v11

PREFACE. . . . . . . . . . . . . . . . . . $\mathrm{x}$

INTRODUCTION . . . . . . . . . . . . . . I

LITERATURE REVIEW. . . . . . . . . . . . . 3

FIELD TESTING. . . . . . . . . . . . . . . 7

Site Selection. . . . . . . . . . . . 9

Site Preparation. . . . . . . . . . . . . 10

Measurement Techniques. . . . . . . . . . . 11

Deformation. . . . . . . . . . . . . . II

Temperature. . . . . . . . . . . . 17

Moisture ............... . 17

Procedure . . . . . . . . . . . . . 25

Data coliection. . . . . . . . . . 25

Data Analysis............... . . . 38

Vertical Moisture Variation. . . . . . 38

Horizontal Moisture Variation. . . . . . 44

Deformation and Strain ......... . 49

Coefficient of Thermal Expansion... . . 58

LABORATORY TESTING . . . . . . . . . . . 72

Coring Scheme . . . . . . . . . . . . 72

Test Core Analysis. . . . . . . . . . . 75

Composition. . . . . . . . . . . . . 76

Physical Condition... . . . . . . . . 79

Infiltration . . . . . . . . . . . 9 96

Thermal Expansion . . . . . . . . . . . 102

Linear Variabie Differentiai Transformer: : 104

Heating Chamber. . . . . . . . . . . 105

Tripod . . . . . . . . . . . . . 107

Sample Support and Extension Rod..... . 108

Testing Technique. ............. 110

Test Cores . . . . . . . . . . . . 112

Moisture Expansion. . . . . . . . . . . 115 
TABLE OF CONTENTS (Con'd.)

Page

Test Cores............. 116

SUMMARY. • • . • . . . • . . . . . . . . 120

Fleld Testing . . . . . . . . . . . . . 120

Laboratory Testing of Pavement Cores. . . . . . 122 CONCLUSIONS. . . . . . . . . . . . . . . . . . 124 CONCLUDING COMMENTARY. . . . . . . . . . . . . 126 LIST OF REFERENCES . . . . . . . . . . . . . . . 128

APPENDIX . . . . . . . . . . . . . . . . . . . 131

Appendlx A. . . . . . . . . . . . . . . . . 128

Field Testing Error of Measurement . . . . 128

Appendix B. . . . . . . . . . . . . . 140

Molsture Gauge Design.......... 140

Appendix C. . . . . . . . . . . . . . . 154

Molsture Probe Calibration Data and

Field Data............ . . . 160

Appendix E. . . . . . . . . . . . . . 167

Cherry Lane Moisture Data. . . . . . . 167

Appendix F. . . . . . . . . . . . . 174

Dally Precipitation. .......... . 174

Appendix G. . . . . . . . . . . . . . . . . 177

Test Core Information. . . . . . . . . 177 
LIST OF TABLES (Con'd.)

Appendix

Table

Page

A6. Ball System Data... . . . . . . . . 164

A7. Ball System Data............. . 166

A8. Average Daily Degree of Saturation . . . . . 167

A9. Purdue Agronomy Farm Daily Precipitation . . . 174 A10. Test Core Information. . . . . . . . . . 177 


\section{LIST OF PIGURES}

Figure

Page

1. Details of the Ball System . . . . . . . . 12

2. Deformation Measurement Position of

the Ball System. . . . . . . . . . . . 14

3. Location of Ball Systems BI Through B8 . . . . 15

4. Base Lengths Between Side Mounted Balls. . . . 16

5. Tyoical Moisture Gauge . . . . . . . . . 20

6. Typical Moisture Probe . . . . . . . . . 21

7. Wiring Diagram for the Determination of

Degree of Saturation... . . . . . . . 23

8. Temperature Change Versus Degree of Saturation for Molsture Probe 3-B Gauge Number 1. . . . . . 26

9. Temperature Change Versus Degree of Saturation for Moisture Probe 3-0 Gauge Number 4. . . . . 27

10. Temperature Change Versus Degree of Saturation for Moisture Probe 3-B Gauge Number 3. . . . . 28

11. Temperature Change Versus Degree of Saturation for Molsture Probe 1-B Gauge Number 4. . . . . 29

12. Calibration Curve for Moisture Probe 1-B. . . 30

13. Calibration Curve for Moisture Probe 2-B. . . 31

14. Calibration Curve for Moisture Probe 3-B. . . . 32

15. Calibration Curve for Moisture Probe 1-0. . . 33

16. Calibration Curve for Moisture Probe 2-0... . 34

17. Calibration Curve for Moisture Probe 3-0 . . . 35

18. Location of Moisture Probes. . . . . . . 36 


\section{LIST OF FIGURES (Con'd.)}

Figure

Page

19. Degree of Saturation Versus Time for

Position 3, Gauges 1 and 2 . . . . . . . . .

20. Degree of Saturation Versus Time for

Position 3, Gauges 3 and 4 . . . . . . . .

21. Degree of Saturation Versus Time for

Position 3, Gauges 1 and 2......... . 40

22. Degree of Saturation Versus Time for

Position 3, Gauges 3 and 4.......... 40

23. Degree of Saturation Versus Time for

Position 3, Gauges 1 and 2.......... . 41

24. Degree of Saturation Versus Time for

Position 3, Gauges 3 and 4.......... 4 I

25. Degree of Saturation Versus Time for

Position 3, Gauges 1 and 2 . . . . . . . . 42

26. Degree of Saturation Versus Time for

Position 3, Gauges 3 and 4 . . . . . . . 42

27. Average Degree of Saturation Versus Time

for the Overlayed Pavement . . . . . . . . . 47

28. Average Degree of Saturation Versus Time

for the Overlayed Pavement . . . . . . . . . .

29. Average Degree of Saturation Versus Time

for the Overlayed Pavement . . . . . . . . 48

30. Average Degree of Saturation Versus Time

for the Overlayed Pavement . . . . . . . . . 48

31. Precipitation and Strain Versus Time . . . . . . 50

32. Precipitation and Strain Versus Time . . . . . 50

33. Precipitation and Strain Versus Time . . . . . . 51

34. Degree of Saturation, Precipitation and

Strain Versus Time . . . . . . . . . . 51

35. Degree of Saturation, Precipitation and

Strain Versus Time . . . . . . . . . . . 52 
LIST OF FIGURES (COn'd.)

Figure

Page

36. Degree of Saturation, Precipitation and Strain Versus Time . . . . . . . . . . . 52

37. Degree of Saturation, Precipitation and Strain Vorsus Time . . . . . . . . . . . 53

38. Precipitation and Coefficient of Thermal Expansion Versus Time. . . . . . . . . . 63

39. Degree of Saturation, Precipitation and Coefficient of Thermal Expansion Versus Time . . . 65

40. Apparent Thermal Coefficient Versus Relative Humidity . . . . . . . . . . . . . 68

41. Apparent Thermal Coefficient Versus Degree of Saturation. . . . . . . . . . . . . 69

42. Details of Heating Chamber . . . . . . . . . 105

Appendix

Figure

Al. Pavement Warping for a Negative Temperature Gradient . . . . . . . . . . . . . . . 133

A2. An Element Subjected to a Negative Temperature Gradient ................. . . 133

A3. The Relationship Between the Vertical

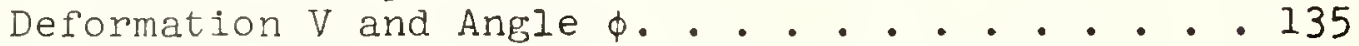

A4. The Relationship Between the Error Term and the Vertical Deformation . . . . . . . . 135

A5. Theoretical Temperature Change Versus Water/ Cement . . . . . . . . . . . 147

A6. Theoretical Temperature Change Versus Aggregate Content. . . . . . . . . . . 148

A]. Theoretical Diffusivity Versus Water/Cement. . . 150

A8. Theoretical Diffusivity Versus Aggregate Content. 


\section{PREFACE}

This research project included an extensive statewide survey of rigid pavements which had received one or more flexible, bituminous, overlays. The information resulting from the survey was subjected to analysis to identify factors which are important contributors to blow-ups in resurfaced pavements. It was also used to identify particular pavements for further investigation and sampling for detailed laboratory investigation.

The statewide survey was reported in an interim report by P. T. Foxworthy (10), "Statewide Survey of Blow-ups in Resurfaced Concrete Pavements", J.H.R.P. Report No. 3, February 1973.

A laboratory investigation was also made upon samples obtained by coring at field locations determined from the data of the statewide survey. This work is reported in detail in this Final Report, pp. 72-118.

Aside from the performance aspects attributable to the materials and conditions of the pavement, an important part of a rigid pavement's volume change will always occur due to thermal and moisture changes. The extent is related to the materials involved but the characteristic behavior occurs irregardless of the material. The field testing was to measure the change in characteristic behavior, over a season, of a section of pavement part of which had overlay and part bare. Insofar as 
possible, these were the only variables. Moisture and temperature gradient were measured as were the physical dimensions and position of the pavements involved. This did not directly relate to the statewide survey but was important to the full understanding of the behavior of concrete pavement slabs, both bare and with overlay. This work is reported in this Final Report, pp. 7-71. 


\section{INTRODUCTION}

Blow-ups of portland cement concrete pavements have been a serious problem encountered by the Indiana state Highway Commission and other highway departments for many years. These blow-ups are sometimes hazardous to the road user and are detrimental to the riding quality of the pavement. They also require expensive corrective maintenance. Blow-ups continue to develop after a concrete pavement is resurfaced with a bituminous overlay. There are some grounds, also, for a belief that blow-up activity is increased by the resurfacing, although the problem has not been investigated prior to this investigation.

The use of bituminous overlays on portland cement concrete has been common practice for upgrading deteriorating pavements. With the completion of the Interstate Highway System many miles of pavement will eventually have to be resurfaced. Although overlaying is extensively used in maintenance, its complete success is open to speculation for certain pavements, because of the blow-up probiem as well as other difficulties, such as reflection cracking and freeze-thaw deterioration under the resurfacing. These problems are naturally interrelated, because cracking increases the access of water to the underlying pavement, 
and aggregates that give blow-up susceptible pavements are also frequently poor in freeze-thaw behavior. 


\section{LITERATURE REVIEW}

The causes of blow-ups are somewhat speculative. The slab expands longitudinally. This causes it to hump up or arch at some weak point, generally a transverse joint or crack. The rise is from a rraction of an inch to more than a foot, and there is cracking and shattering dependent on the extent and character of the expansion and on other conditions, such as slab strength. Frequent vertical or alignment curves appear like bends in a steam pipe, to take up the expansion without disruptive movement ( 1$)^{*}$.

"The most frequent occurrence of blow-ups is when a hot day is followed by a rainy night succeeded by another hot day, causing both temperature and moisture expansion". Although this statement (I) was published fifty years ago, it has significance today. Surveys have shown that blowups occur predominately in mid-afternoon at a temperature in excess of $90^{\circ} \mathrm{F}$ which period was usually preceded by varying amounts of rain $(2,3,4,5,6)$.

Extensive field performance surveys and studies $(2,7,8,9)$ of concrete pavements have shown correlation to exist between coarse aggregates used in the concrete and

\footnotetext{
* Numbers in parentheses refer to references ilsted in the
} List of References. 
the blow-up performance of the pavements. However, other studies $(5,10)$ have not shown such a correlation, but the possibility could not be disproven.

To date, work in this area has been qualitative and empirical and has not resulted in an understanding of the blow-up mechanism. It is known that temperature and moisture content of the concrete affect blow-ups, but the quantitative relationships of these variables as they affect the expansion of concrete is not well understood.

The coefficient of thermal expansion of the concrete is obviously a predominate factor. It is proportional to the individual coefficients of the components of the concrete (the cement paste, the fine aggregate, and the coarse aggregate) and to their volume proportion in the concrete. A small overall coefficient is, presumably, desirable in preventing blow-ups. The small amount of work to date (11) suggests, at least for Indiana aggregates, that limestone coarse aggregates with relatively small thermal expansion coefficients are more associated with blow-up fallures than are gravels with siliclous components of a higher coefficient. These findings are obviously contrary to the simple assumptions of the expansion process.

With respect to the hardened cement paste component, the thermal coefficient has been shown to be related to the water content, with intermediate values giving a higher coefficient than that of either dry or saturated pastes 
$(12,13)$. Although the thermal coefficient of cement and concrete has been shown to be some function of molsture and temperature $(14,15,16,17,18,19,20)$, the relationships between all these factors and the susceptibility of a pavement to blow-ups is still largely conjectural.

It is possible that all pavements are potentially susceptible to blow-ups. Perhaps if the temperature and moisture content were increased to some critical level the pavement would leave its dormant state and become just as bad concerning blow-up performance as the pavements with the now condemned aggregates. This possibility is the result of previous work $(22,23)$ concerning an increase of blow-ups with the advent of concrete resurfacing. The cause was probably not due to an increase of temperature, since the new surface was of similar material to the old, but the moisture content may have increased. A flowing film of water was found by Gotham and Lord (23) at several places between the two layers of concrete. This was noticed when normal maintenance required cutting a section in the pavement.

Another variable just as 1mportant for some pavements as those already mentioned is the functioning of the joints. One premise is that blow-ups occur because incompressible materlal lodges in open joints and cracks and restricts subsequent expansion and causes disruptive stresses (2I). Poor performance of joint sealant compounds is suspected of 
being a primary cause of surface infiltration (6). Field inspections of pavement blow-ups have shown the presence of joint infiltration $(3,4)$. This action may be responsible for many blow-ups, but it does not explain why a pavement can become blow-up susceptible after being resurfaced. Therefore joint failures do not themselves preclude other mechanisms also coming into play. The whole picture is probably one of combined influences playing their parts. 
FIELD TESTING

The coefficient of thermal expansion of a porous material is a function of its moisture content. Meyers has shown the coefficient of thermal expansion of a cement paste to vary by a factor of two for some relative humidity between zero and 100 percent, where the coefficients are approximately equal (12). The maximum increase in the coefficient of thermal expansion occurs at approximately 75 percent relative humidity. Since cement paste is a porous material and a component of concrete, the thermal expansion of concrete is a function of its moisture content. Most aggregates are not porous compared with cement paste; therefore, their coefficients of thermal expansion are not a function of moisture content. In light of the above, the aggregate component lessens the effect of changing moisture content on the thermal expansion of concrete. Assuming a linear law of composition holds for concrete, the coefficient of thermal expansion $\alpha_{T}$ can be calculated as

$$
\alpha_{\mathrm{T}}=\left(\% \text { Paste } \mathrm{x} \alpha_{\mathrm{TP}}+\% \text { Aggregate } \mathrm{x} \alpha_{\mathrm{TA}}\right) / 100
$$

where $\alpha_{T P}$ is the coefficlent of thermal expansion of the paste and $\alpha_{T A}$ is the coefficient of thermal expansion of the aggregate component. 
If $\alpha_{\mathrm{TA}}=\frac{1}{2} \alpha_{\mathrm{TP}}$, which is a reasonable assumption, the above equation expressed in terms of $\alpha_{\mathrm{TA}}$ becomes

$$
\alpha_{\mathrm{T}}=\left(\% \text { Paste } \times 2 \alpha_{\mathrm{TA}}+\% \text { Aggregate } \times \alpha_{\mathrm{TA}}\right) / 100
$$

A typical concrete pavement contains approximately 20 percent paste and 80 percent aggregate. These values result in a concrete with a coefficient of thermal expansion of

$$
\begin{aligned}
\alpha_{\mathrm{T}} & =.20 \times 2 \alpha_{\mathrm{TA}}+.80 \alpha_{\mathrm{TA}} \\
& =1.20 \alpha_{\mathrm{TA}}
\end{aligned}
$$

A maximum coefficient is expected at approximately 70 to 80 percent relative humidity and can be calculated by substituting the $\alpha_{T P}$ value at this relative humidity into the equation. This gives

$$
\begin{aligned}
\alpha_{\mathrm{T}_{\operatorname{Max}}} & =.20 \times 4 \alpha_{\mathrm{TA}}+.80 \alpha_{\mathrm{TA}} \\
& =1.60 \alpha_{\mathrm{TA}}
\end{aligned}
$$

The maximum percent difference of the coeffictent of thermal expansion of concrete to be expected is

$$
\begin{aligned}
\operatorname{Max} \Delta \alpha_{\mathrm{T}} \% & =\frac{1.60 \alpha_{\mathrm{TA}}-1.20 \alpha_{\mathrm{TA}}}{1.20 \alpha_{\mathrm{TA}}} \times 100 \\
& =33 \%
\end{aligned}
$$

Therefore the maximum difference that is expected for a typical concrete pavement under the most adverse molsture conditions is 33 percent.

A premise of increased blow-up activity for an overlayed pavement versus a bare pavement is that the asphalt 
forms a barrier on the surface of the pavement, causing an internal moisture increase. This increased moisture state not only increases the coefficient of thermal expansion, a maximum of perhaps 33 percent as noted above, but will also increase the internal strain of moisture expansion. The net result is an increase in the length of the pavement slab and also an increased response to length change caused by fluctuating temperatures. This in turn reduces the joint openings if the joint were originally open, or increases the stress level within the slab if the joint openings were closed or filled by infiltration. As shown by Euler's column buckling analogy, when the stress level reaches a certain level a blow-up can occur. Therefore it is possible these conditions could result in a pavement blow-up. An approach to analyzing such a premise is to observe an actual pavement system. Variables to monitor include change in length, temperature, and molsture content for both an overlayed pavement and a bare pavement under common environmental conditions.

\section{Site Selection}

Ideally to test the above premise two pavement slabs should be selected that abut each other, in order to maintain constant environmental conditions. This was not possible because traffic was to be maintained as normal and an asphalt wedge was required to create a reasonably smooth 
transition between the bare section and the overlayed section.

An area was found that contained two relatively long uncracked slabs separated by ample distance to build a satisfactory asphalt transition wedge. For all practical. purposes, the slabs were close enough together to be subject to the same environmental conditions. This area was found on State Road 126, locally known as Cherry Lane, in West Lafayette, Indiana. State Road 126, hereafter referred to as Cherry Lane, was constructed in 1957. The design specifications required the slab to be eight inches thick, construction joints only, no steel except for tie bars, and they allowed the use of salvage material for the base material. Concrete mix specifications were in accordance with the 1952 Standard Specifications for Road and Bridge Construction and Maintenance of the Indiana State Highway Commission. These specifications required six bags of cement per cubic yard, with a maximum of 5.5 gallons of water per bag of cement, slump between one and three inches and an air content between three and six percent.

\section{Site Preparation}

Preparations toward making Cherry Lane a test road began in the Spring of 1973. Four expansion joints were cut across the full width and depth of the pavement to make the slabs independent of each other and of the remaining pavement not included in the test section. These joints 
were four inches wide. A pre-formed expansion material was placed in each. This was done by the Indiana State Highway Commission and was in accordance with their maintenance procedures for relieving pressures in bridge approach pavements. During July 1974 one test slab was overlayed with 1.25 inches of surface mix asphalt, while the other was left bare.

\section{Measurement Techniques}

\section{Deformation}

Several methods of measuring strains in the field were possible, but no single method had the necessary properties of long term stability, accuracy and simplicity. Therefore a new method of measuring strains was devised. This method, referred to as the ball system, is capable of measuring vertical as well as horizontal deformations, as a function of environmental changes. The ball system proved to give reliable measurements of deformations with sufficient accuracy to calculate a coefficient of thermal expansion. Appendix A contalns an analysis of the maximum error to be expected for the ball system method of measuring deformation.

Details of the ball system are shown in Figure 1. This system consists of three one-quarter inch diameter stainless steel balls, two mounted on top of a four foot rod driven in the subgrade near the edge of the pavement and one mounted on the edge of the concrete pavement. The construction 
殅岕
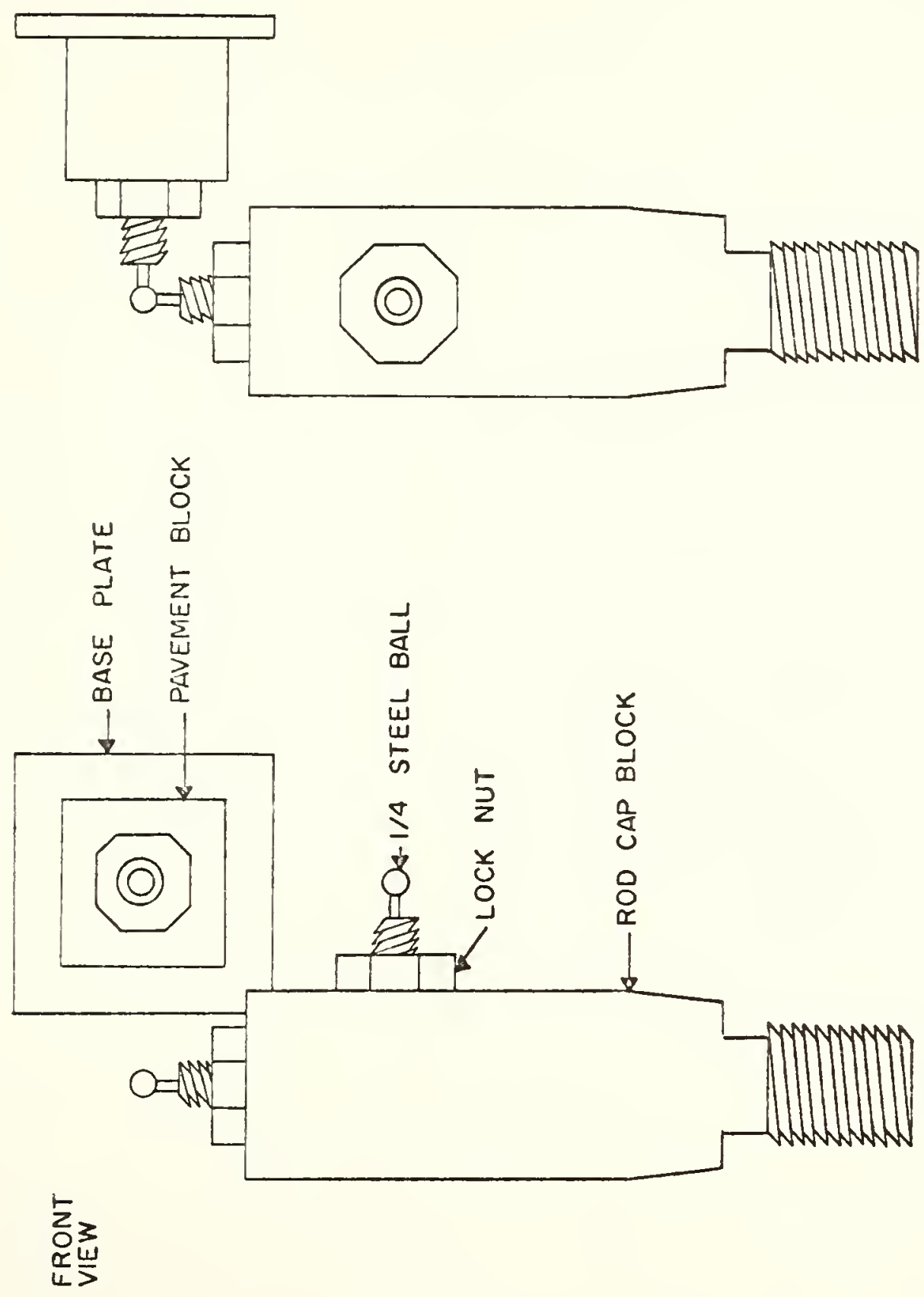
balls were pressed into a threaded rod, which was screwed into the rod and pavement blocks, and secured in place with a lock nut. The rod cap block was tightly screwed into the top of the four foot rod. The pavement block was held in place by a lead anchor rigidly secured at the centerline of the pavement's edge. An aluminum base plate was used to separate the pavement block from the pavement to compensate for surface irregularities and oversized anchor holes. All parts were made of stainless steel except for the aluminum base plate and the four foot steel rod. Longitudinal deformation corresponds to a change in Position 1 as shown in Figure 2. Vertical deformation likewise corresponds to a change in Position 2. Both Position 1 and Position 2 were measured using a micrometer with a non-rotating shaft and capable of reading to 0.0001 inches.

A one-half inch thick steel plate supported by two sections of channel iron driven into the subgrade provided ample protection of the ball system from traffic. The top steel plate was covered with shoulder material to minimize the possibility of vandalism.

Three ball systems were installed along the edge of each test $s l a b$, one on each end and one in the center. One additional system was placed on the slab closest to the test slabs. These were labeled BI through B8 and are as shown in Figure 3. The base distances between the side mounted balls for the bare and overlayed test sections are shown in Figure 4. 

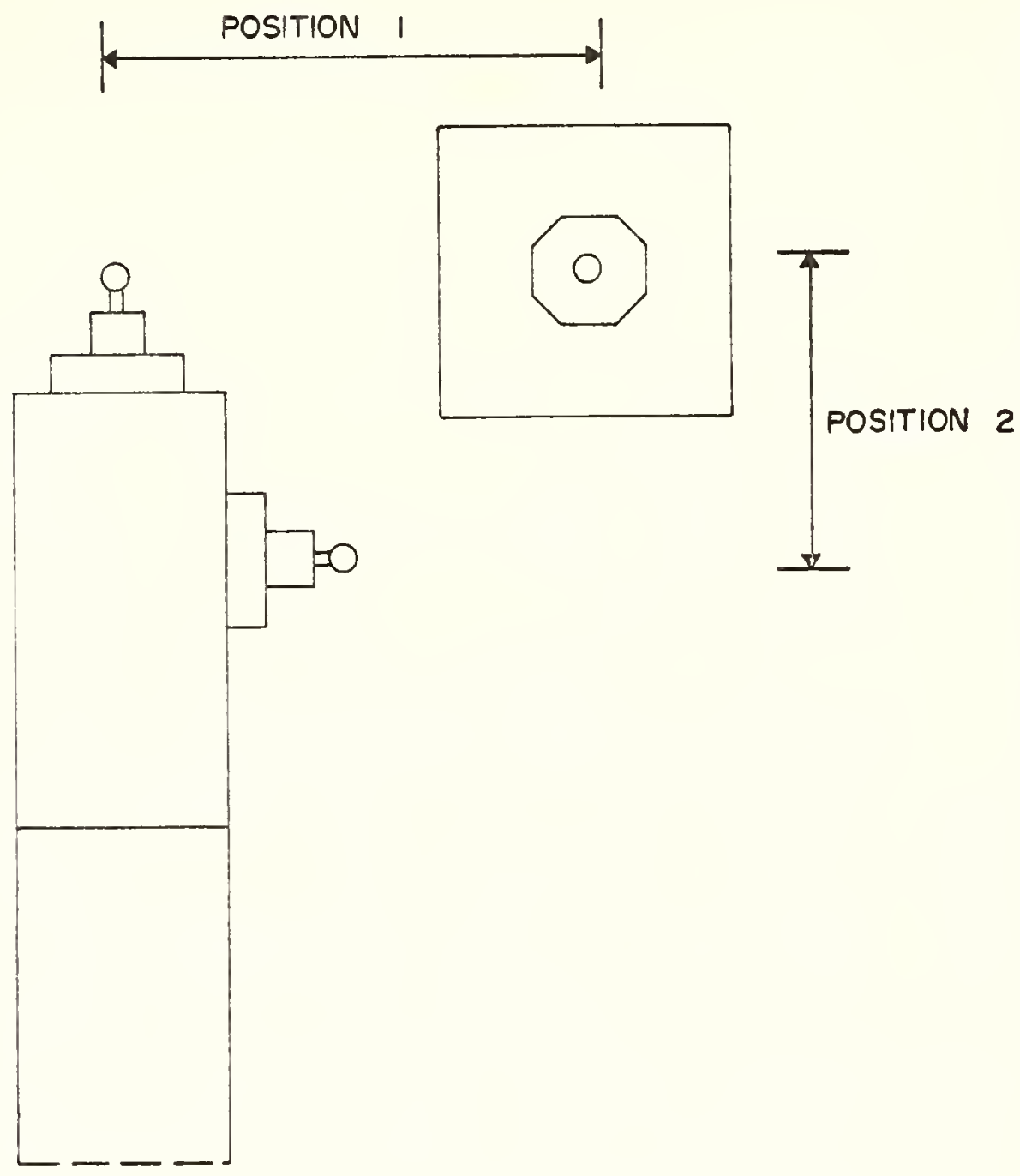

FIGURE 2. DEFORMATION MEASUREMENT POSITION OF THE BALL SYSTEM 


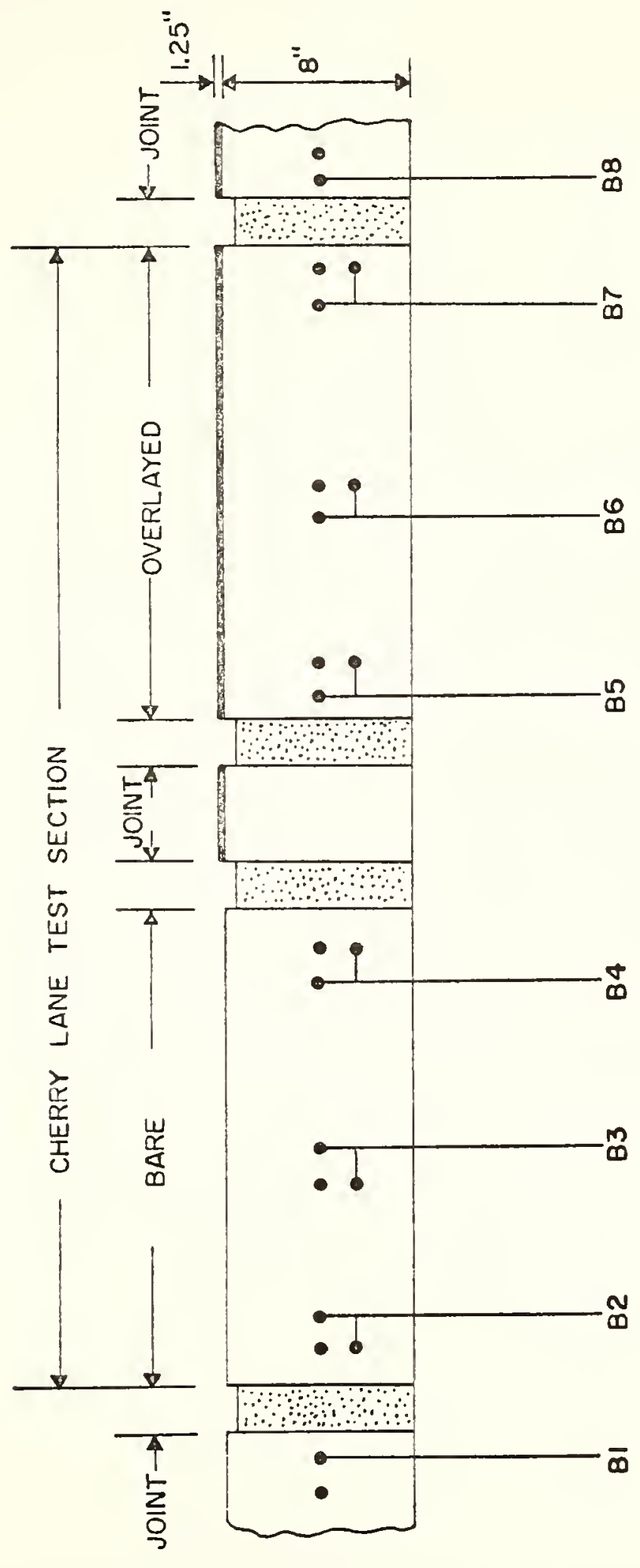

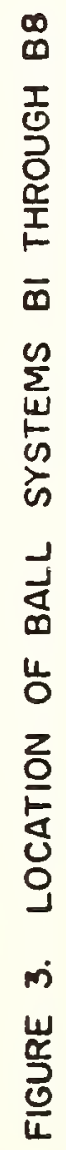




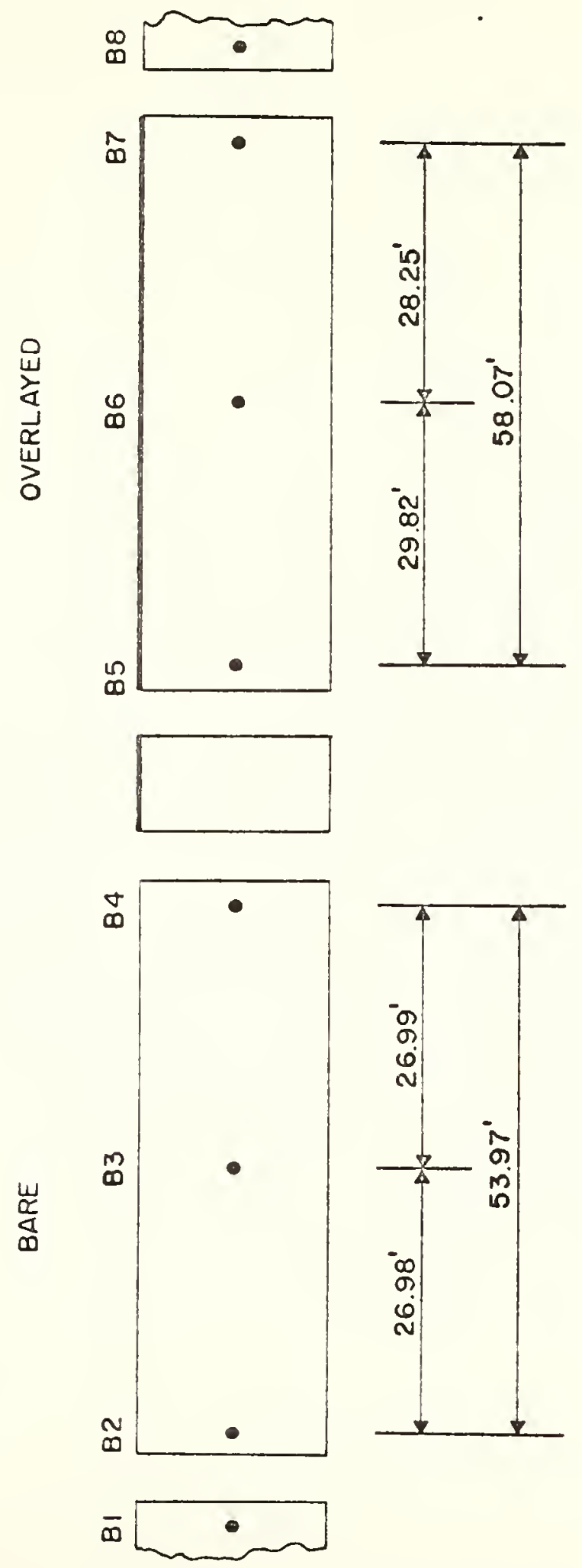

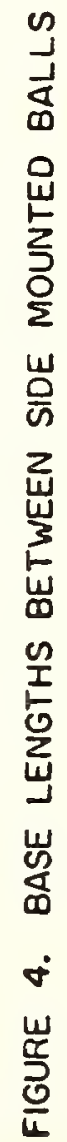




\section{Temperature}

Temperature must be recorded along with slab deformation to calculate a coefficient of expansion. Thermocouples were selected for measuring temperatures. Thermocouples were chosen as the mode of temperature measurement over other methods because of their reliability, durability, ease of installation, and simplicity of use. When used in conjunction with an electronic reference junction, an accuracy of $0.1^{\circ} \mathrm{F}$ was achieved. Temperature probes were constructed in the laboratory, then grouted into a one inch hole cored into the test slabs. These probes were located midway between the pavement's edge and centerline and five reet from the expansion joints. No attempt was made to measure temperature within the asphalt. Lead wires were protected from traffic by placing them in a one inch deep groove cut into the pavement with a portable concrete saw, then sealed with an epoxy resin. This method has shown no sign of deterioration to date, and is expected to last indefinitely. Five thermocouples were placed in each probe, spaced at two inches center-to-center with the top and bottom being located approximately $1 / 16$ of an inch from the surface.

\section{Moisture}

In conjunction with temperature and deformation a measurement of moisture content and especially changes in the moisture content would be very meaningful in determining 
the effect of overlaying a concrete pavement. An extensive Iiterature search did not reveal a reliable method of obtaining such measurements (24). The nuclear density method of moisture measurement can be used to detect changes in moisture content and was selected as a possible method to investigate.

The nuclear density gauge in principle should be a useful method, but unfortunately its bulb of influence is very shallow in the back-scatter mode and is therefore highly influenced by the moisture state near the surface. It was shown that this area does not change in moisture content drastically except immediately after a rain shower and therefore gave a poor indication of change in moisture for the whole slab. An alternative method was devised: The principle of this alternative method is simple in nature and is based on the fact that the thermal conductivity, heat capacity and density of a porous material are dependent upon its moisture content. Lentz and Monfore (25) used much the same principle in their method for the determination of thermal conductivity of concrete.

A gauge was constructed by placing a thermocouple in the center of a $3 / 4$ inch diameter loop of number 30 gauge nichrome wire and then surrounding both with mortar. Twenty such gauges were fabricated at one time by using a modified one-by-one-by-eleven inch bar mold. Special emphasis was given to compaction of the mortar by using a 
vibrating table and placing the mortar in several layers. This was done to minimize the number of entrapped air bubbles, which would have an effect on the calibration of the gauge. The one-to-one mortar mix used was made of shrinkage compensating cement and graded Ottawa sand with a water cement ratio of 0.35 . This mix was selected on bases of stability and sensitivity, as described in Appendix B.

Ten such gauges were thus cast one inch apart in each eleven inch bar. These bars were cured in a fog room for a minimum of 28 days. The gauges and their surrounding mortar block were cut from the bar and were ground on a polishing wheel until their thicknesses were approximately $1 / 4$ inch, as shown in Figure 5. These gauges were then tested and those that responded similarly to the same degree of saturation were selected for extensive calibration.

An experiment revealed that if the gauges were surrounded by at least one inch of mortar, any size effect of the mortar block would no longer be present. Therefore, it was decided to place the gauges in three inch diameter by eight inch high cylinders, hereafter referred to as moisture probes. Four gauges were placed in each moisture probe with a $2 \frac{1}{2}$ inch center-to-center spacing, as shown in Figure 6. The mortar used in the moisture probes was made using a Type I cement with the same mix proportions as the moisture gauge mix. 


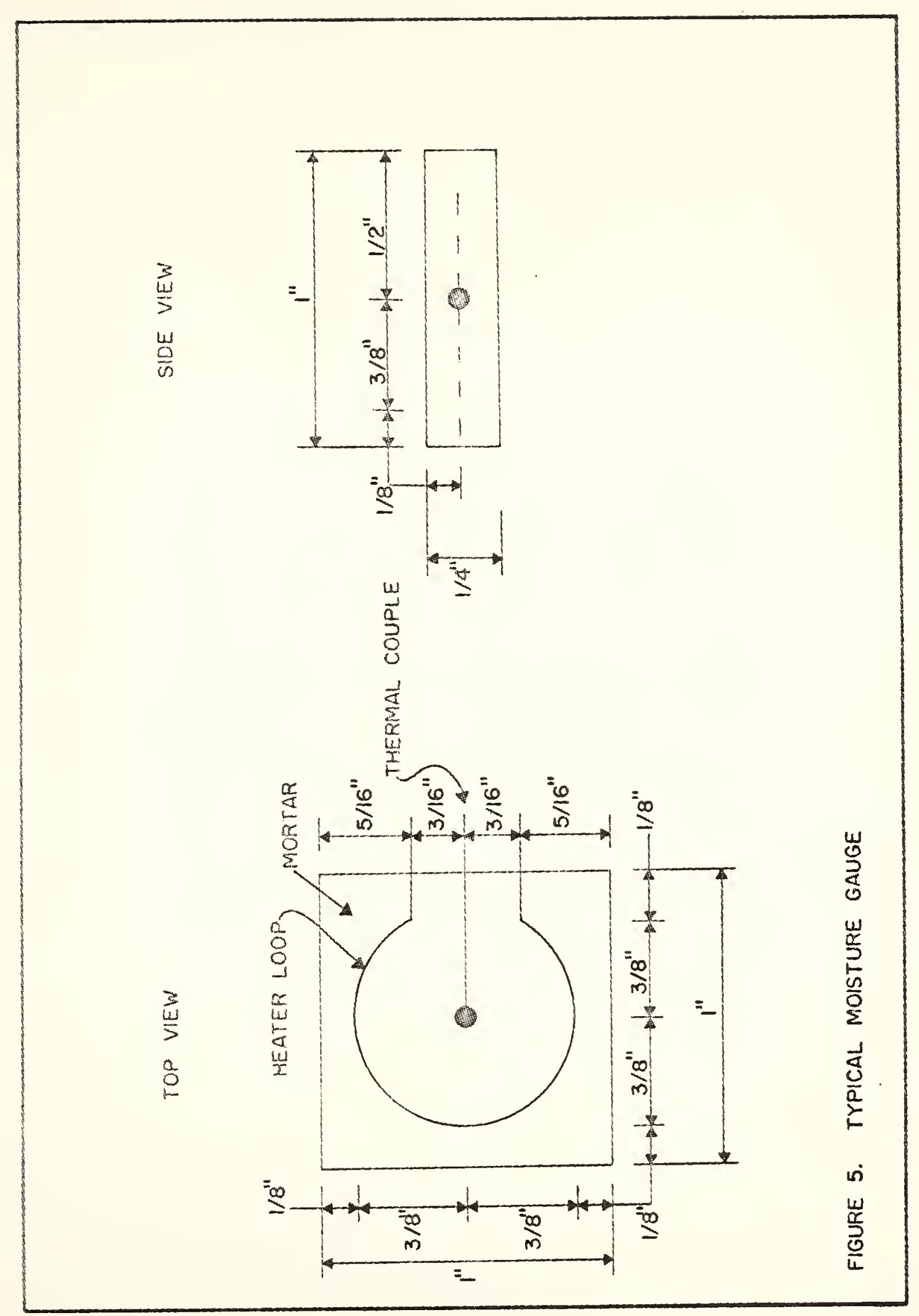



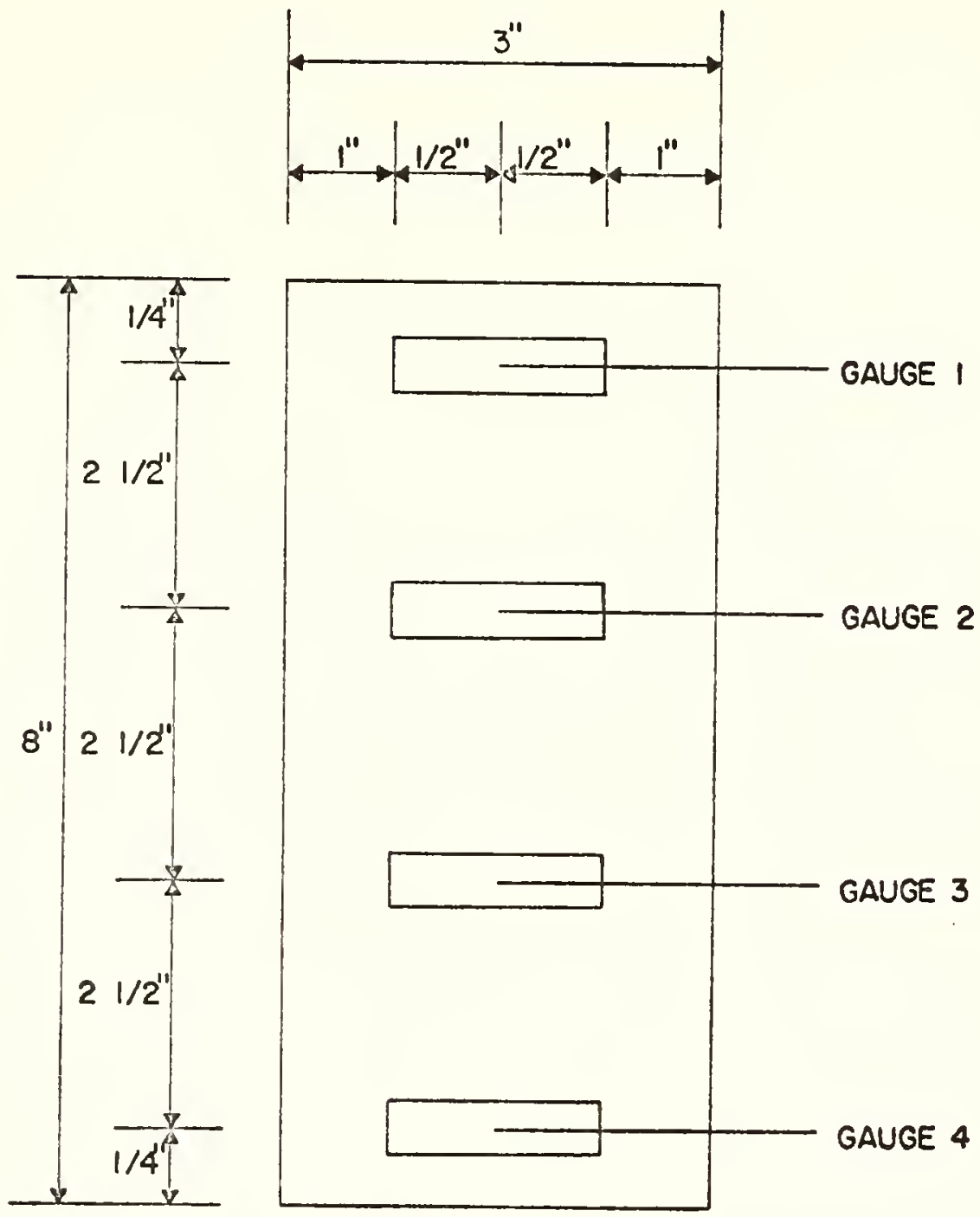

FIGURE 6. TYPICAL MOISTURE PROBE 
Each gauge was callbrated, at varlous molsture states, by applying a constant current of one ampere across the heater wires for a perlod of 30 seconds and recording the maximum temperature rise. This corresponds to an average total energy input of 60 joules. The zero percent degree of saturation was defined as the moisture state that exists after three days of oven drying at $105^{\circ} \mathrm{C}$. The 100 percent degree of saturation was defined as the moisture state that exists after vacuum saturation for three to four hours plus an additional submersion under water for twenty-four hours. The various intermediate points were determined by drying and resaturating the moisture probes. The degree of saturation was assumed to be uniformly distributed throughout the volume of the probes. The calibration data are presented in Appendix $C$.

The wiring diagram for the moisture probe testing is given in Figure 7. The Omega, Model No. CJ, temperature reference junction converted the thermocouple's electromotive force to a $32^{\circ} \mathrm{F}$ reference and was recorded directly from the Fluke digital voltmeter, Model No. $8300 \mathrm{~A}$, in millivolts direct current. The Topaz invertor, Model No. 250-GWD, supplied power to the digital voltmeter, the Heath kit timer Model No. N-15, and the Lambda power supply, Model No. LPHIIFM.

These moisture probes were calibrated against their own degree of saturation and not the concrete's in which 


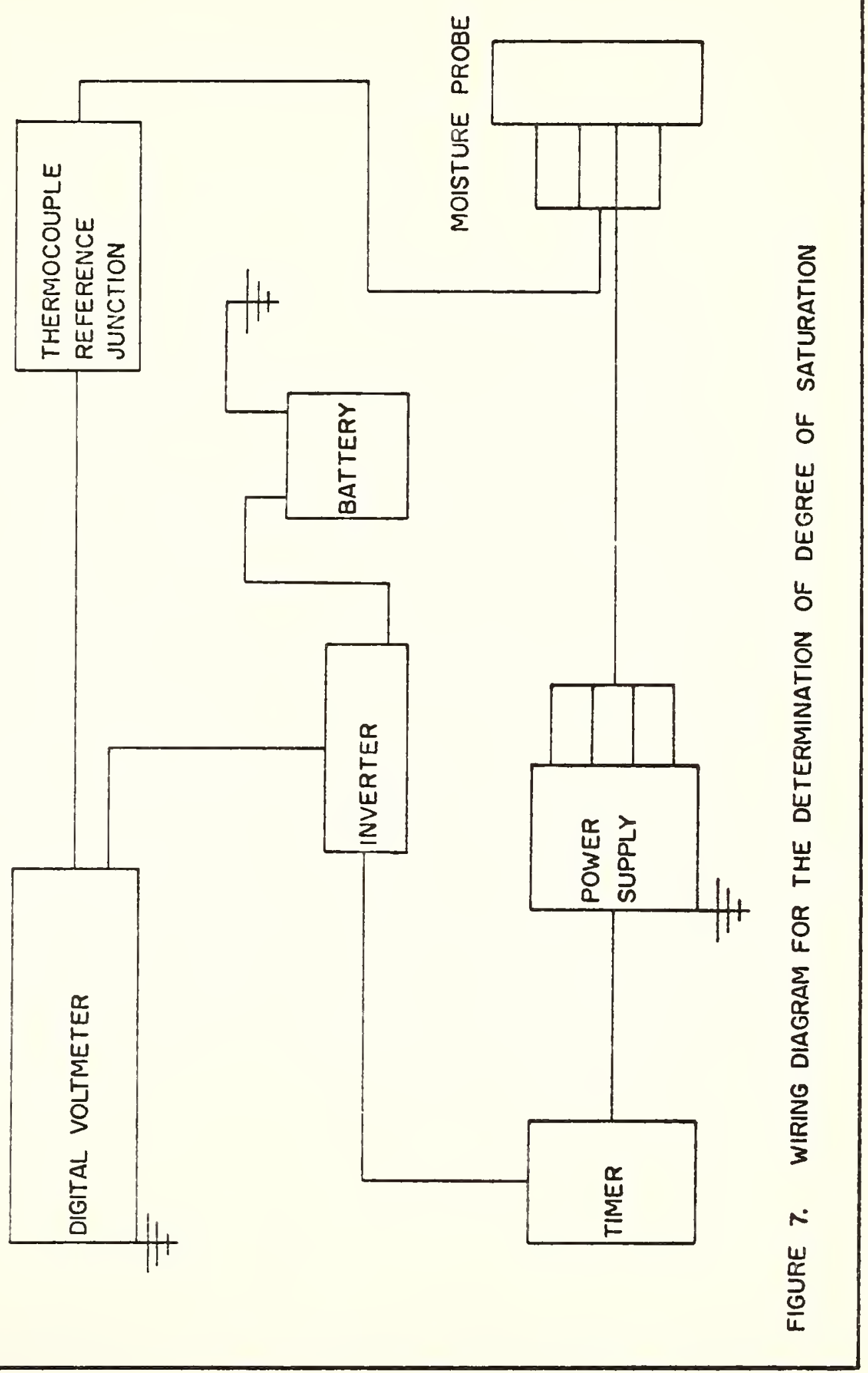


they were placed. It was necessary to assume that the degree of saturation of the probe was equal to the degree of saturation of the concrete. This seems reasonable in light of a recent publication (26) that shows while the moisture content for a tested mortar is not equal to that of a concrete subjected to the same moisture conditions, their degrees of saturation are approximately equal. The calibration data, temperature change versus the degree of saturation, were plotted for each gauge and visually analyzed. An inflection point was found to occur at a degree of saturation of 85 percent to 95 percent on all the gauges except three. The gauges having an inflection point were broken into two sections by visually drawing two best fit lines. The best fit regression equations were determined for each line. Those data points located in the near vicinity of the intersection of the two lines were included as common data for both regression equations. The inflection point was assumed to be the intersection of the two regression equations. A single regression equation was determined over all of the data for the three gauges without apparent inflection points. Regression equations determined by this method assume a linear relation between temperature change and degree of saturation. This has recently been shown to be a valid assumption (26) and is not a restriction. The regression equations, of each gauge with an inflection point were expressed by singularity functions so that one 
equation could be used to express the entire calibration range.

Typical regression equations and calibration data are shown in Figures 8 through Figure 11 . Gauge 1 of moisture probe $3-3$, shown in Figure 8 , is typical of all the two curve type gauges. Gauge 4 of moisture probe $3-0$, shown in Figure 9, is typical of the three single curve gauges. The equations of gauge 3 and gauge 4 of moisture probe $3-B$ and moisture probe 1-B, shown in Figure 10 and Figure 11 , describe the data with the least accuracy of all the gauges. Even though these are the least accurate, their regression $R^{2}$ values are both larger than 0.91 . Data with regression $R^{2}$ values of this magnitude are commonly used with sufficient accuracy for most engineering applications.

The calibration curves of the six moisture probes are shown in Figures 12 through Figure 17.

The moisture probes were installed in the test slabs during July 1974. Their locations and identifications are shown in Figure 18. The distance measured from the pavement's edge to Position 1, Position 2 and Position 3 are two, five and eight feet, respectively.

\section{$\underline{\text { Procedure }}$}

Data Collection

Investigation of the test section was inftiated during the Summer of 1973. The testing procedure through the Fall 


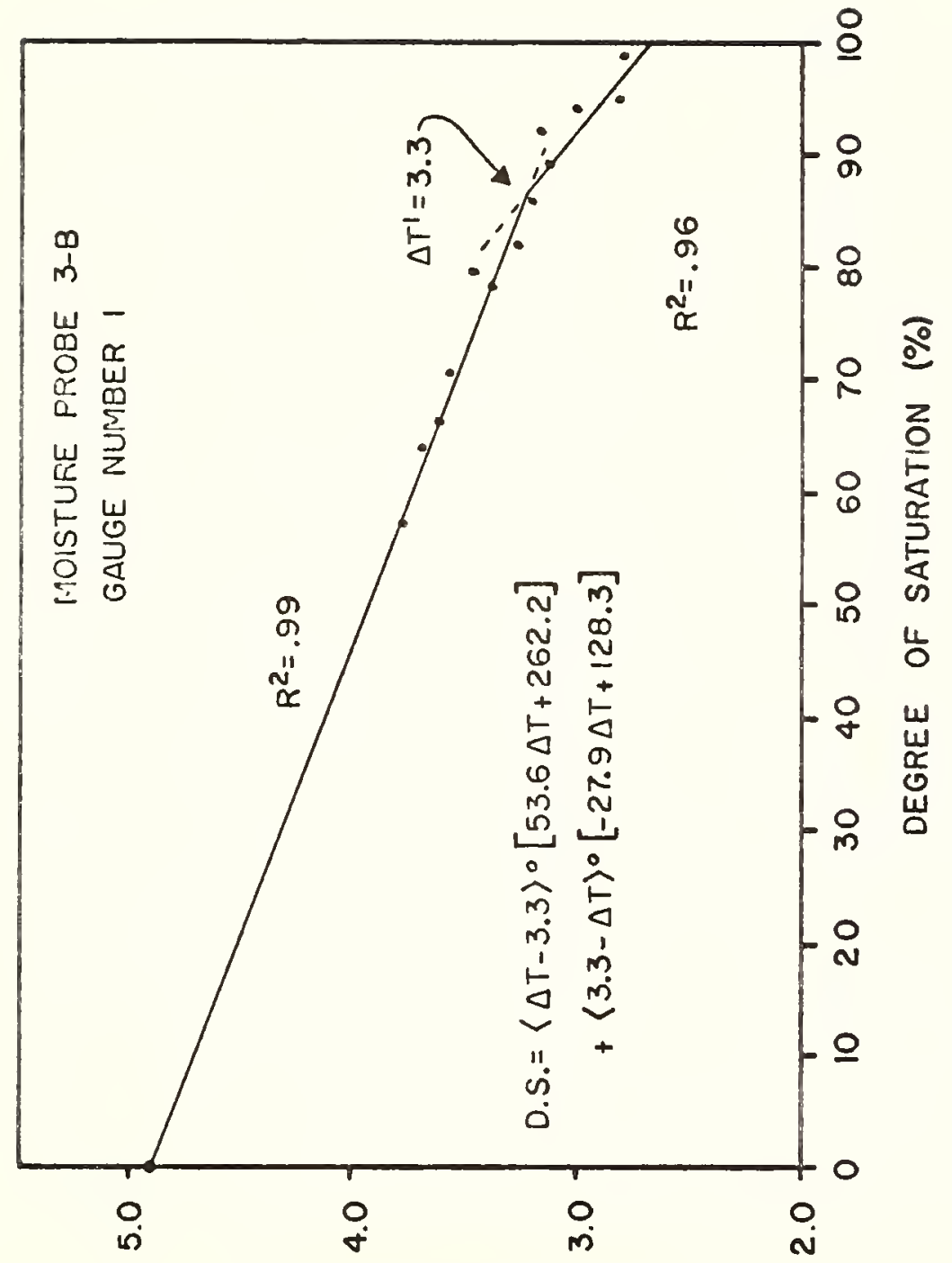

(Jo) $39 N \forall H O ~ \exists Y \cap \perp \forall Y \exists d W \exists \perp$

$m$

$w$
0
0
$\frac{\alpha}{a}$
$\frac{\alpha}{2}$

$\frac{u}{\alpha}$
$\frac{5}{5}$
$\frac{0}{0}$

$\stackrel{r}{0}$

을

u

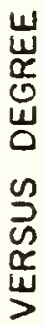

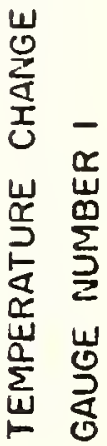

$\infty$

$\frac{\omega}{\frac{\alpha}{丂}}$ 


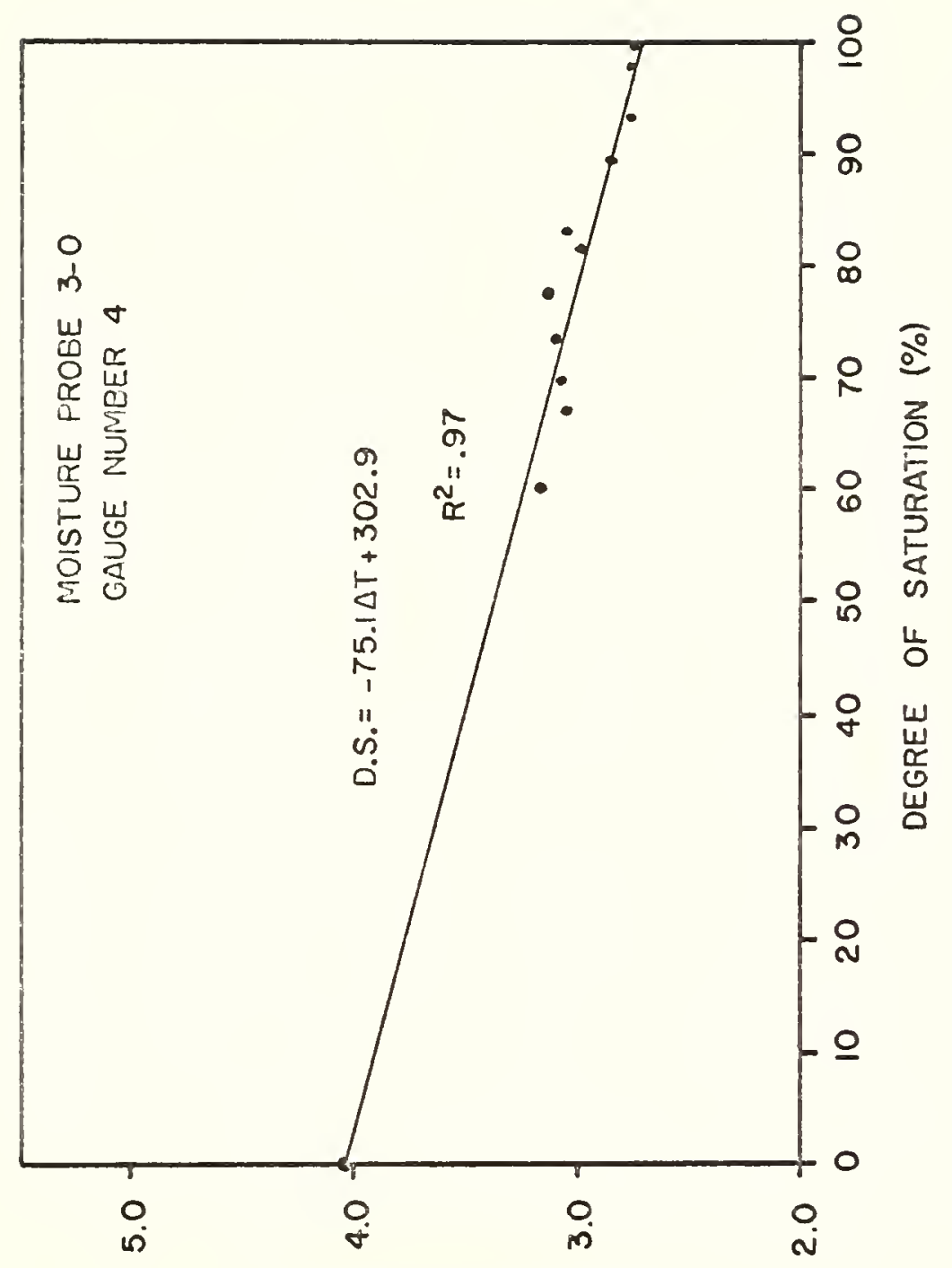

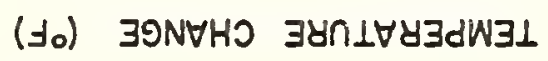




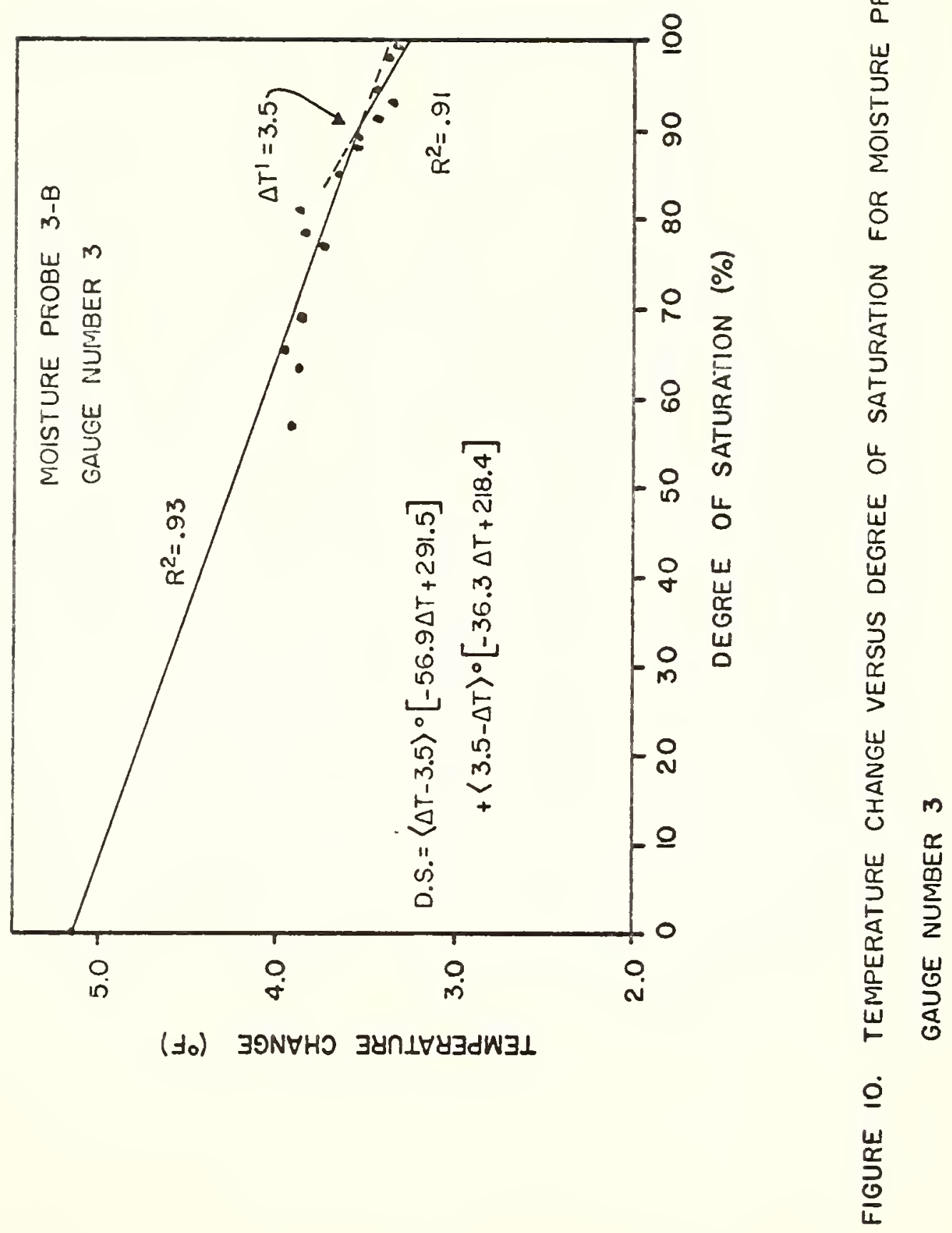




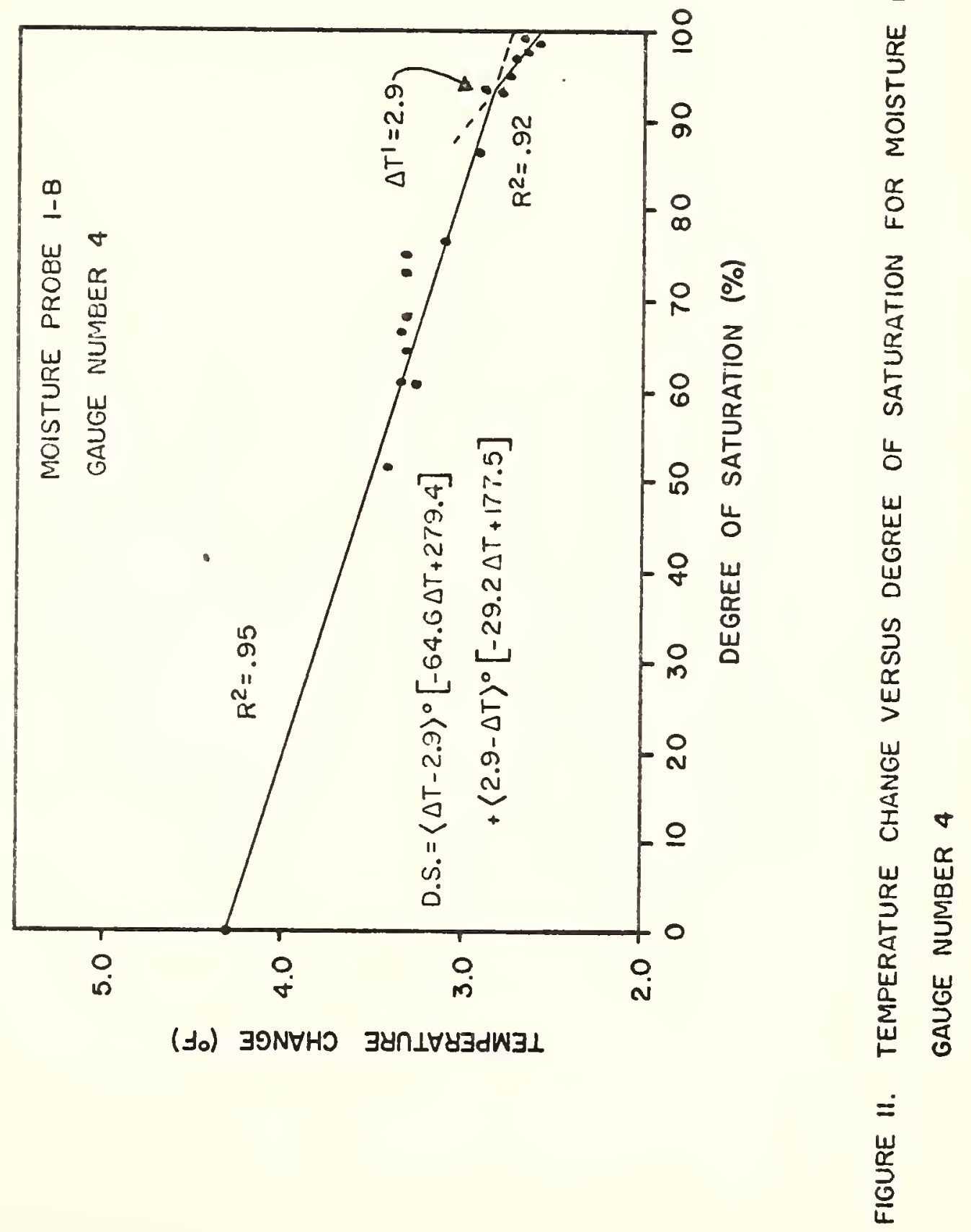




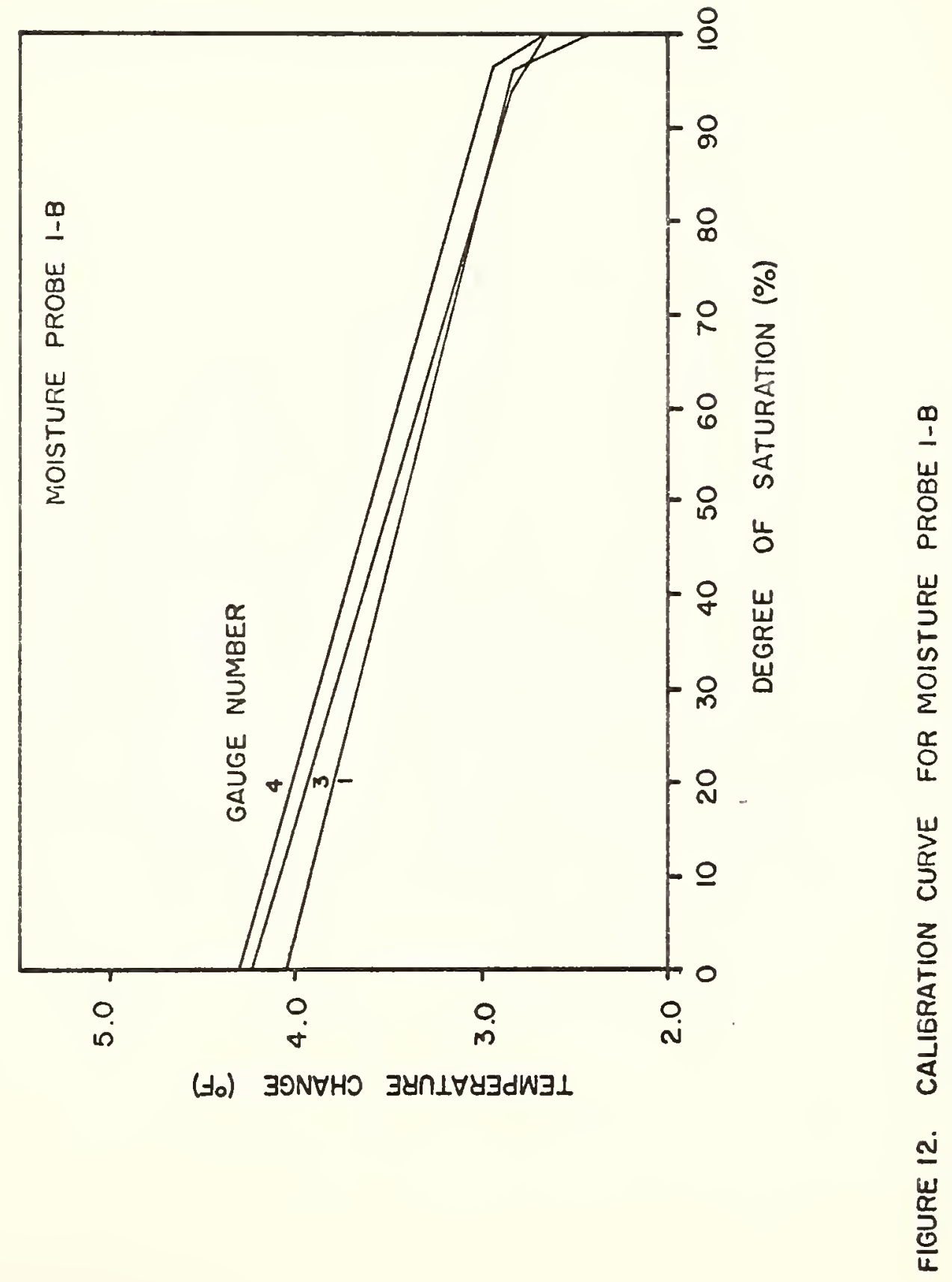




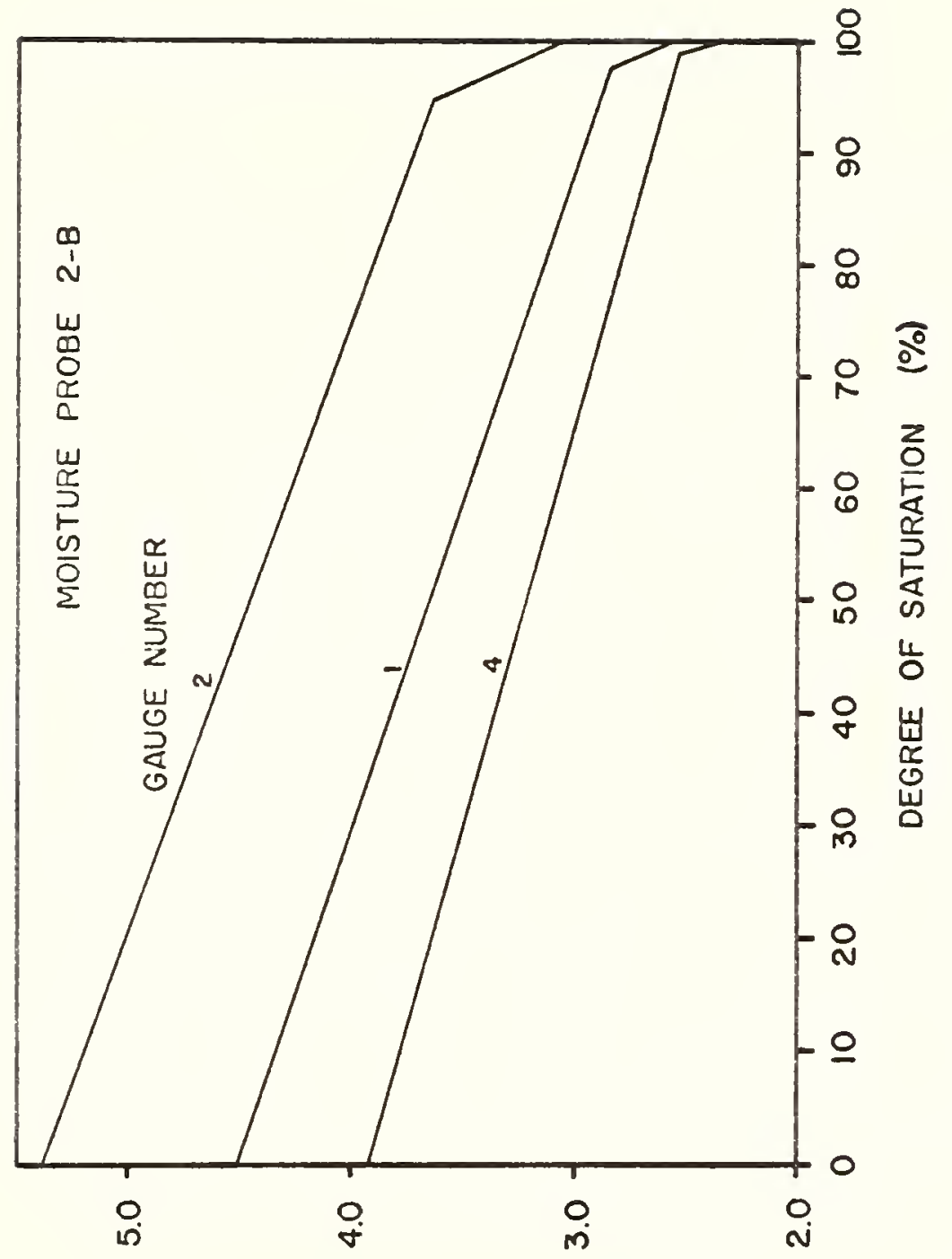

(Ј) $\exists 9 N \forall H O \quad \exists \forall \cap \perp \forall Y \exists d W \exists \perp$

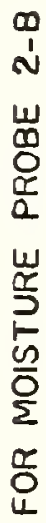

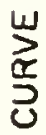

$\frac{z}{\frac{Z}{5}}$

$\frac{\underline{m}}{\underline{\underline{T}}}$ 


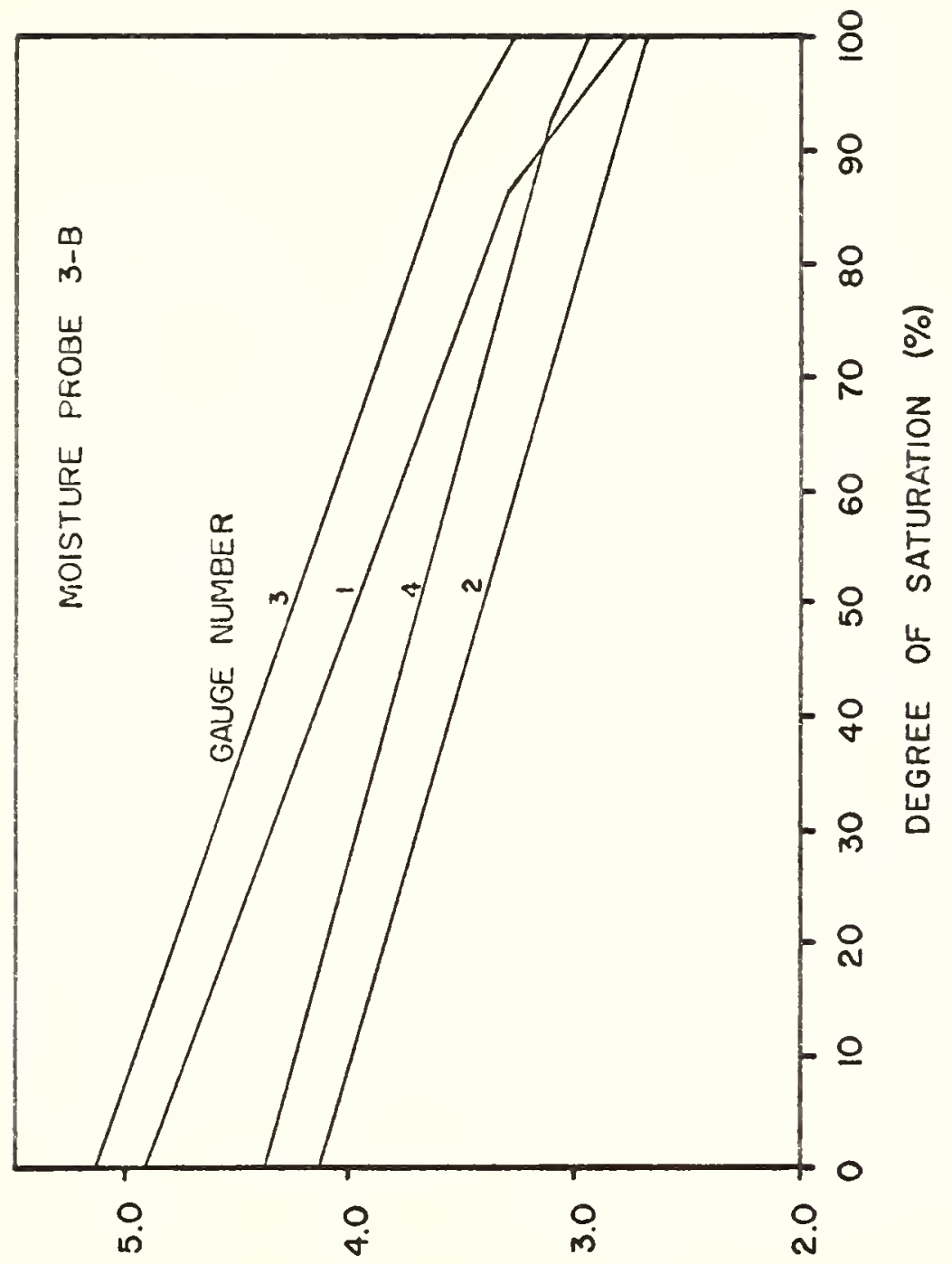

(†0) $\exists 9 N \forall H O \quad \exists \forall \cap \perp \forall Y \exists d W \exists \perp$

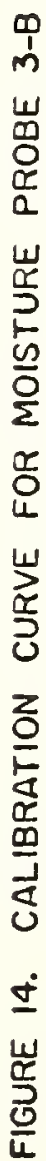




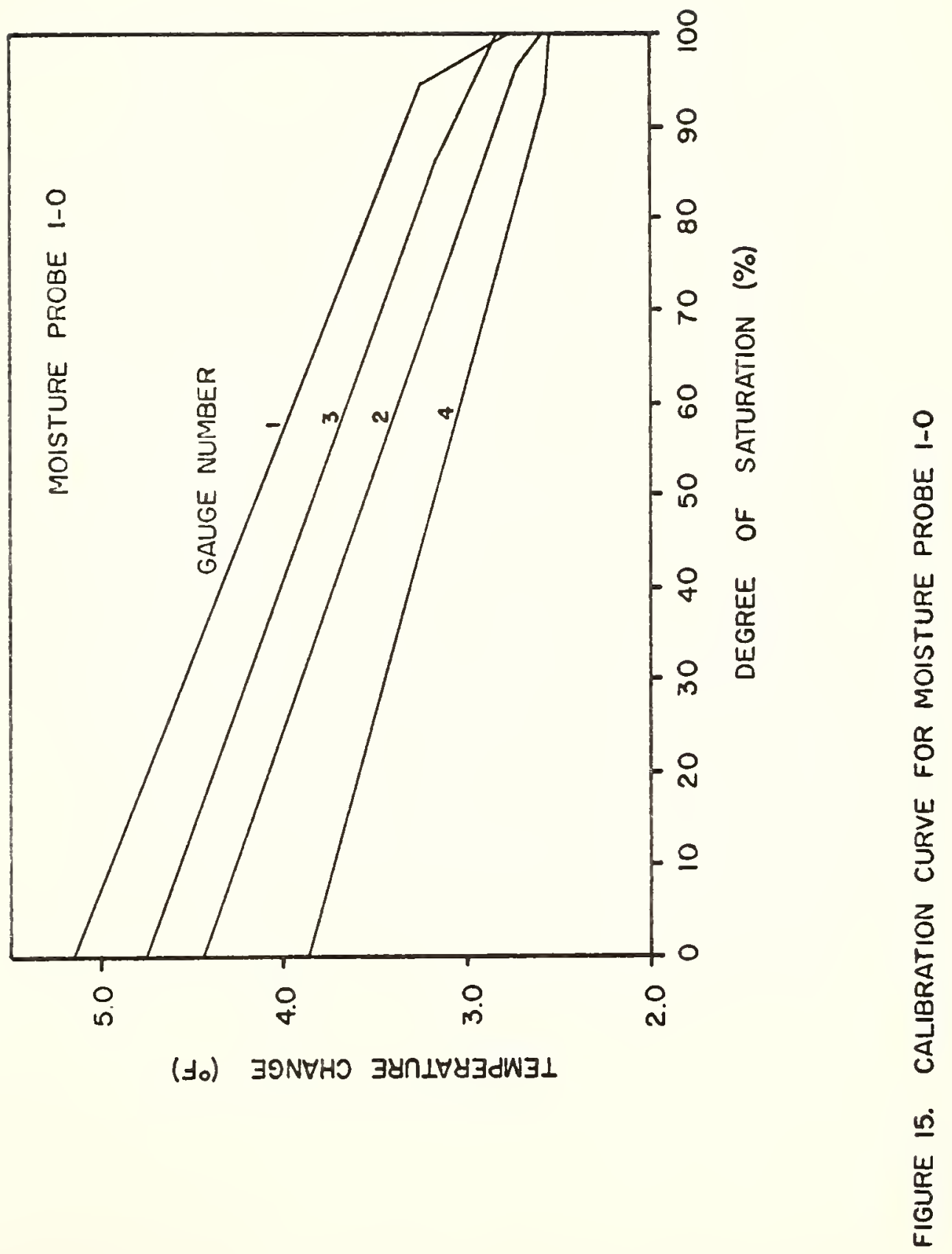




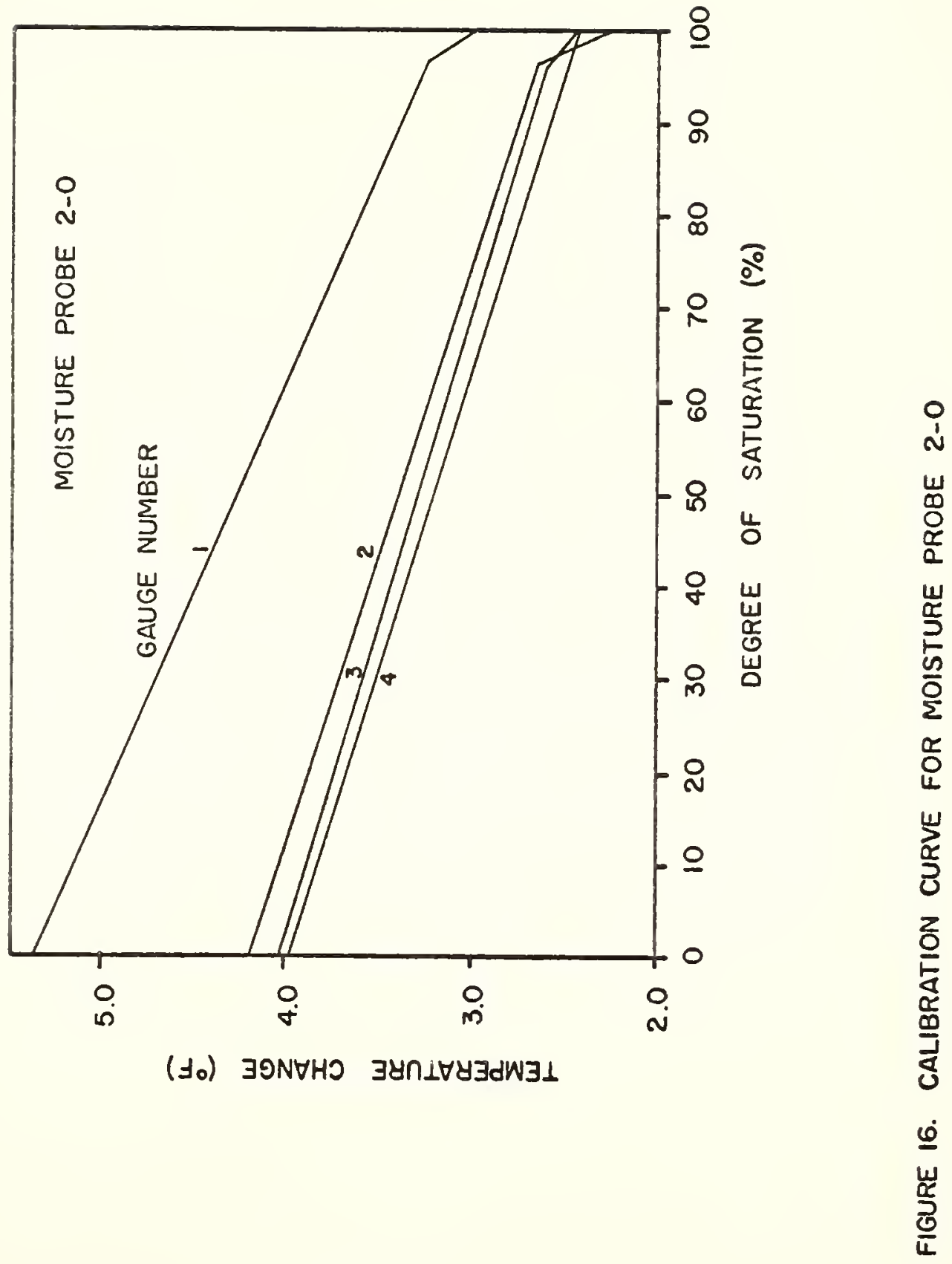




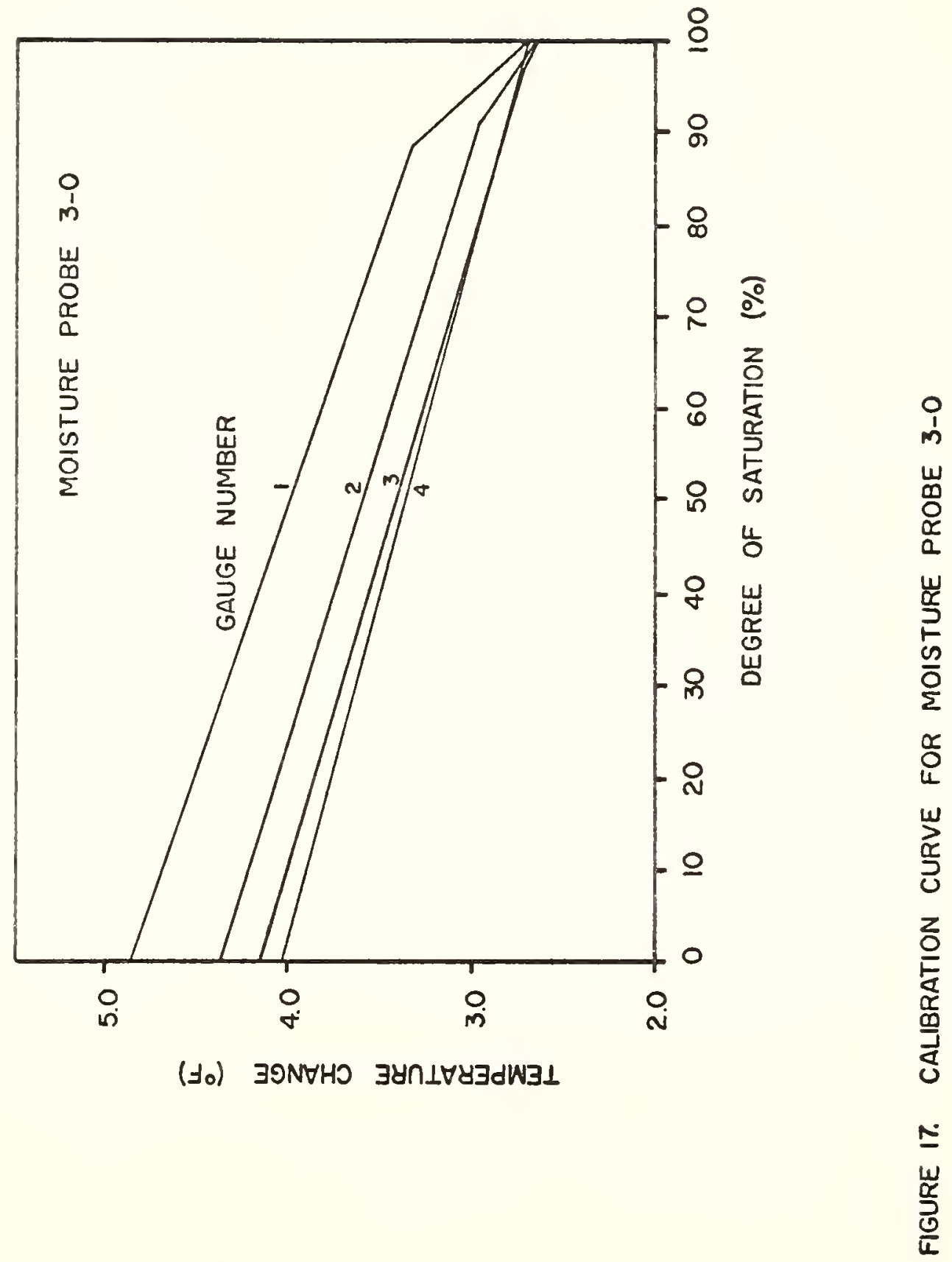



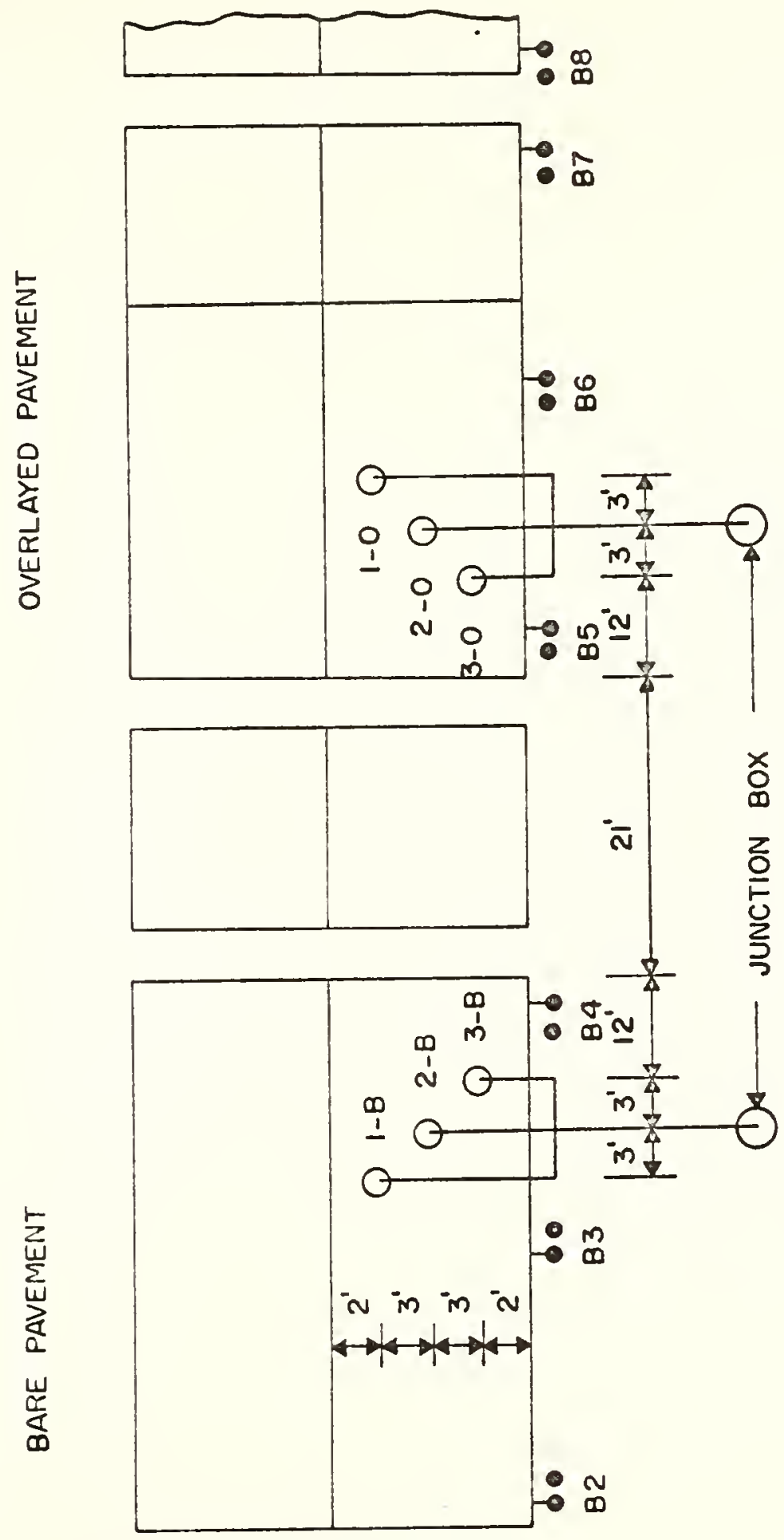

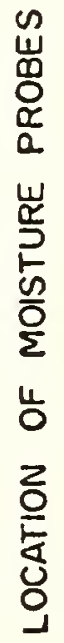

$\infty$

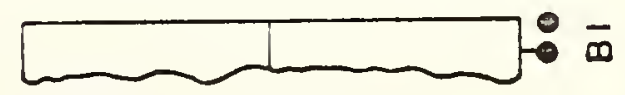

$\frac{\omega}{\frac{\omega}{2}}$ 
of 1973 was to measure Position 1 and Position 2 of each ball system and the temperature of the five gauges in the temperature probe simultaneously. These data were taken for each ball system as quickly as possible to minfmize temperature variation within the concrete slab. The order of testIng was to measure the ball systems B5, B7, B6 and B8 of the overlayed section first, then B1, B2, B4 and B3 of the bare section, all in the order as listed. The moisture probes were installed in July 1974, and the procedure since then has been as above with the following exceptions: simultaneously with each set of ball measurements temperatures were recorded from each gauge in the temperature moisture probes. The moisture readings were taken immediately after completion of the ball measurements starting with Gauge $I$ of molsture probe $1-B$ and ending with Gauge 4 of moisture probe 3-B. A second set of data were then taken in the same order to assure repeatibility. Occassionally repeatibility was not obtained, and the testing with the individual gauge was continued until the $\Delta T^{\prime}$ s agreed within $0.09^{\circ} \mathrm{F}$. The two values were then averaged, and the degree of saturation was determined by using the appropriate linear regression equation. Similarly, moisture readings were taken on four gauges of moisture probes $1-0,2-0$, and 3-0 of the overlayed section.

To calculate a coefficient of expansion it is necessary to have two independent measurements of temperature and 
length. Therefore it was necessary to take two sets of data each day. In order to minimize errors of measurement, an attempt was made to take the readings at as large a temperature difference as possible.

The ball system data, length change, and average temperatures are presented in Appendix D. The average temperatures during the 1973 testing period were determined by taking the average of the five thermocouples. During the 1974 testing period the average temperatures were determined by averaging the four thermocouples of Position 3. The corresponding degree of saturation measurements are given in Appendix E.

\section{Data Analysis}

\section{Vertical Moisture Variation}

The six moisture probes were monitored over a period of one year, from July 1974 through June 1975. The average dally degree of saturation of each gauge is given in Appendix E. The lead wires of Gauges 2 and 3 of moisture probe 1-B and 2-B respectively were destroyed during installation and data collection was impossible. However, the remaining twenty-two gauges functioned properly throughout the test period. Position 3 data were complete for both the bare pavement and the overlayed pavement and will be used for comparisons of moisture states.

Figures 19 through Figure 26 show the degree of saturation of Positon 3 for the various gauges for the bare 


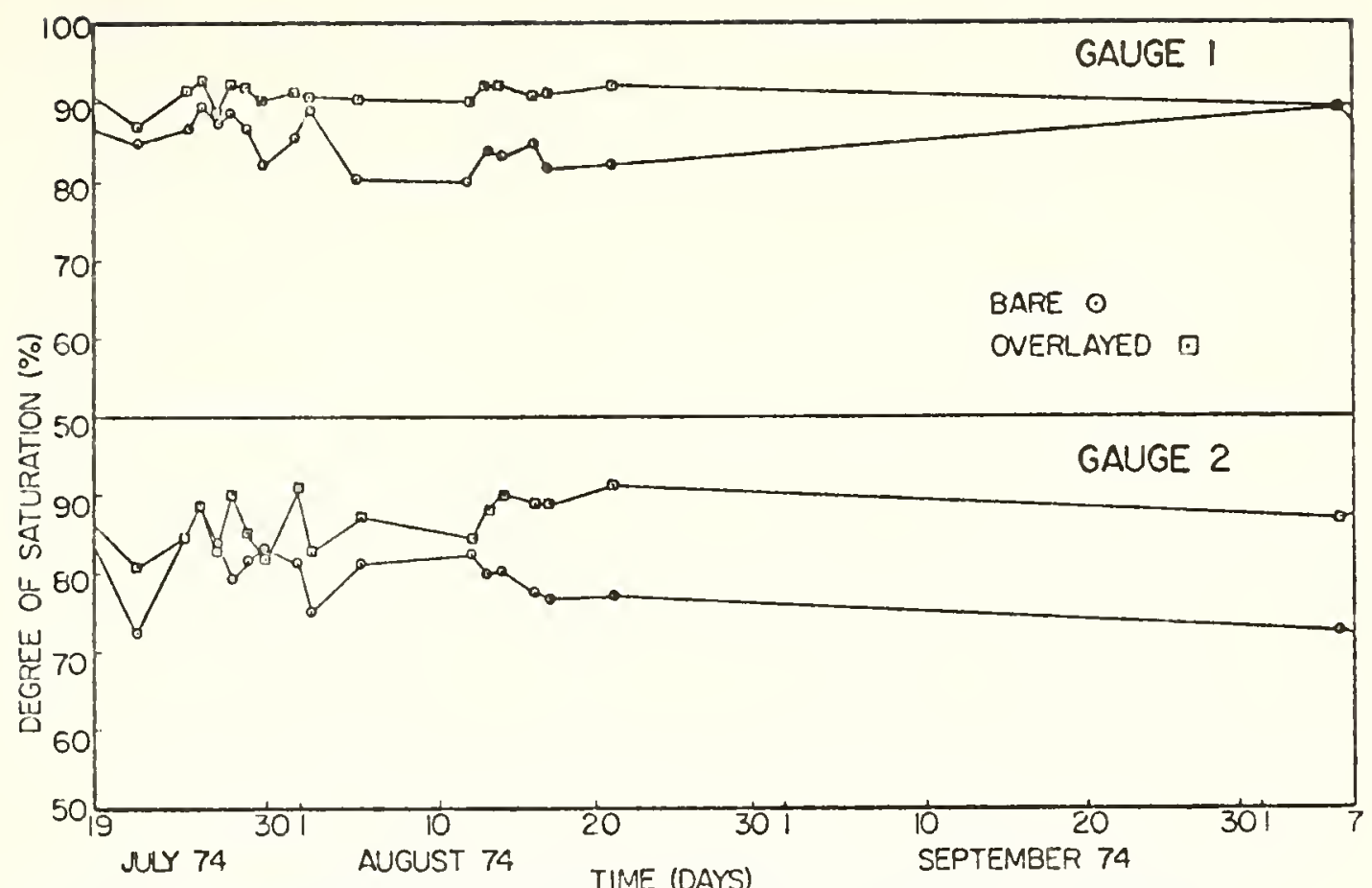

FIGURE 19. DEGREE OF SATURATION VERSUS TIME FOR POSITION 3, GAUGES I AND 2

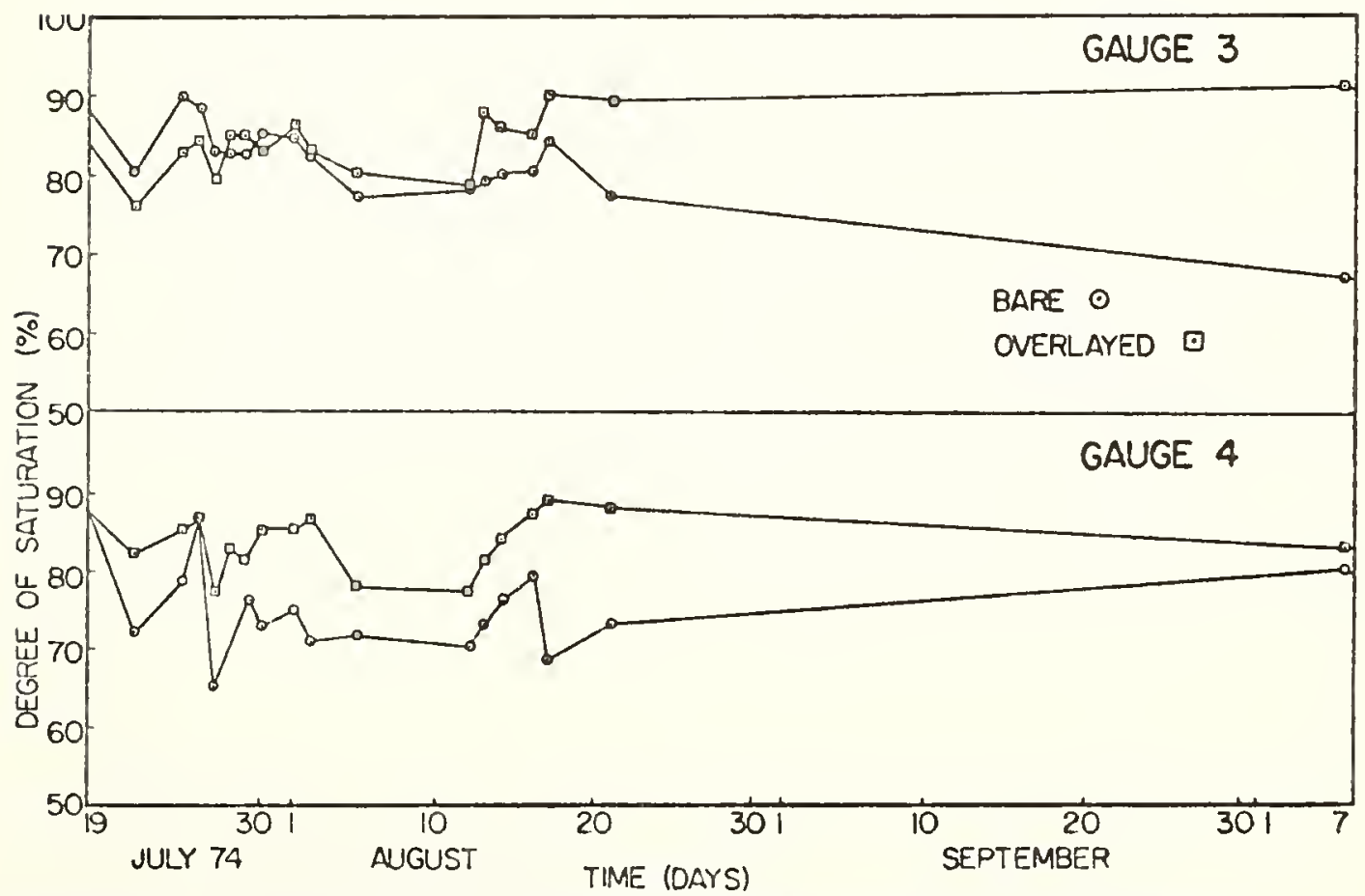

FIGURE 20. DEGREE OF SATURATION VERSUS TIME FOR POSITION 3 , GAUGES 3 AND 4 


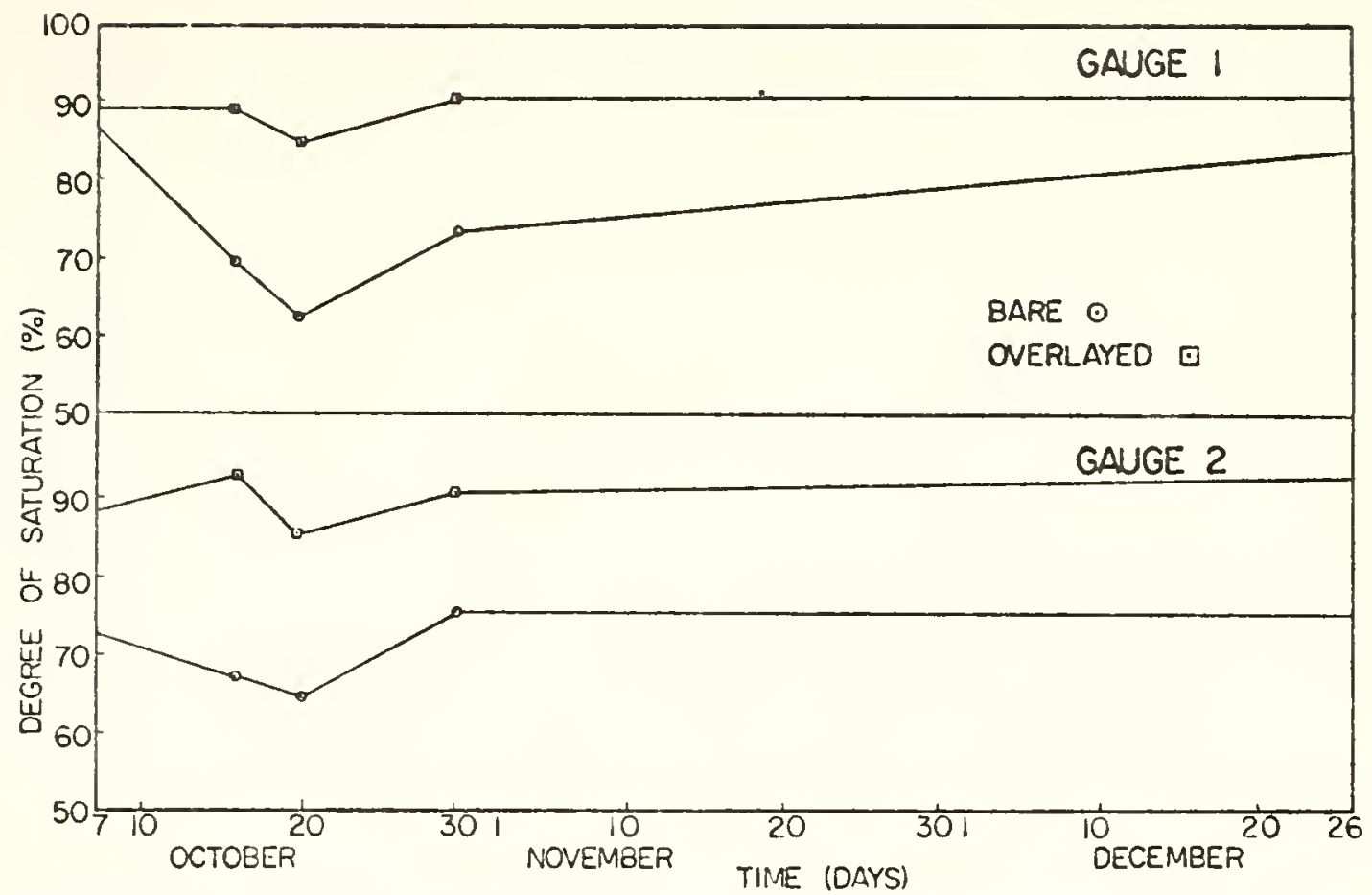

FIGURE 21. DEGREE OF SATURATION VERSUS TIME FOR POSITION 3, GANGES I AND 2

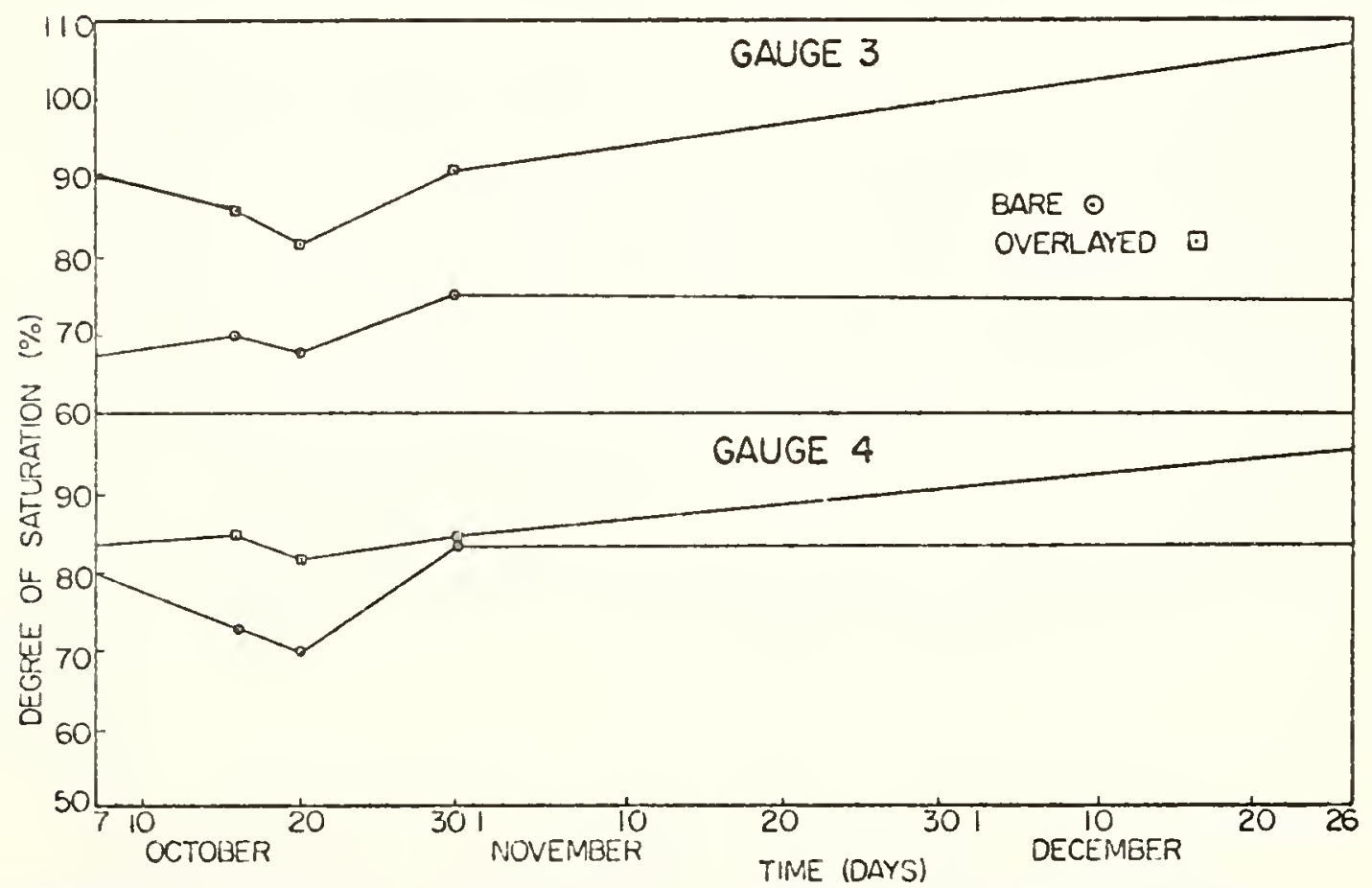

FIGURE 22. DEGREE OF SATURATION VERSUS TIME FOR POSITION 3, GAUGES 3 AND 4 


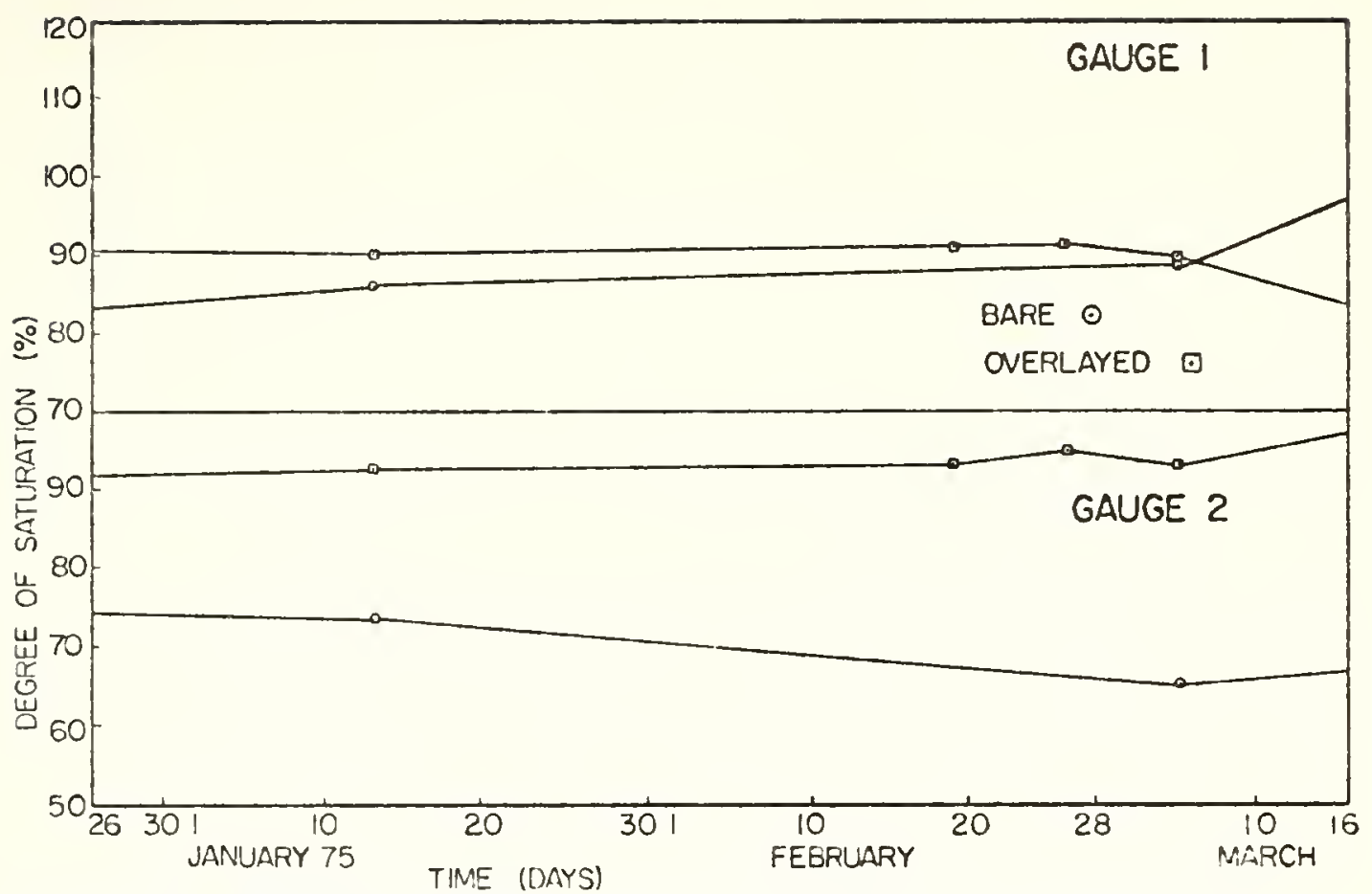

FIGURE 23. DEGREE OF SATURATION VERSUS TIME FOR FOSITION 3, GAUGES I AND 2

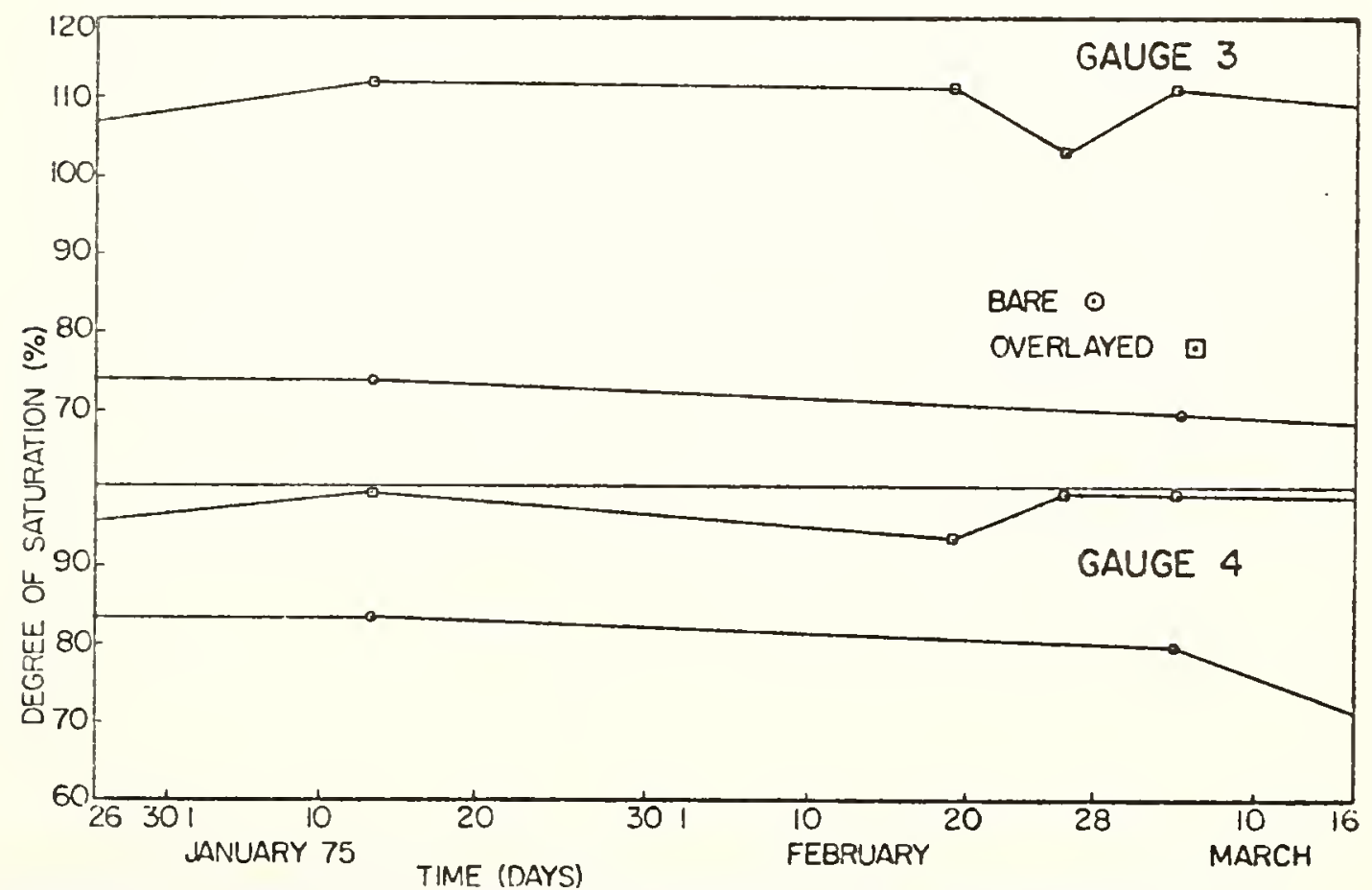

FIGURE 24. DEGREE OF SATURATION VERSUS TIME FOR POSITION 3, GAUGES 3 AND 4 


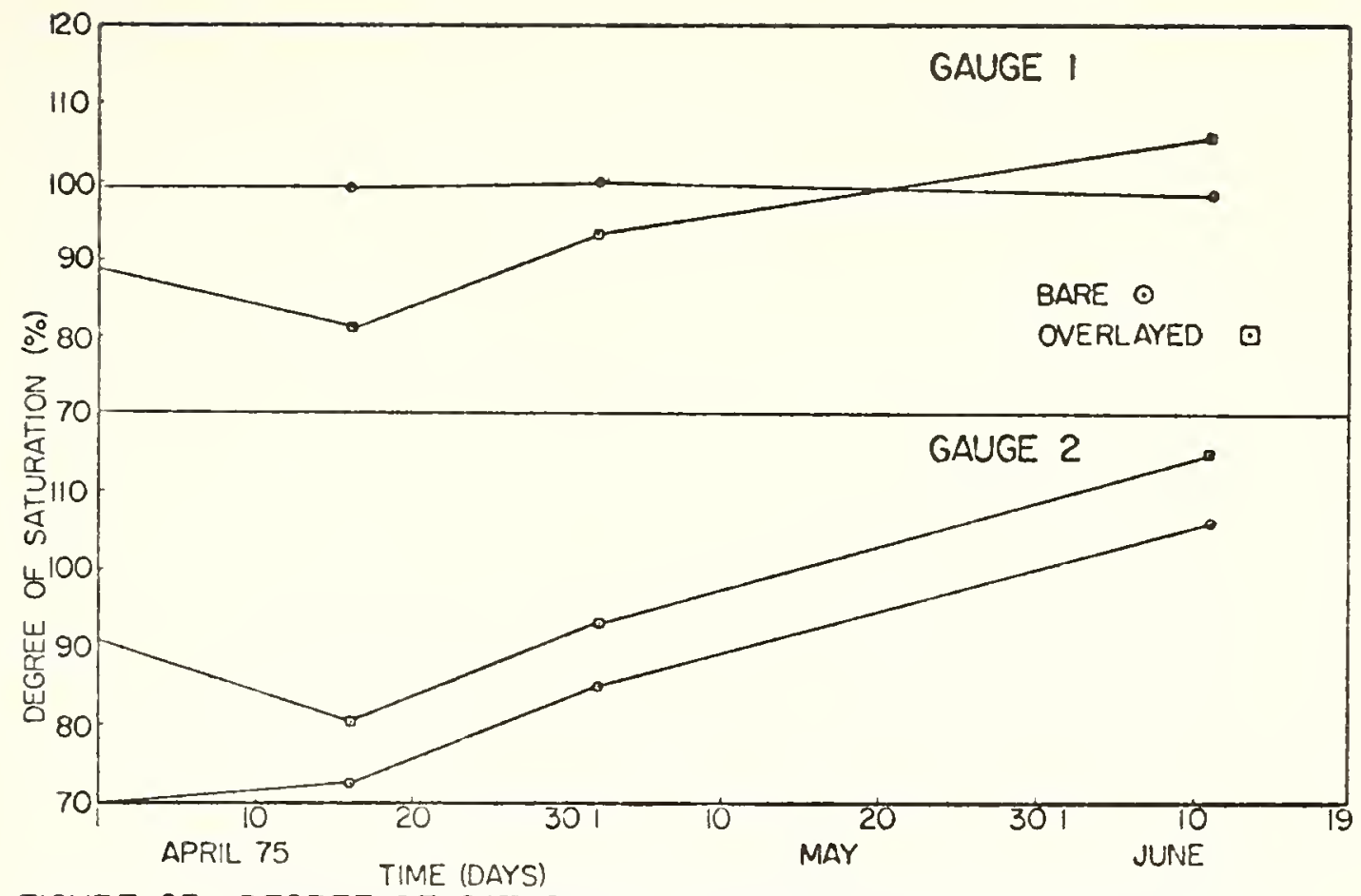

FIGURE 25. DEGREE OF SATURATION VERSUS TIME FOR POSITION 3. GAUGES I AND 2

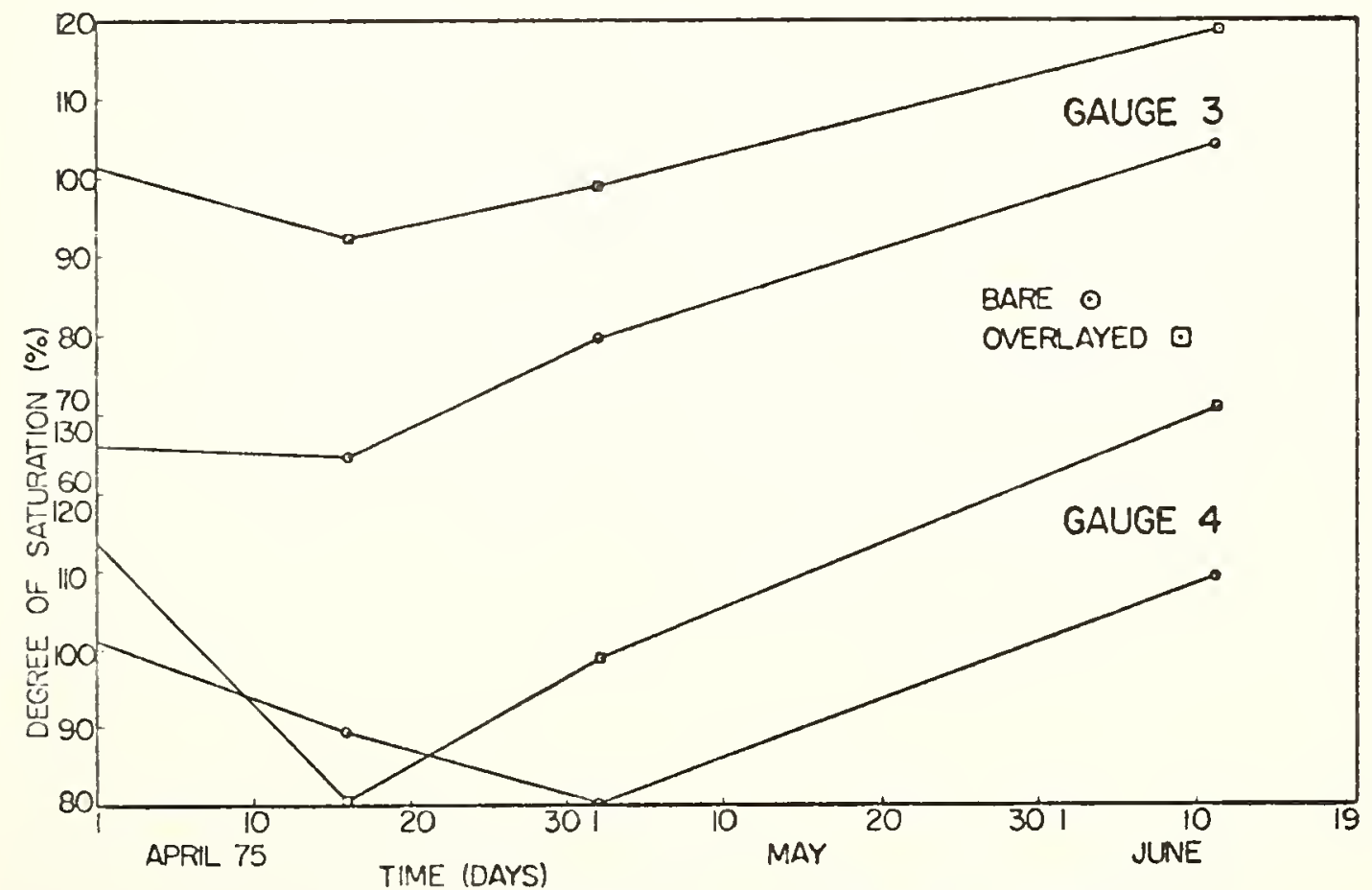

FIGURE 26. DEGREE OF SATURATION VERSUS TINE FOR POSITION 3, GAUGES 3 AND 4 
pavement and overlayed pavement as a function of time. The general trend is for the overlayed pavement always to have a higher degree of saturation for a given vertical position, and the overlayed pavement shows a smaller seasonal variation with time than the bare pavement. Vertical moisture gradients always exist in the overlayed pavement. In general the degree of saturation increases from the top to the bottom of the pavement. Except for the winter season the bare pavement shows an approximately constant degree of saturation throughout its depth. Gauge I of the bare pavement as will be shown later is more dependent upon weather cond1tions than Gauge 1 of the overlayed pavement. The overlayed pavement tends to hold moisture and not dry out as readily as the bare pavement. Both pavements surpassed the level of critical saturation with respect to freezing and thawing durability during the test period. The overlayed pavement obtained this critical moisture state during the winter season when freezing temperatures were prevalent, whereas the bare pavement did not obtain this critical moisture state until late spring when freezing conditions were no longer prevalent. When these critical moisture states occurred Gauge I had the lowest degree of saturation and Gauge 4 the highest degree of saturation whereas prior to this time Gauges 1 and 2 were approximately equal and had a higher degree of saturation than Gauges 3 and 4 which were also approximately equal. 
With the exception of Gauge 1 of the bare pavement all gauges had degrees of saturation in excess of 100 percent on June 10, 1975. In accordance w1th the caltbration procedure 100 percent degree of saturation was the molsture state after three to four hours of vacuum saturation plus an additional twenty-four hours of submersion under water. However, it is entirely possible that conditions could exist in the pavement causing a higher absorption of water than occurred in the calibration of the gauges thus giving degrees of saturation in excess of 100 percent. However, the relative values are the important ones, and they will still be valid.

\section{Horizontal Moisture Variation}

The average dally degree of saturation for Position 1 through Position 3 of the overlayed pavement and Position 3 of the bare pavement are given in Table 1 . These data were calculated by taking the average of all four gauges for each test day. Figures 27 through Figure 30 show the effect of horizontal position on degree of saturation as a function of time. Moisture gradients occur horlzontally as well as vertically. Through February 1975 Position 3 had the highest degree of saturation, Position 2 the intermediate degree of saturation and Position 1 the lowest degree of saturation. At this time the horizontal moisture gradient across the pavement was approximately five percent per foot, increasing from the side to the middle. 


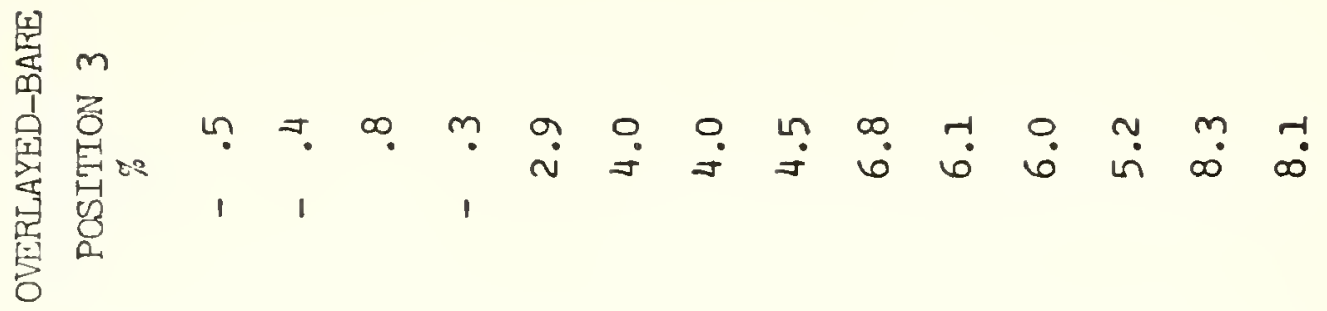

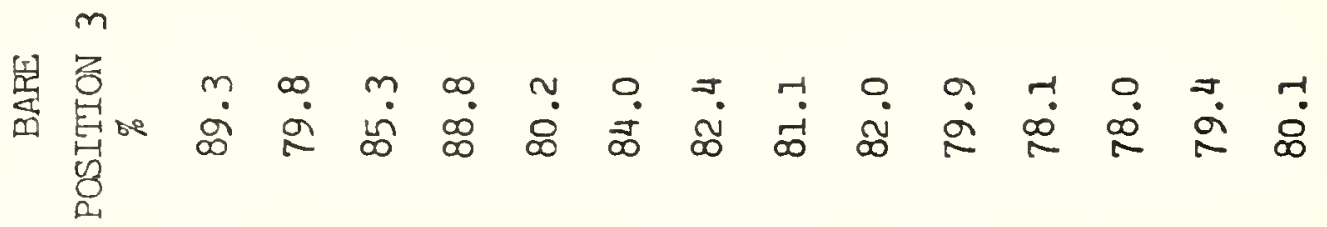

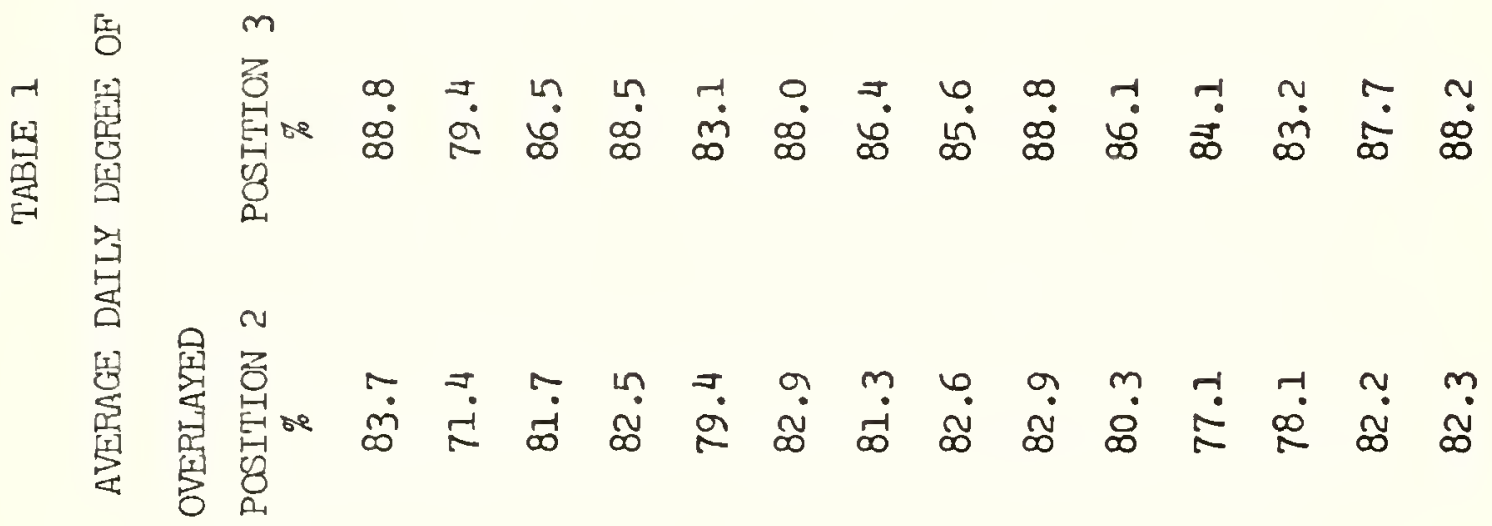

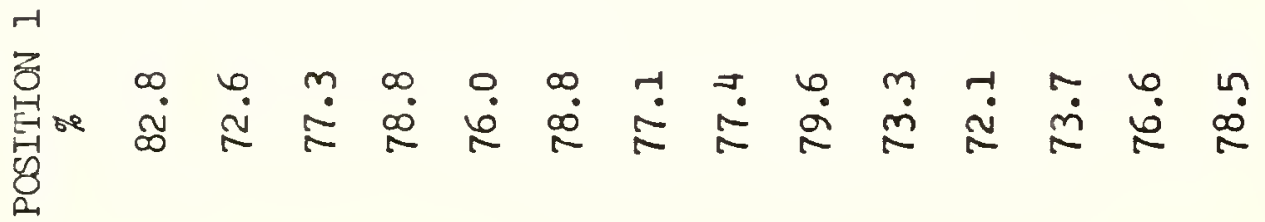

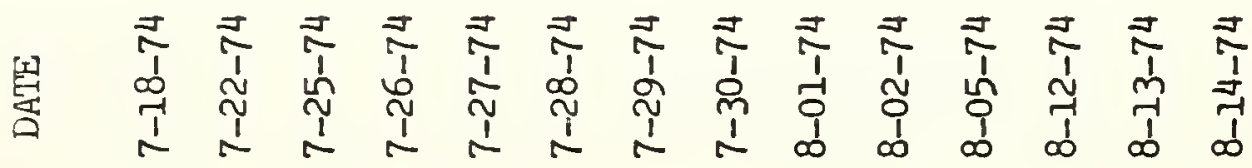




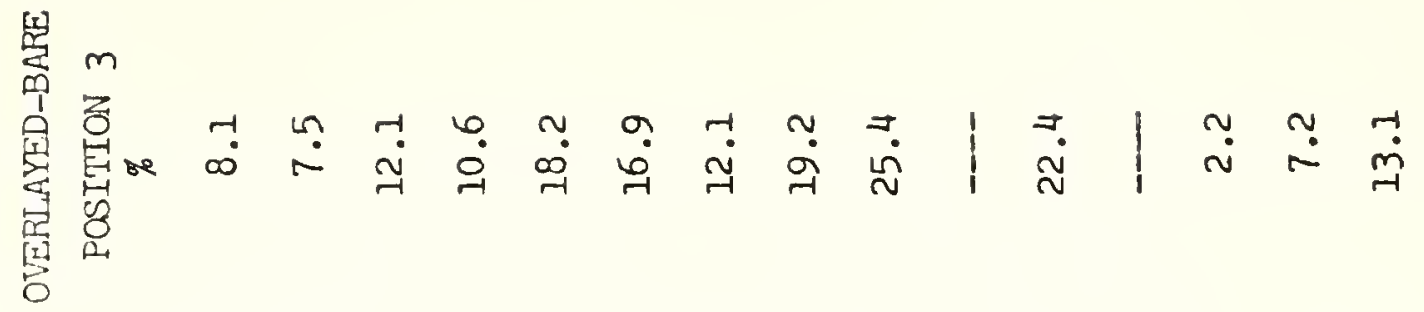

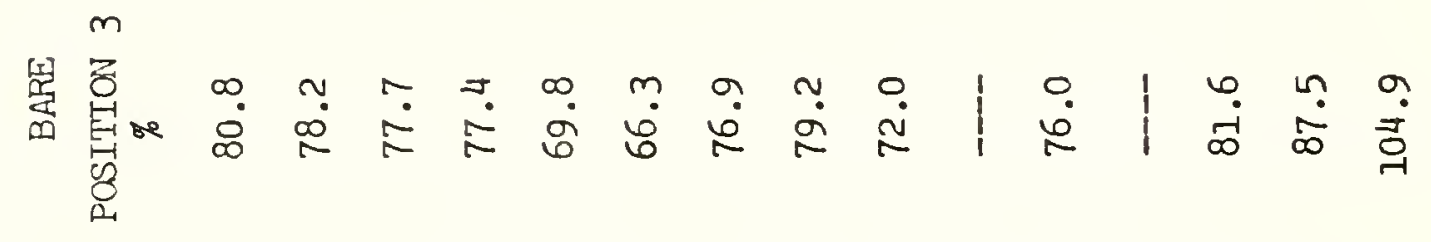

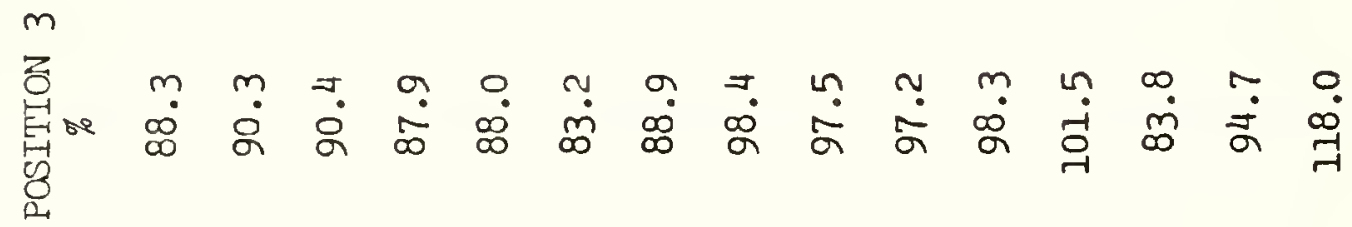

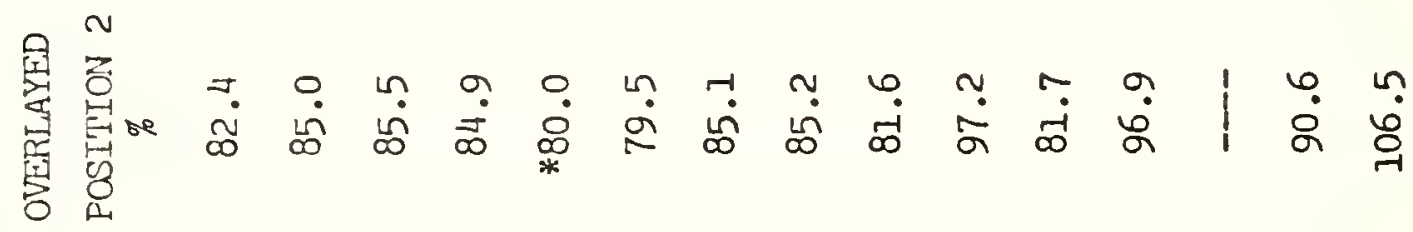

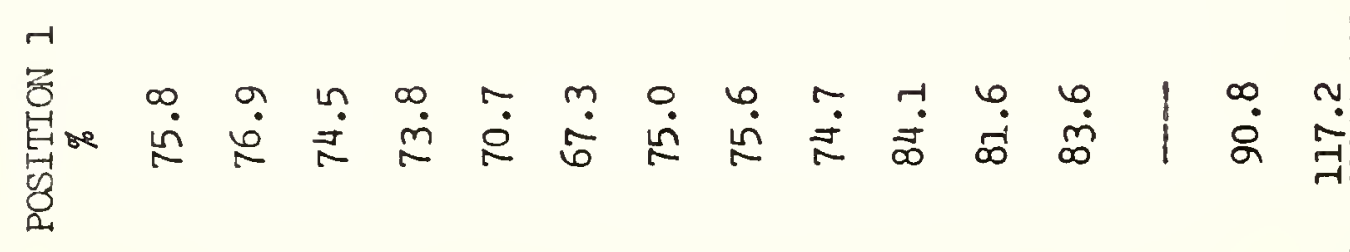

产

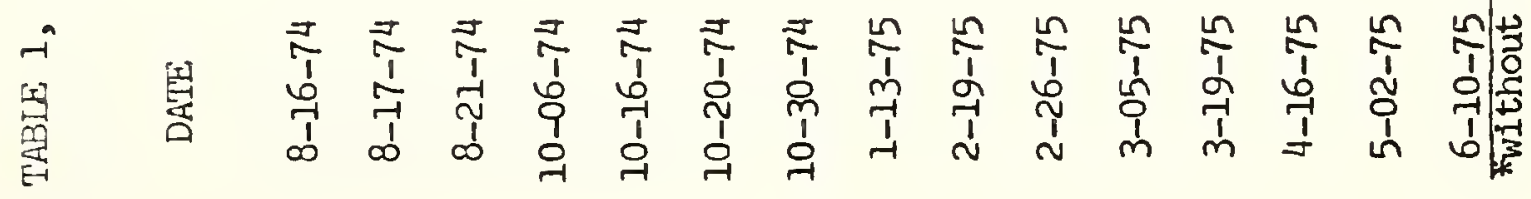




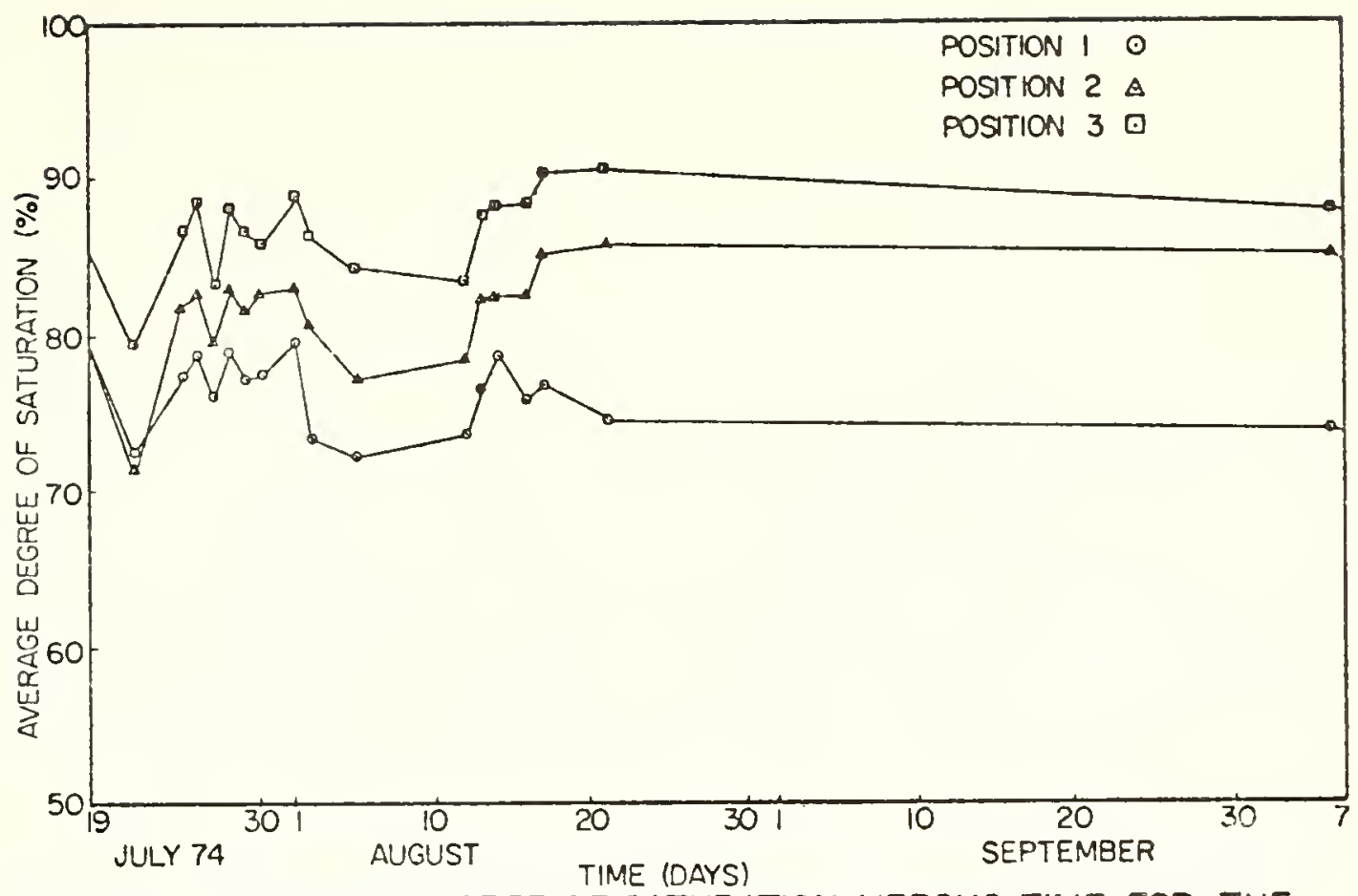

FIGURE 27. AVERAGE DEGREE OF SATURATION VERSUS TIME FOR THE OVERLAYED PAVEMENT

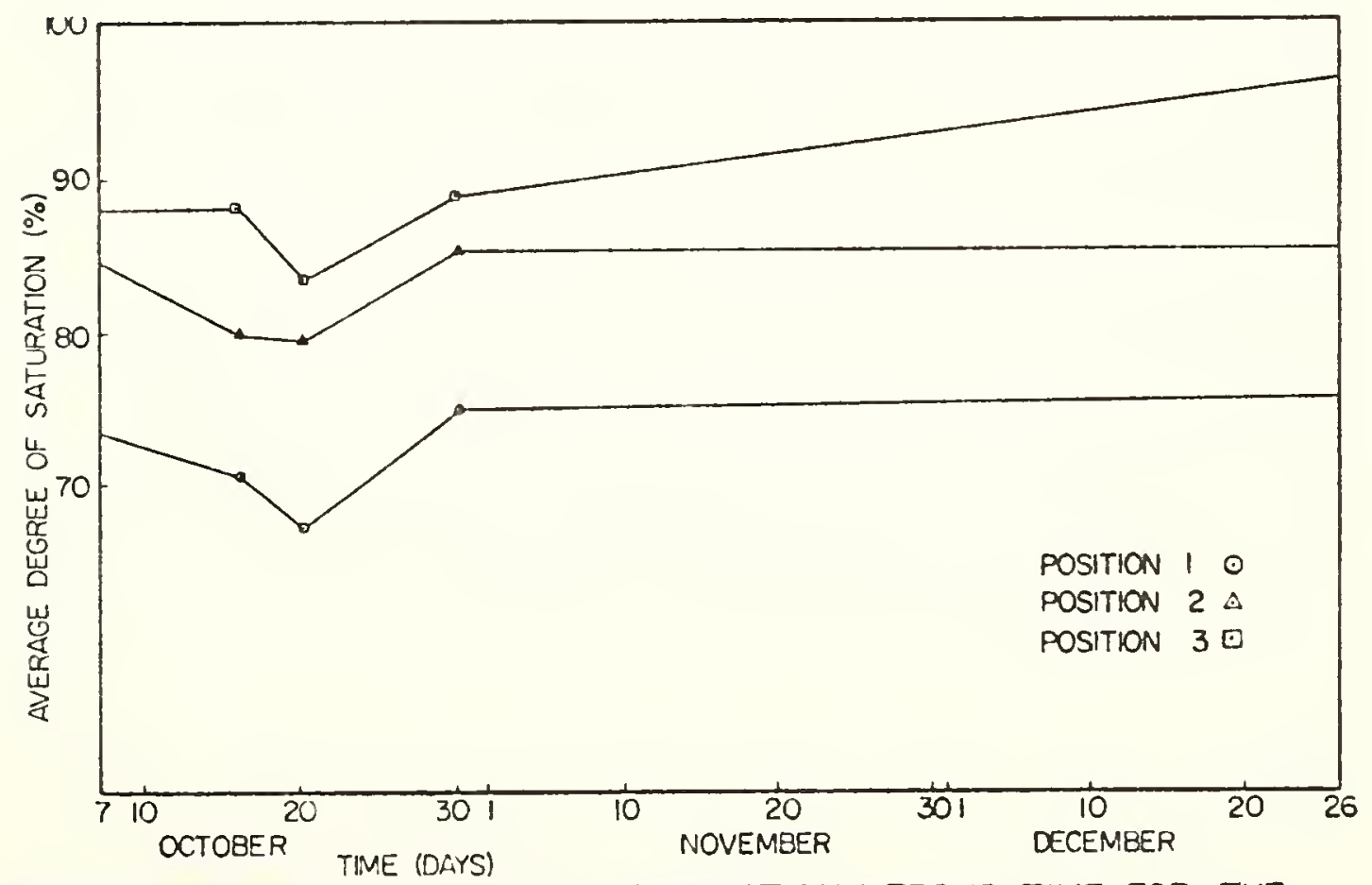

FIGURE 28. AVERAGE DEGREE OF SATURATION VERSUS TIME FOR THE OVERLAYED PAVEMENT 


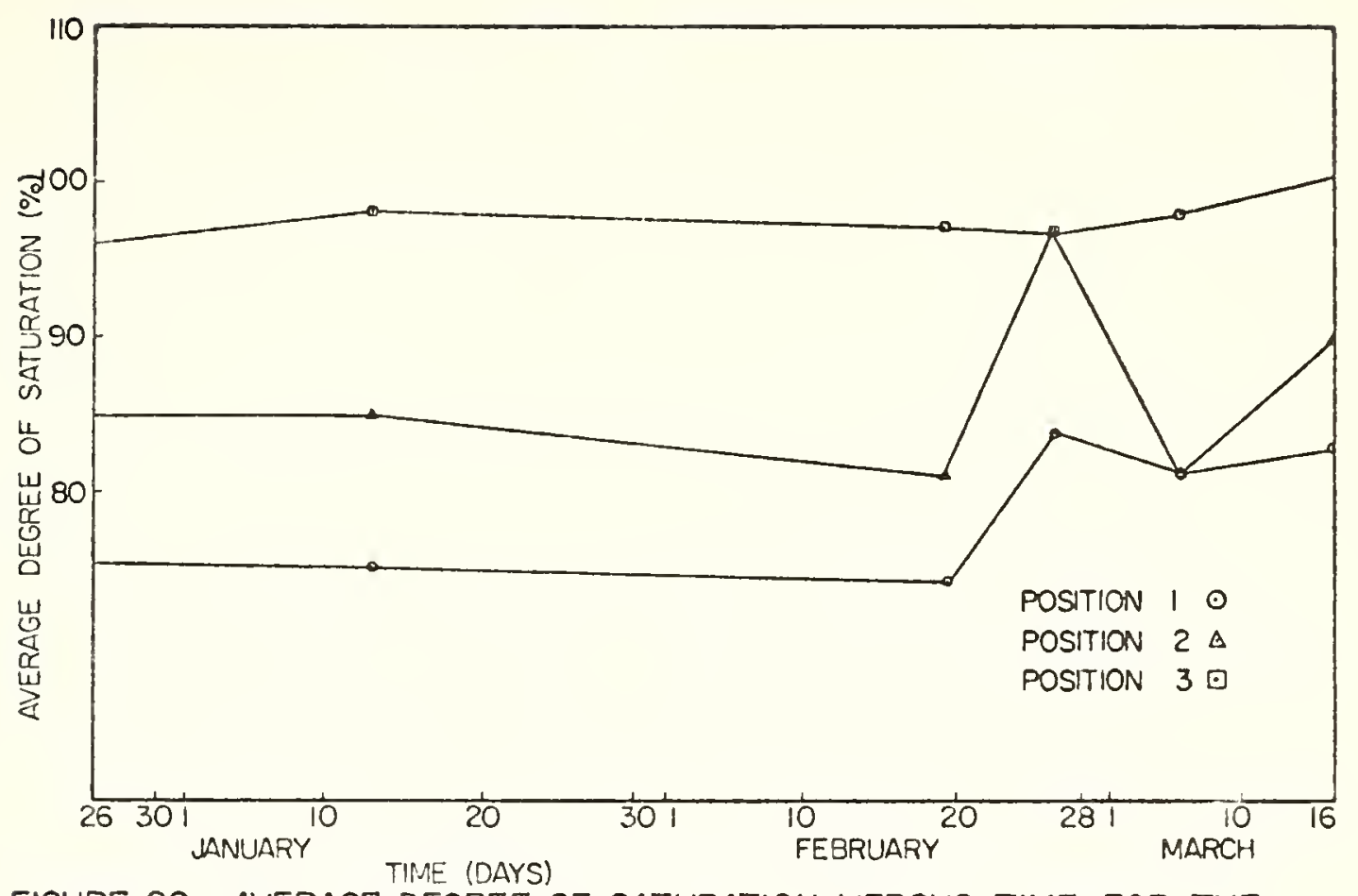

FIGURE 29. AVERAGE DEGREE OF SATURATION VERSUS TIME FOR THE OVERLAYED PAVEMENT

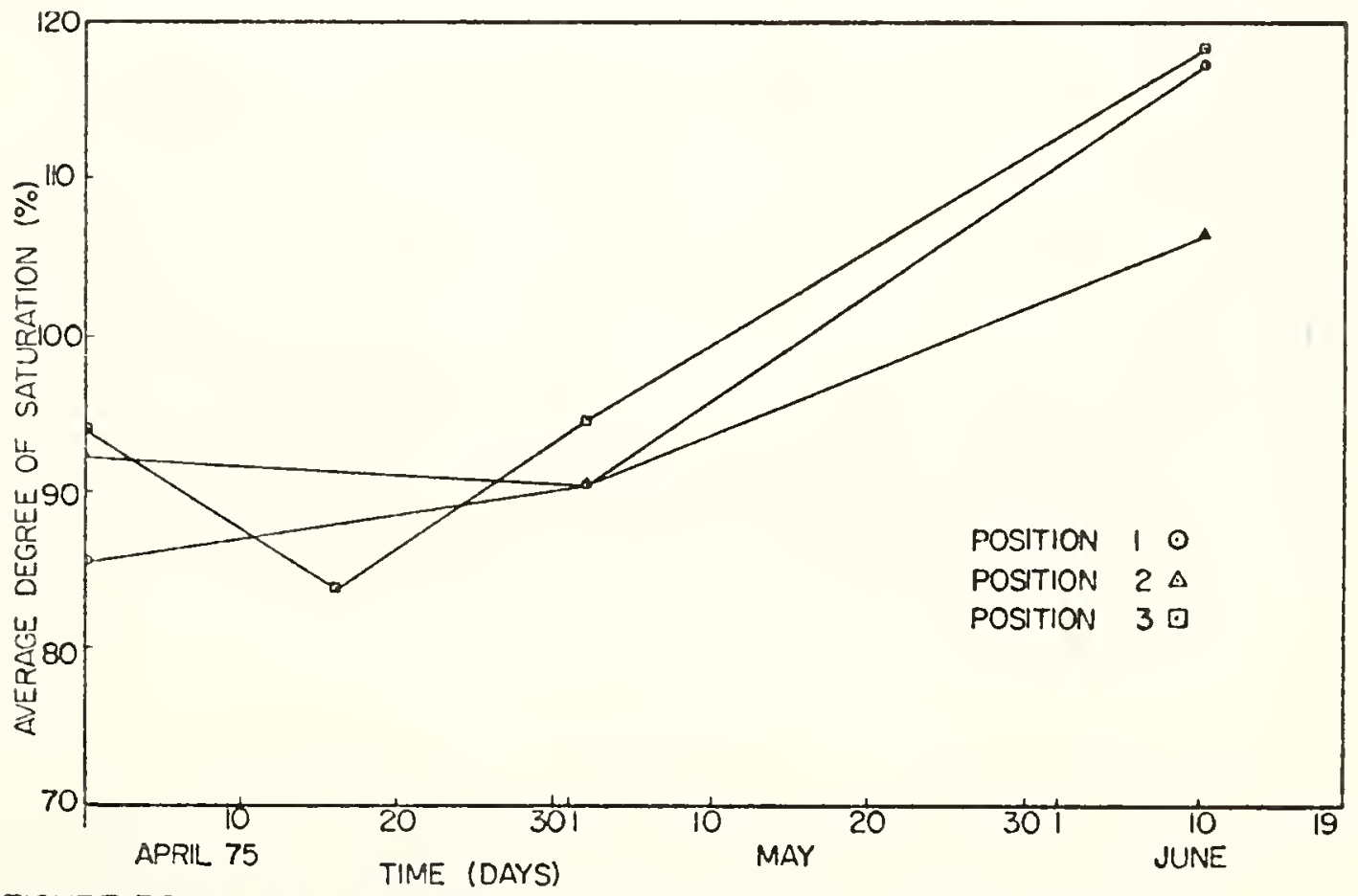

FIGURE 30. AVERAGE DEGREE OF SATURATION VERSUS TIME FOR THE OVERLAYED PAVEMENT 
During the early spring, conditions caused the gauges to go through a period of fluctuation. As of June 10, 1975 Position 2 had the lowest degree of saturation and Position 3 remained the highest at which time all were in excess of 100 percent degree of saturation. This horizontal moisture gradient was also approximately five percent per foot. Unlike the moisture state during February, this diminished from the pavement side to Position 2 and then increased towards the middle. This seems reasonable in light of the heavy rainfall that occurred in that time period.

Deformation and Strain

One premise of pavement blow-ups is pavement growth which could occur by increased moisture content when a pavement is overlayed. The deformations were monitored from August 1973 through June 1975. These data, w1th the da11y precipitation occurring in the proximity of the test site, and degree of saturations are included in Figures 31 through Figure 37.

The pavement strains were based on the original measurements taken three days after the pavement was overlayed, and they are corrected for temperature by assuming average values for the coefficients of thermal expansion. These data are given in Table 2. The average daily precipitation occurring within the proximity of the test site during July 1973 through June 1975 are given in Appendix F. 


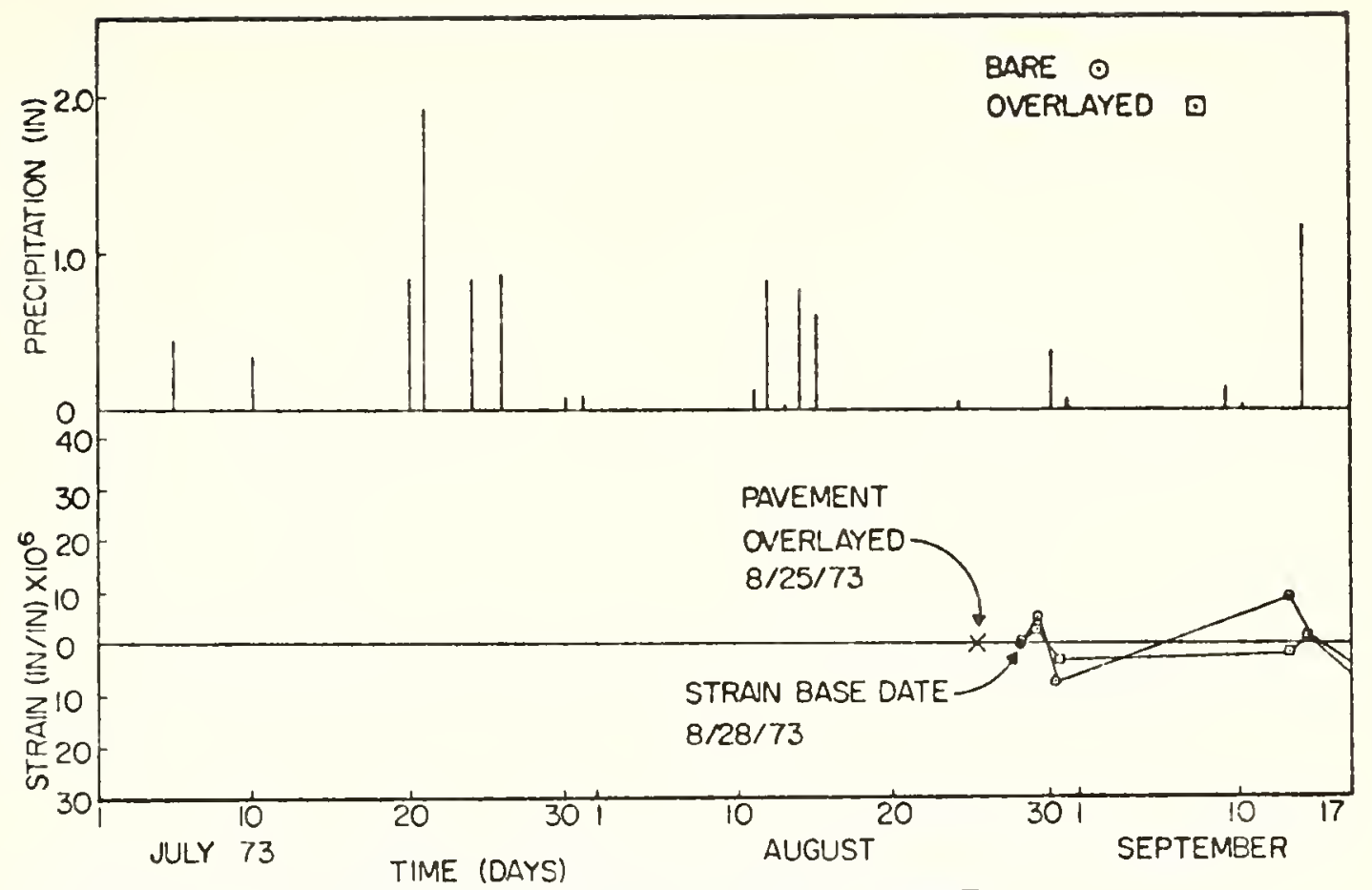

FIGURE 31. PRECIPITATION AND STRAIN VERSUS TIME

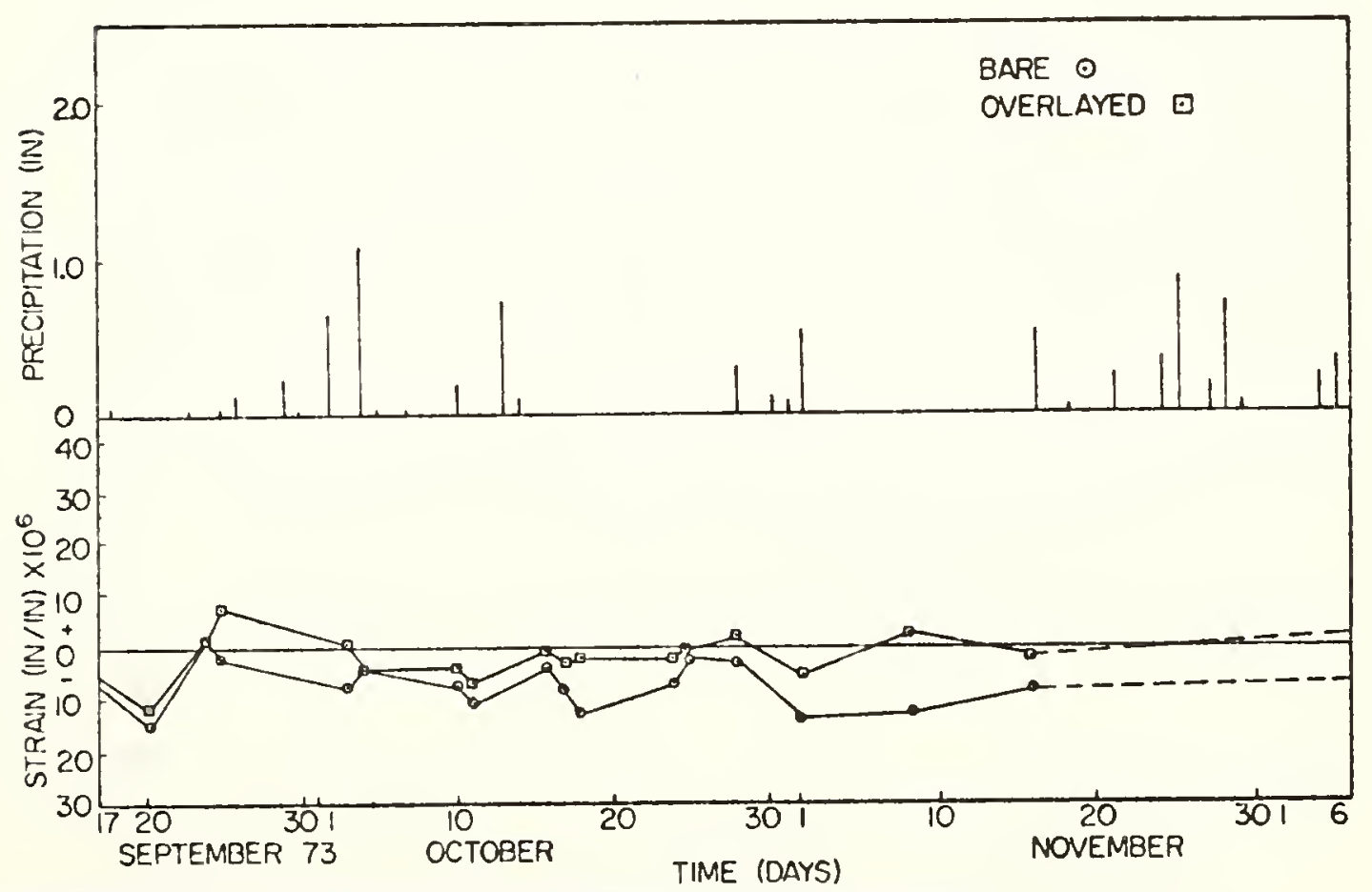

FIGURE 32. PRECIPITATION AND STRAIN VERSUS TIME 


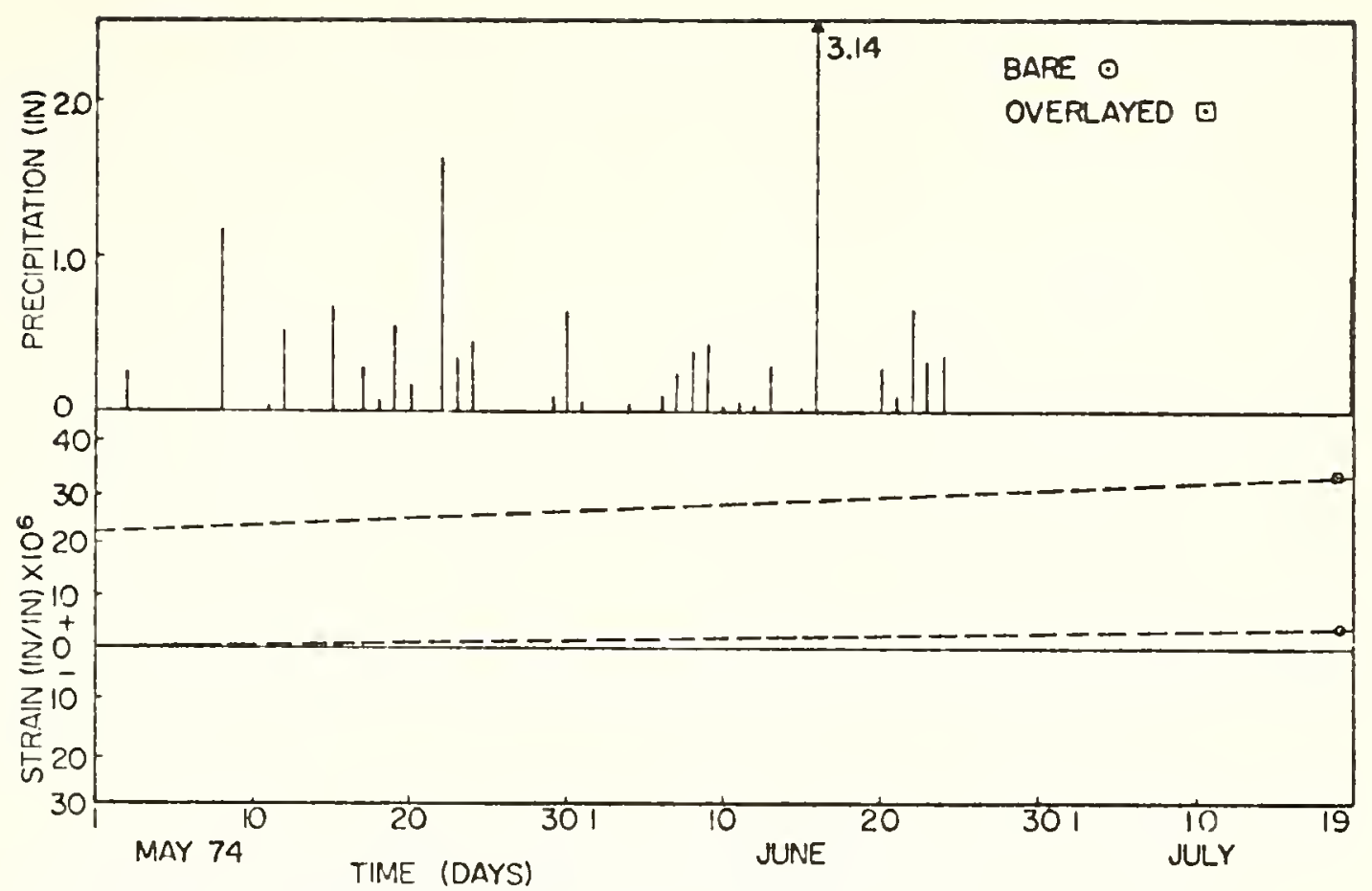

FIGURE 33. PRECIPITATION AND STRAIN VERSUS TIME

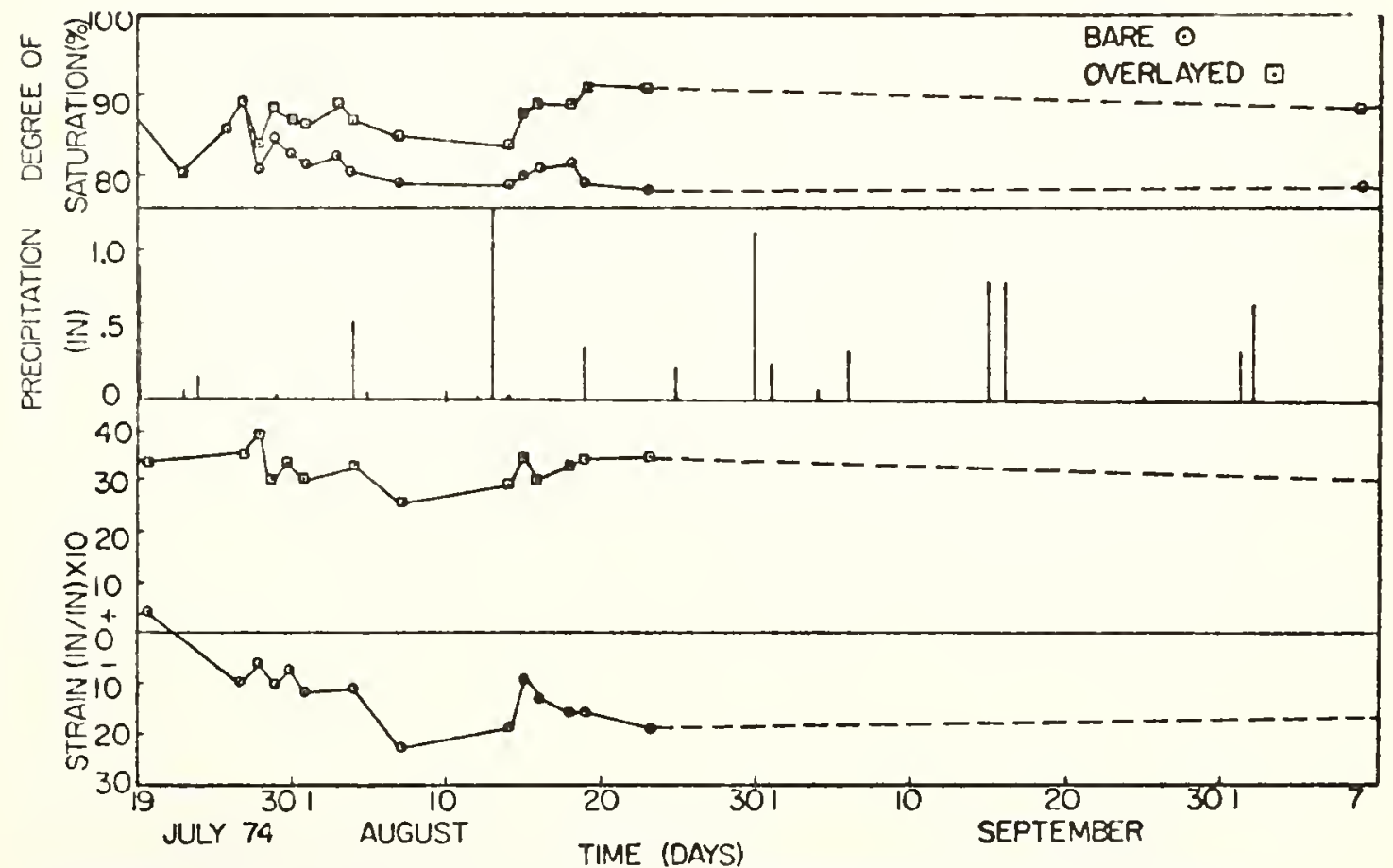

FIGURE 34. DEGREE OF SATURATION, PRECIPITATION AND STRAIN VERSUS TIME 


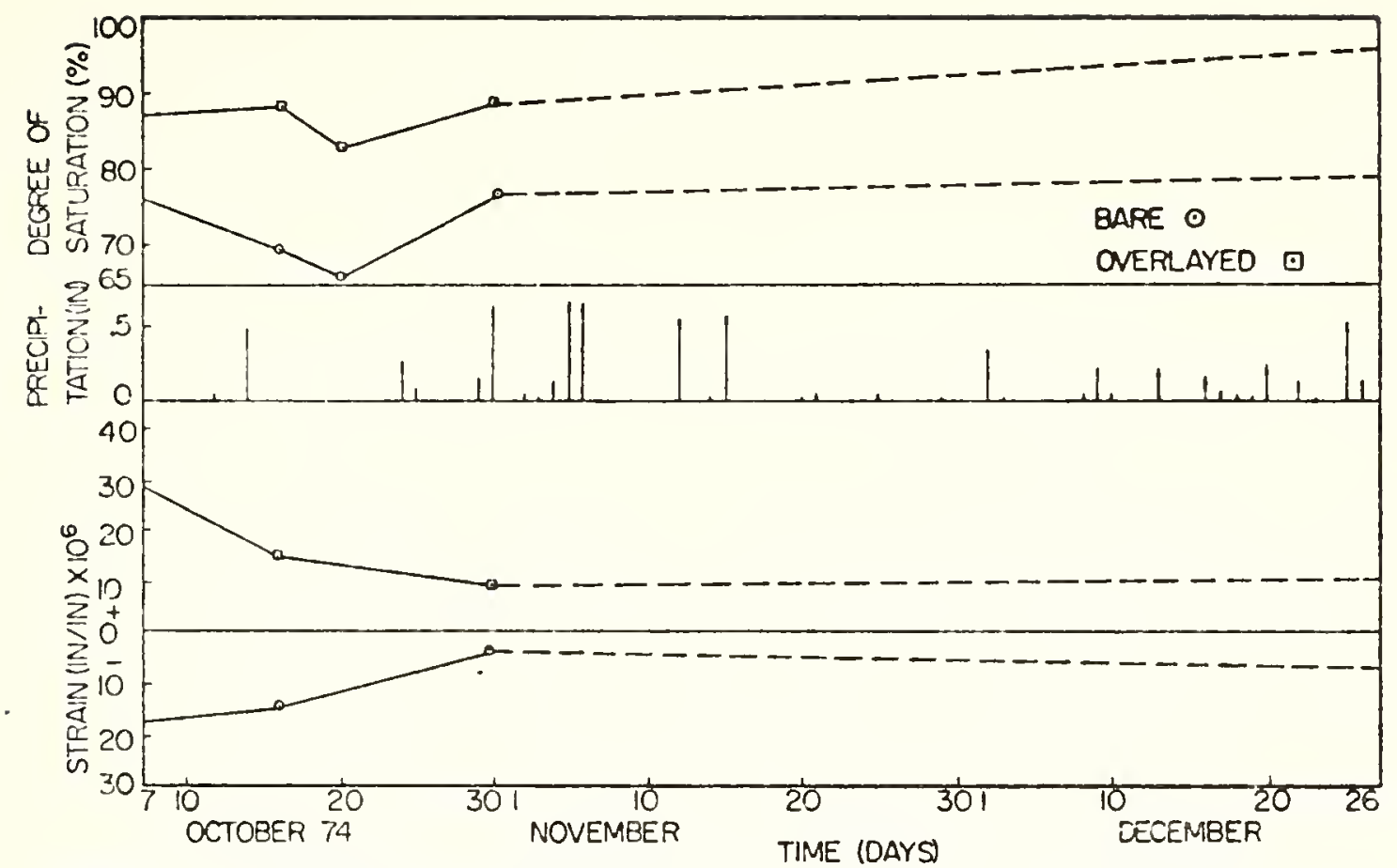

FIGURE 35. DEGREE OF SATURATION, PRECIPITATION AND STRAIN VERSUS TIME

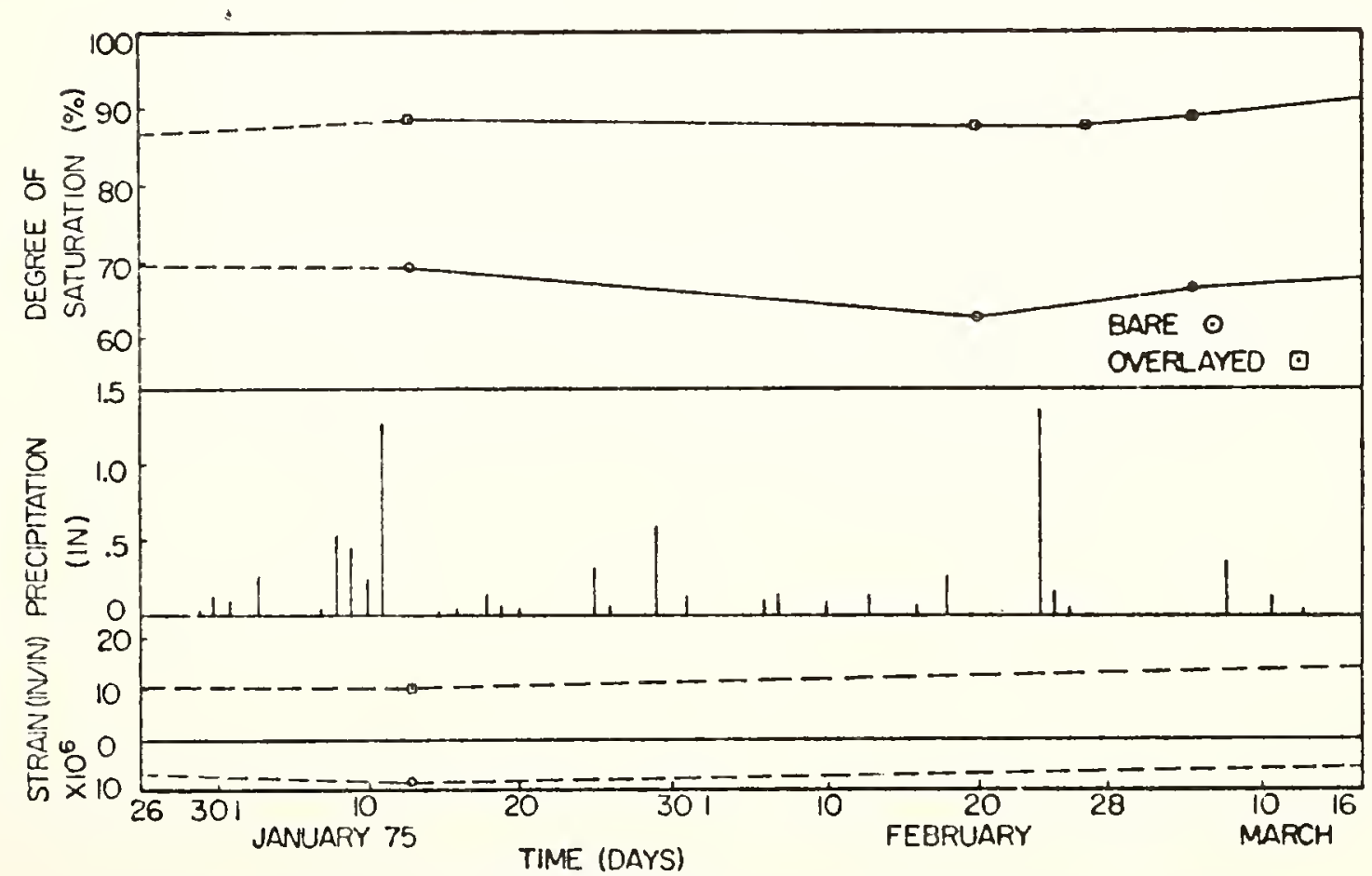

FIGURE 36. DEGREE OF SATURATION, PRECIPITATION AND STRAIN VERSUS TIME 


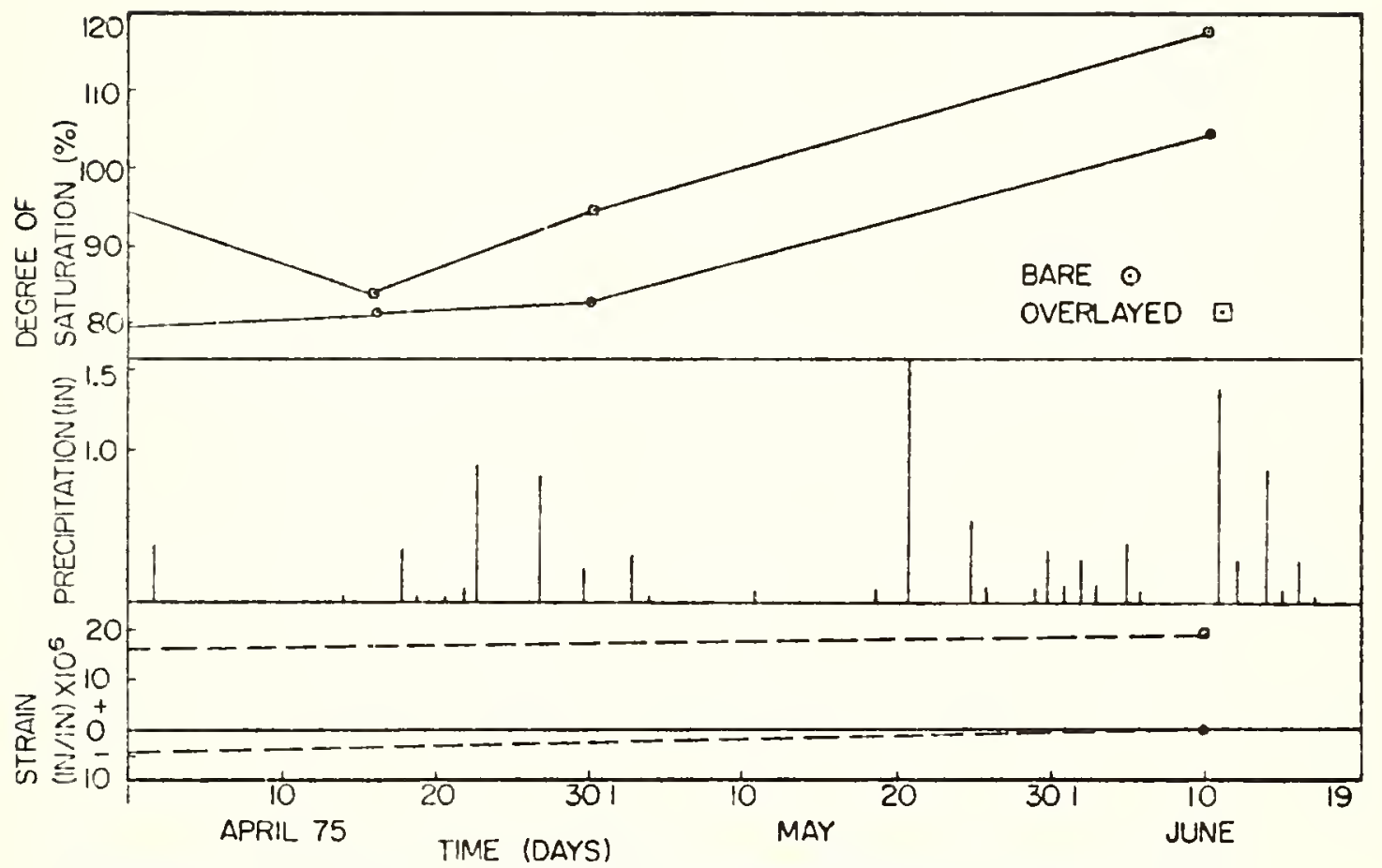

FIGURE 37. DEGREE OF SATURATION, PRECIPITATION AND STRAIN VERSUS TIME 
的

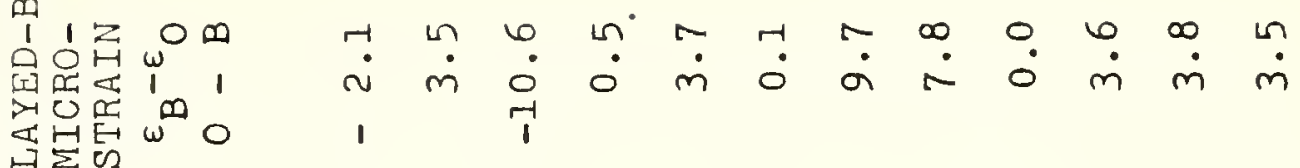
空

1 $\mathrm{Z}$

我

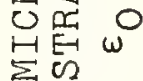

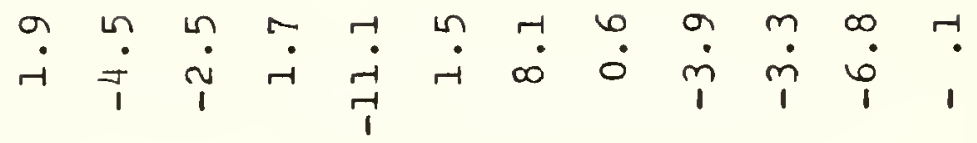

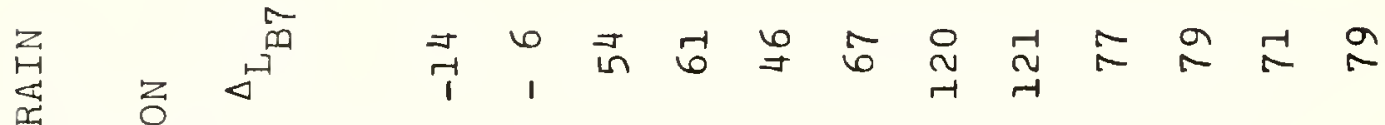

언

낭ㅇ

赵

是 $\sum_{i=1}$

品品

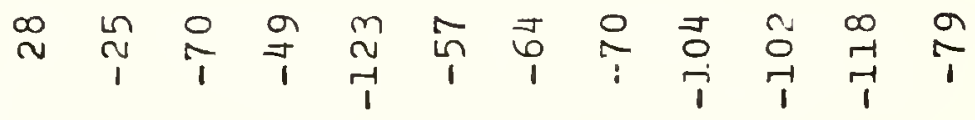

$1 \geq$

总蛋

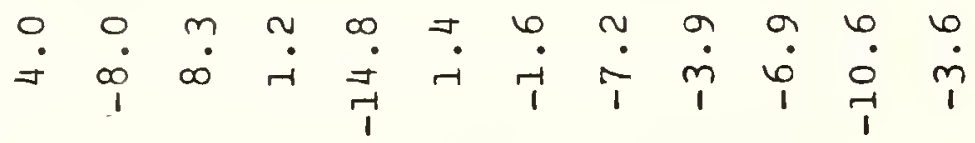

E

焉

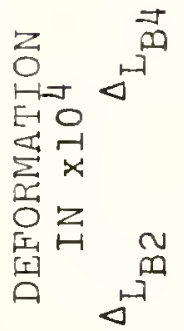

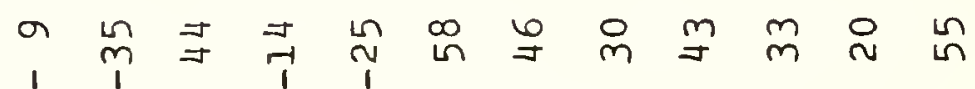

$\infty$

됩 시

II

is $\stackrel{2}{a}$

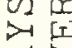

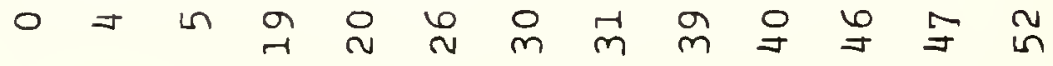

$\stackrel{1}{2}$

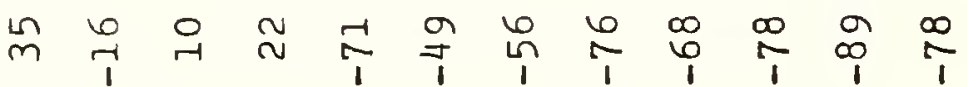

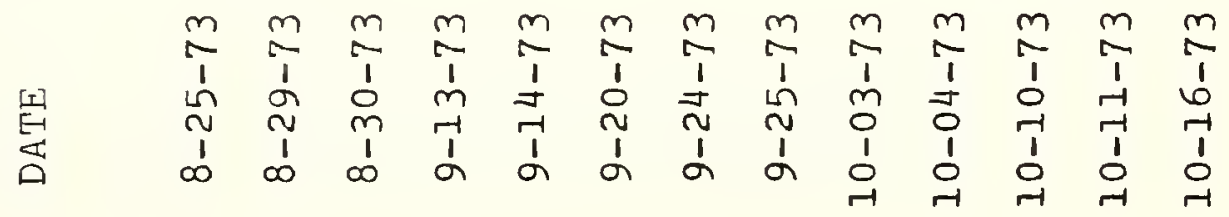


帚

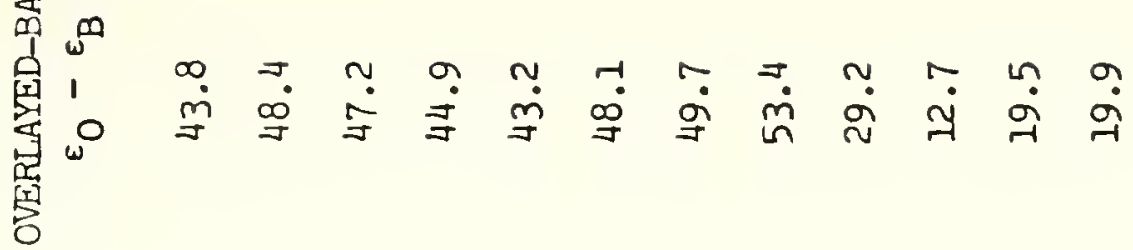

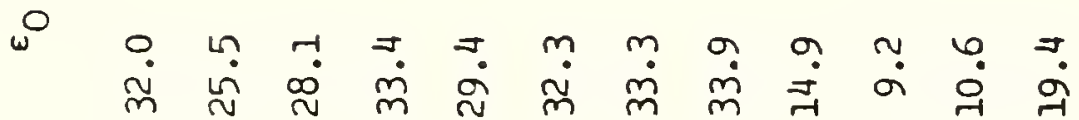

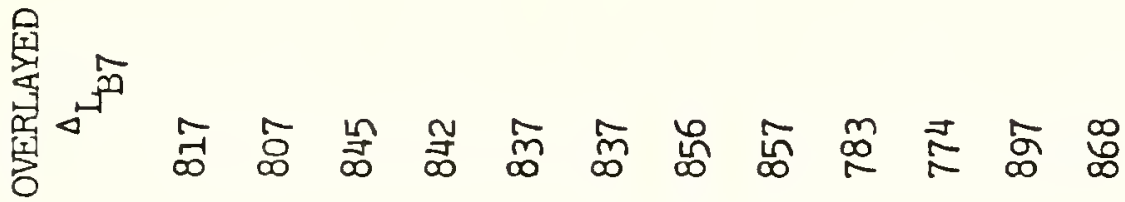

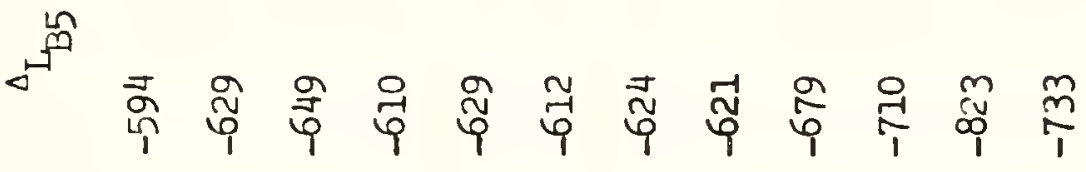

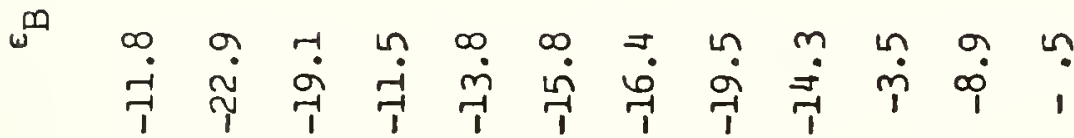

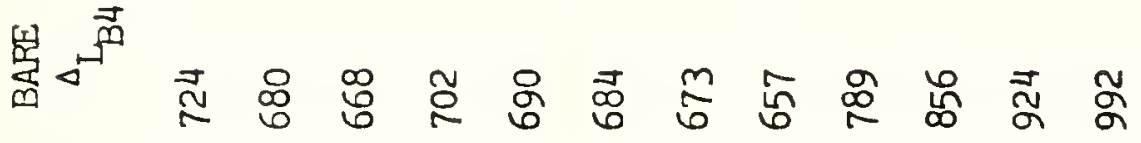

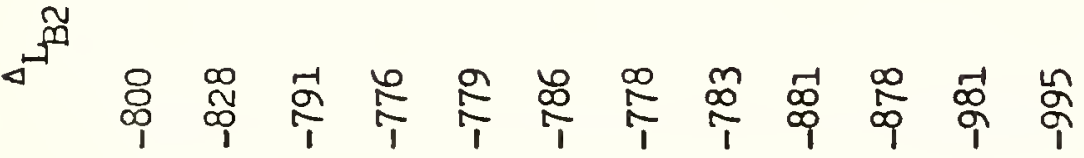

舀㬉

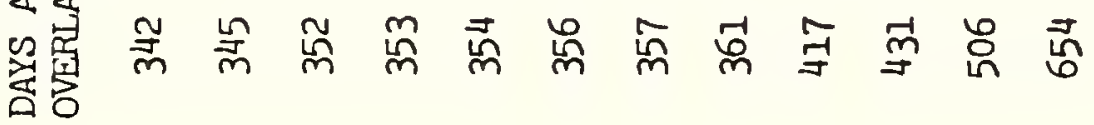

힝

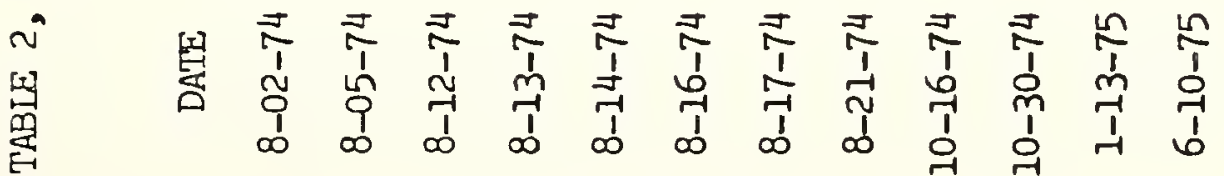




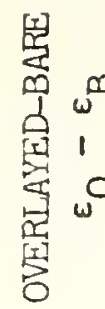

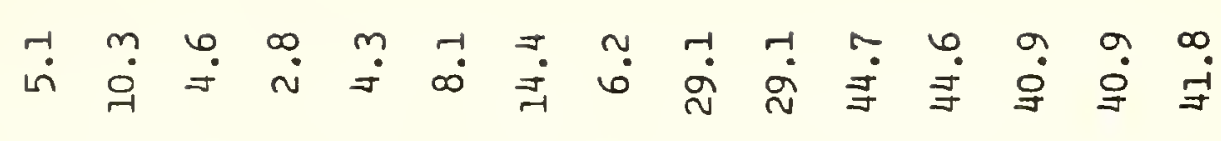

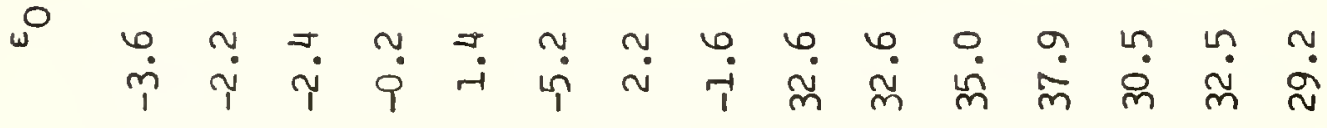

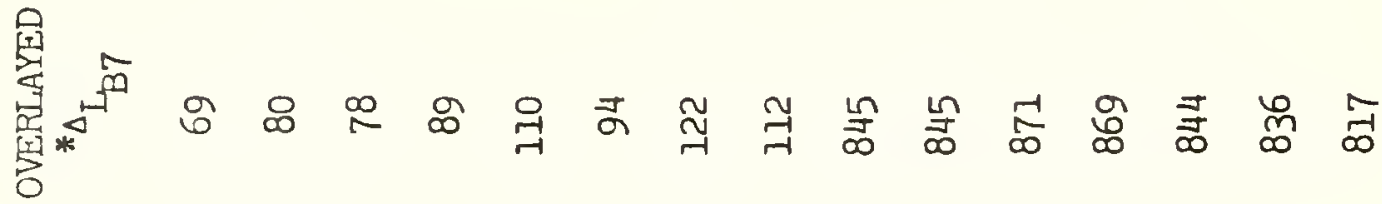

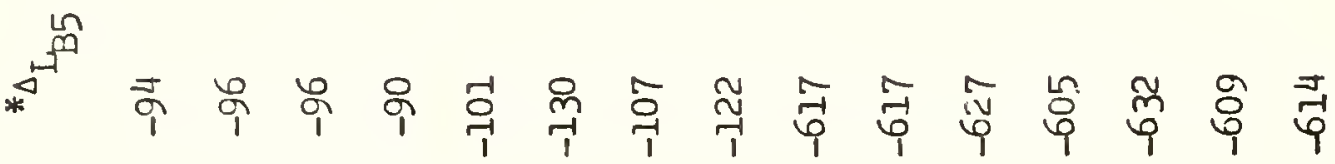

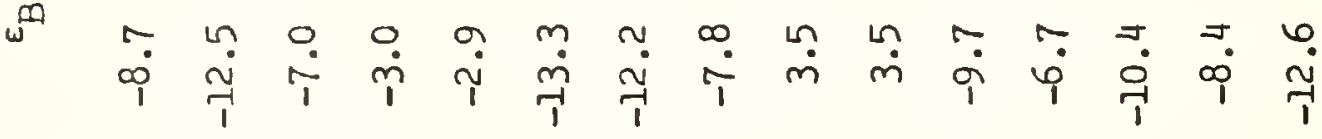

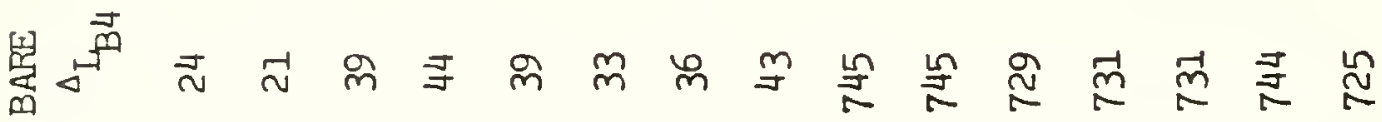

先

国星

留

㚜

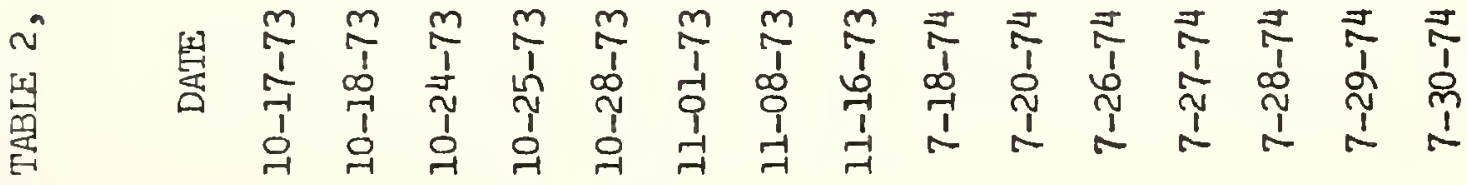


The degrees of saturation for the bare pavement and the overlayed pavement are based upon the average values of Position 3 as given in Table 1 .

During the time period August 1973 through November 1973 the strain: were approximately equal to each other and on the average tend to be negative, which implies shrinkage when compared to the base length. The precipitation occurring during the spring of 1974 caused both pavements to undergo expansion. The overlayed pavement on July 19, 1974 had a strain of approximately thirty micro-strains more than the bare pavement. At this time the bare pavement had a strain of approximately four micro-strains, thus showing little change when compared to its base length. During the month of August 1974 the difference between the overlayed pavement and the bare pavement obtained a maximum of about fifty micro-strains. At this point the overlayed pavement showed an expansion of about thirty micro-strains while the bare pavement showed a contraction of about twenty microstrains.

The relationship between precipitation, degree of saturation and strain followed a general pattern. The gauges respond directly to precipitation, especially precipitation in excess of one inch, and to extended dry periods. The strain also followed this relationship, with the bare pavement being more sensitive to precipitation changes. 
The strain in the overlayed pavement decreased from thirty-four micro-strains to nine micro-strains from August through October 1974, whereas during this same period the bare pavement increased from negative twenty micro-strains to negative four micro-strains.

The trend from October 1974 through June 1975 was to Increase the expansion of the overlayed pavement from nine micro-strains to nineteen micro-strains while during the same time period the bare pavement increased from negative four micro-strains to negative one micro-strain.

The general seasonal trend was for the overlayed pavement to show an expansion, while the bare pavement had a tendency to be equal to or less than its origlnal base strain, thus showing a contraction. The overlayed pavement showed its greatest expansion during the summer months, a period critical to blow-up actlvity. Although this strain is not of sufficient magnitude by itself to cause a blow-up to occur, it could certainly be, and probably is a contributing factor to the blow-up mechanism. A strain of this magnitude corresponds to a temperature change of approximately ten degrees.

Coefficient of Thermal Expansion

The analysis of error presented in Appendix A concludes that a restriction must be imposed on the temperature differences between deformation measurements. This restriction is necessary in order to minimize the error of 
measurement. A conservative maximum error of approximately ten percent can be achieved by restricting the temperature change between measurements to greater than about six degrees. A time interval Iimitation must also be imposed to minimize the testing error. A long time interval between deformation measurements could affect the coefficient of expansion due to the effect of a change in moisture over such an interval. Obviously, if the molsture content increases considerably an expansion caused by moisture movement will be compounded with that caused by temperature change. The end result would be an apparent increase in the coefficient of thermal expansion. Conversely a reduction in molsture content would cause an apparent decrease in the coefficient of thermal expansion. The effect of moisture change was minimized by analyzing only those data taken on the same day or late one night and early the next day. This method does not eliminate all error but should minimize it, because field moisture states, although continuously changing, do take time to change significantly. Coefficients of expansion were calculated from data satisfying the above restrictions and are presented in Table 3 and Table 4. Temperature differences between measurements are included in Table 3. The second table also contains the average daily degree of saturation for moisture probes $3-B$ and $3-0$ and the ratios of the differences in the coefficients of thermal expansion and the degrees of 
TABLE 3

COEFFICIENT OF THERMAL EXPANSION OF TEST SITE

DATE

TEMPERATURE

COEFFICIENT OF THERMAL

CHANGE ${ }^{\circ} \mathrm{F}$

EXPANSION,${ }^{\circ} \mathrm{F} \times 10^{6}$

BARE OVERLAYED BARE OVERLAYED OVERLAYED-BARE

$\begin{array}{lrrrrr}10-04-73 & -9.6 & -8.2 & 4.62 & 4.59 & -0.03 \\ 10-10-73 & -10.2 & -8.7 & 3.27 & 3.45 & 0.18 \\ 10-11-73 & 11.7 & 10.4 & 3.98 & 4.11 & 0.13 \\ 10-16-17-73 & -10.9 & -10.1 & 4.64 & 4.52 & -0.12 \\ 10-17-18-73 & 11.8 & 9.0 & 3.85 & 4.34 & 0.49 \\ 10-24-73 & 11.7 & 11.6 & 4.52 & 4.05 & -0.47 \\ 10-24-25-73 & -14.9 & -14.2 & 4.27 & 3.93 & -0.34 \\ 10-25-73 & 13.9 & 12.8 & 4.43 & 3.98 & -0.45 \\ 10-25-73 & -10.6 & -8.7 & 3.90 & 3.83 & -0.07 \\ 10-28-73 & -8.9 & -7.6 & 3.32 & 4.51 & 1.19 \\ 11-01-73 & 6.2 & 6.7 & 5.02 & 4.70 & -0.32 \\ 11-16-73 & 8.8 & 8.5 & 3.40 & 4.15 & 0.75\end{array}$




$$
\begin{aligned}
& \Omega
\end{aligned}
$$

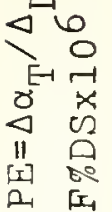

$$
\begin{aligned}
& \text { a. }{ }_{0}^{\left[y_{1}\right.}
\end{aligned}
$$

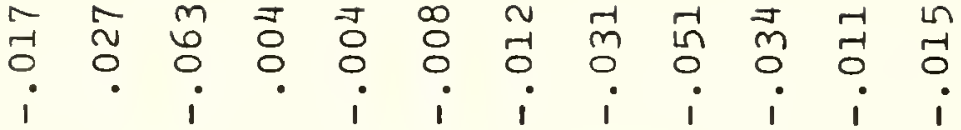

$$
\begin{aligned}
& \begin{array}{l}
2 \\
0 \\
1-1 \\
02 \\
21 \\
04 \\
01 \\
01
\end{array}
\end{aligned}
$$

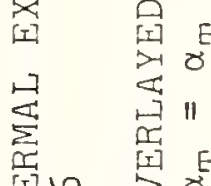

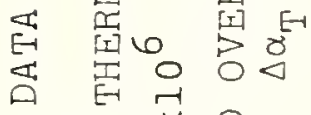

$$
\begin{aligned}
& \text { If I I }
\end{aligned}
$$

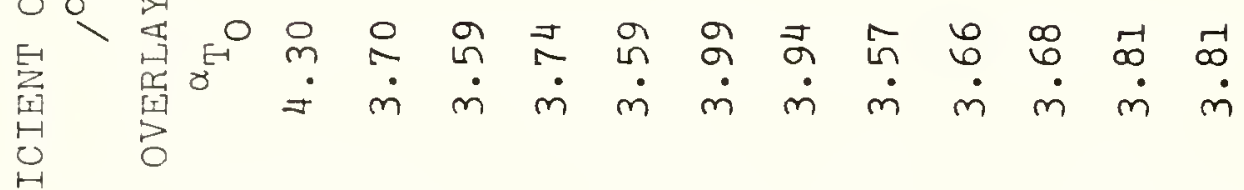

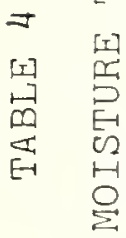

$$
\begin{aligned}
& \text { ज्ञ }
\end{aligned}
$$

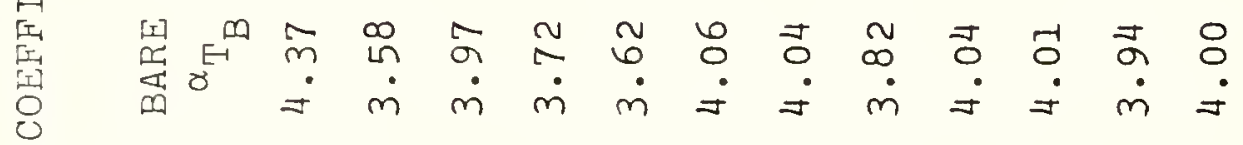

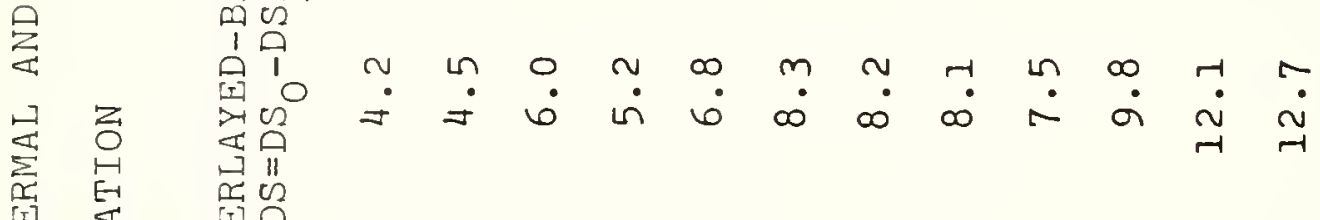

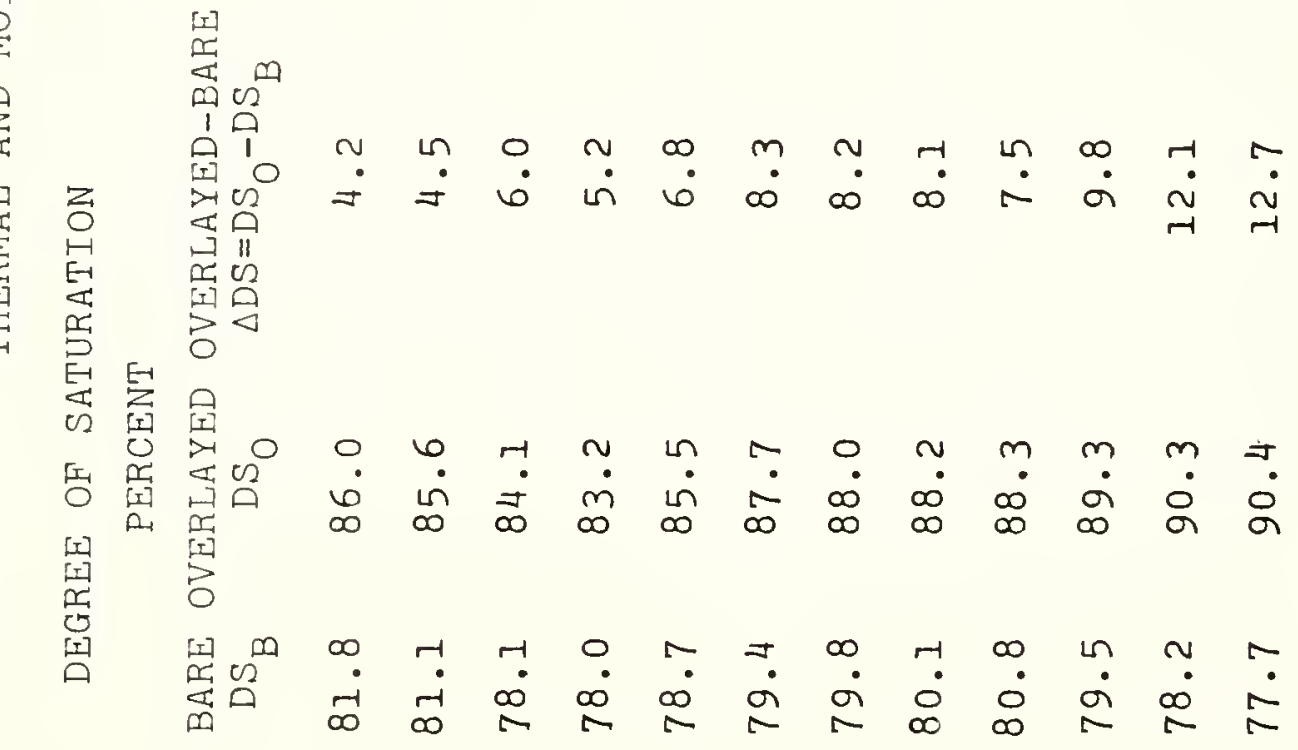

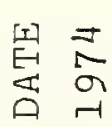

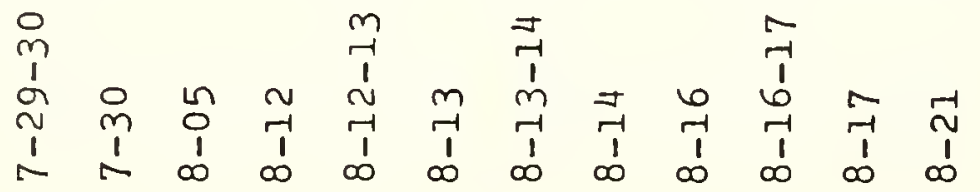


saturation. The average temperature differences between measurements for the bare pavement and the overlayed pavement were 21.2 and $18.2^{\circ} \mathrm{F}$ respectively for the data presented in Table 4. The coefficients were analyzed statistically as paired observations to test the hypothesis that there is a difference in the coefficient of expansion between the bare pavement and the overlayed pavement. The data of 1974 are significantly different at the 0.01 level. The average coefficients of expansion for the two test periods were 4.10 and $3.93 \times 10^{-6} /{ }^{\circ} \mathrm{F}$ for the bare pavement and 4.18 and $3.78 \times 10^{-6},{ }^{\circ} \mathrm{F}$ for the overlayed pavement. The average degrees of saturation for the bare pavement and the overlayed pavement were 79.4 percent and 87.6 percent, respectively. The 1973 data imply that the coefficient of expansion for the overlayed pavement was on the average approximately two percent larger than that of the bare pavement, which is certainly not of significant magnitude to be the main factor in the blow-up mechanism. Conversely, the 1974 data imply the opposite, namely that the bare pavement on the average had a coefficient approximately four percent larger than the overlayed pavement.

Figure 38 shows the relationship between coefficient of thermal expansion, precipitation and time for the bare pavement and the overlayed pavement for the 1973 testing period. The average values of the coefficients of thermal expansions are 4.10 and $4.18 \times 10^{-6} /{ }^{\circ} \mathrm{F}$ for the bare pavement 


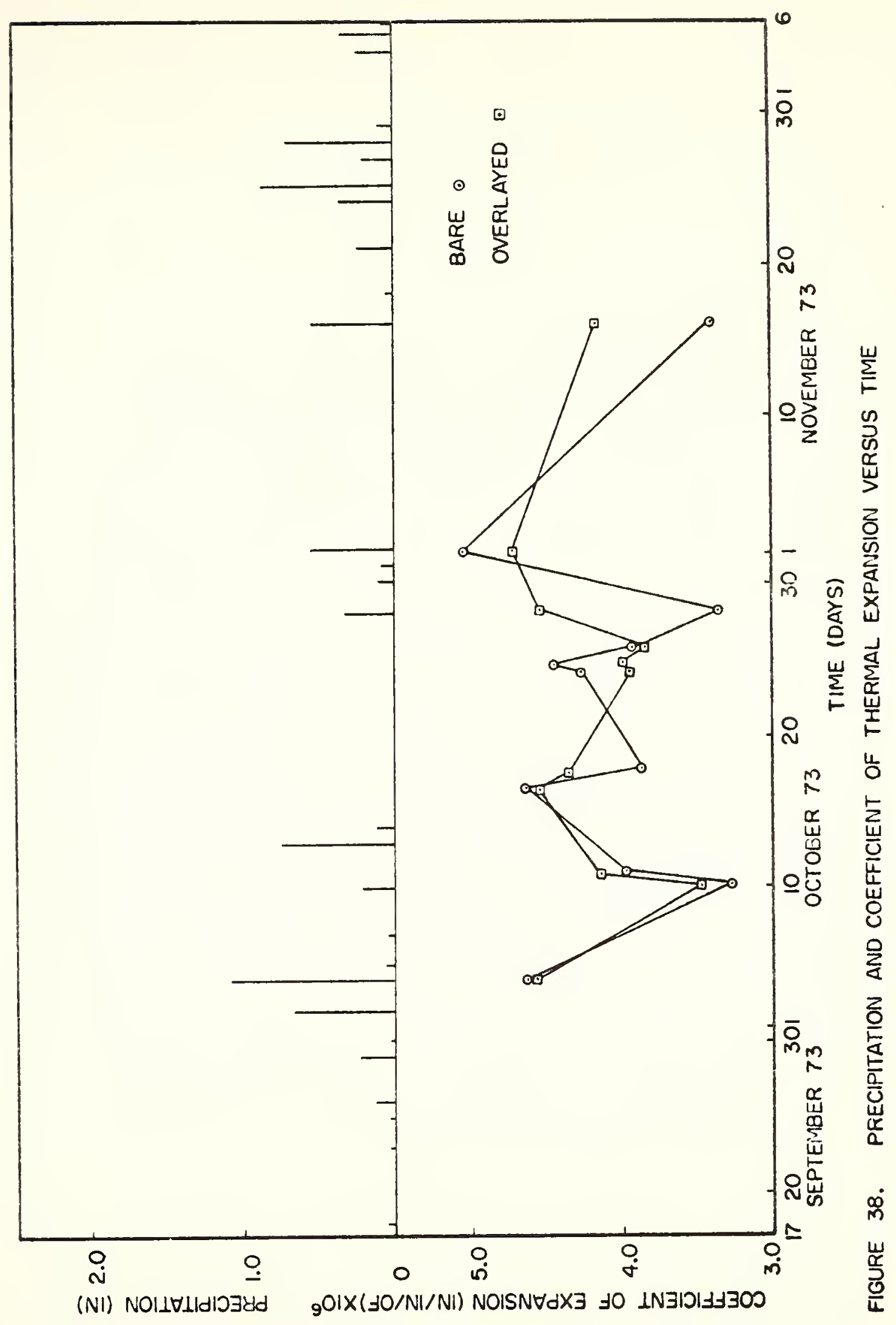


and the overlayed pavement, respect1vely. The corresponding standard deviations are 0.57 and $0.37 \times 10^{-6} /{ }^{\circ} \mathrm{F}$.

The coefficients of the bare pavement and the overlayed pavement follow a general trend of increasing with rainfall and decreasing during dry periods. The higher standard deviation of the bare pavement's coefficient implies a higher sensitivity to climatological conditions than the overlayed pavement.

Figure 39 shows the relationship of degree of saturation, precipitation and coefficient of thermal expansion as a function of time for the 1974 testing period. Both the bare pavement and the overlayed pavement followed the same general trend as during the 1973 testing period, increasing after precipitation and decreasing during periods of dryness. The degrees of saturation followed a similar trend. The average value of the coefficients for the bare pavement and the overlayed pavement were 3.93 and $3.78 \times 10^{-6} /{ }^{\circ} \mathrm{F}$, respectively. These data are significantly different at the 0.01 level. During this time period the average degrees of saturation for the bare pavement and the overlayed pavement were 79.4 percent and 87.6 percent, respectively. The coefficients determined on July 29, 1974 and July 30,1974 had average values of 4.34 and $3.64 \times 10^{-6},{ }^{\circ} \mathrm{F}$. This result corresponds to a decrease of 20 percent within a period of less than one day. While their reduction is in agreement with the general trend, it cannot be explained in 


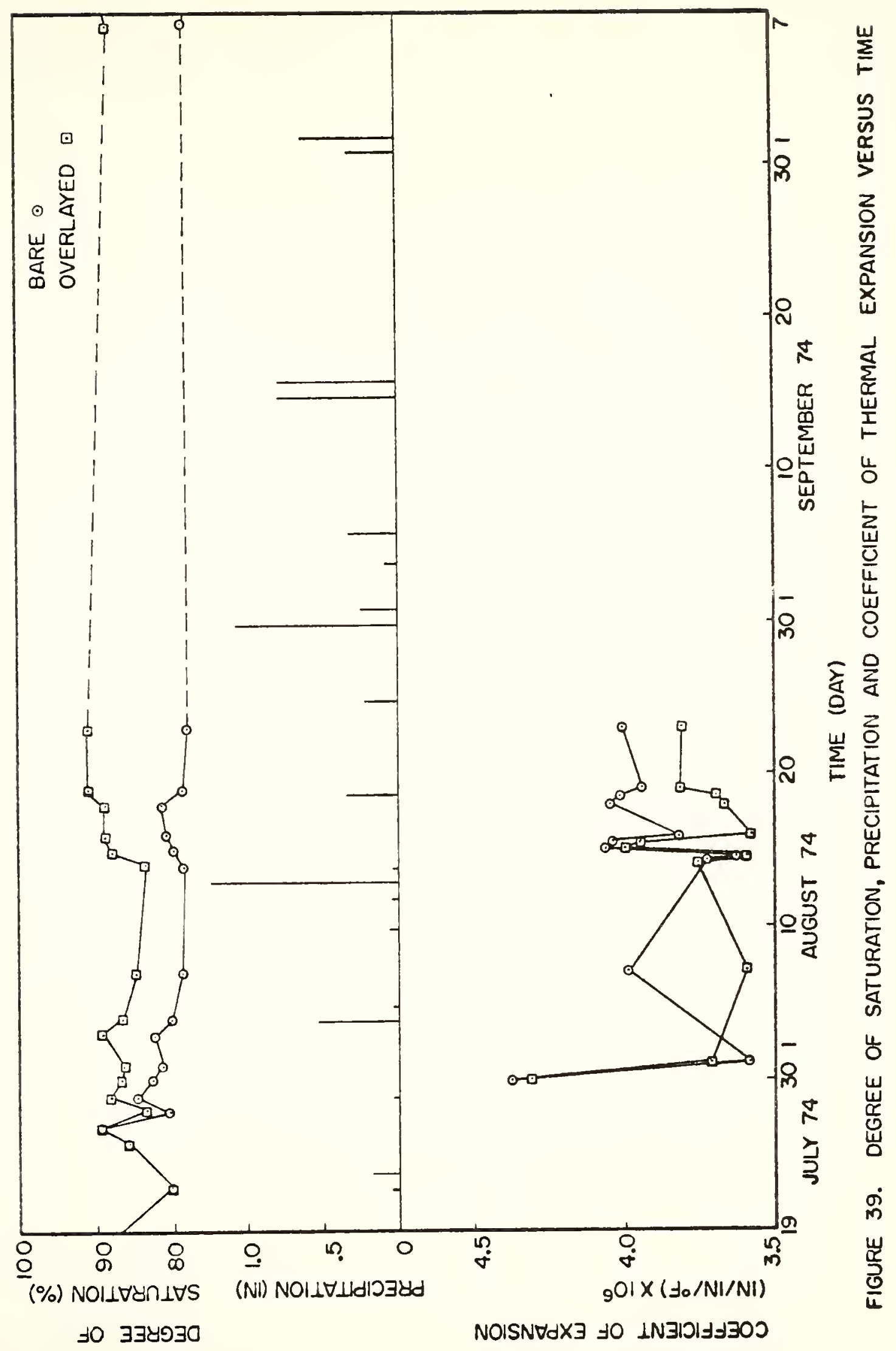


terms of changing degree of saturation or precipitation. This sudden reduction was common to both the bare pavement and the overlayed pavement. This effect can be normalized by analyzing the data with respect to each other. Table 4 gives the change in the coefficient of thermal expansion and degree of saturation and their ratio for each test day. Th1s ratio, $\Delta \alpha_{T} / \Delta D S$, is the slope of the coefficient of thermal expansion versus degree of saturation curve. W1th the exception of two values this was always negative, implying that an increase in degree of saturation causes a decrease in the coefficient of thermal expansion. The average value of this slope is calculated by

$$
\begin{aligned}
& \frac{3.78-3.93}{87.6} \times 10^{-6}, 0_{\mathrm{F}} \mathrm{FDS} \\
& =-0.018 \times 10^{-6},{ }^{\circ} \mathrm{F} \% \mathrm{DS}
\end{aligned}
$$

The significance of the negative sign is to imply that the moisture content of the overlayed pavement was higher than the maximum of their thermal expansion versus relative humidity curve.

The significance of the magnitude and sign of this experimentaliy determined slope was evaluated by analyzing independent data. Portland Cement Association Bulletin 90 (27) shows the relationship between apparent thermal expansion coefficient and relative humidity for a concrete made with quartz aggregate. The test pavements were made of a local aggregate composed of approximately equal amounts of igneous and sedimentary particles and would be expected to 
behave similar to the quartz aggregate concrete. Data points were extrapolated from the bulletin and are given in Figure 40. Conversion from relative humidity to degree of saturation can be accomplished by assuming typical properties for the paste component of the concrete. To accomplish this conversion data were taken from Portland Cement Association Bulletin 22 (28), Table A-12, page 321. The Type I cement had a water cement ratio of 0.433 and was cured for 180 days before being tested. These data were used to develop the relationship between degree of saturation and relative humidity. Assuming the pavement concrete had a corrected water cement ratio of 0.433 and the aggregate has zero absorption, the apparent thermal coefficient can be expressed as a function of the degree of saturation, as presented in Figure 41. The apex of the curve has shifted to the left and occurs at a degree of saturation of around 47 percent. The best fit slope from 45 percent to 100 percent degree of saturation assuming a linear relationship is $-0.017 \times 10^{-6} / 0^{\circ} \%$ DS which compares well with the average experimental value from the pavements of $-0.018 \times 10^{-6} /{ }^{\circ} \mathrm{F} \% \mathrm{DS}$.

The effect of increasing the water cement ratio of the concrete on the curve of coefficient of thermal expansion versus degree of saturation is to decrease the value of degree of saturation at which the maximum coefficient occurs. Since the lowest recorded degree of saturation for 


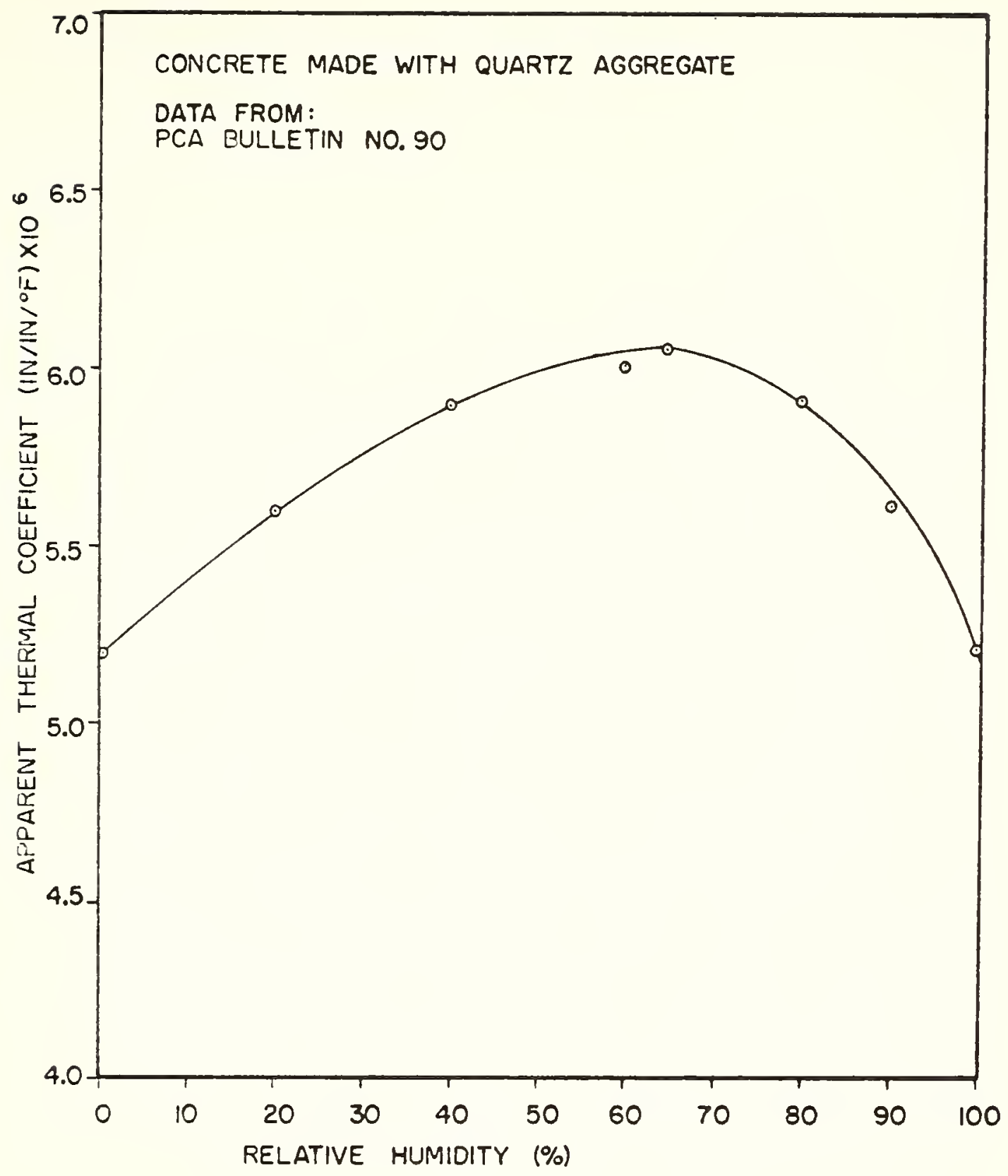

FIGURE 40. APPARENT THERMAL COEFFICIENT VERSUS RELATIE HUMIOITY 


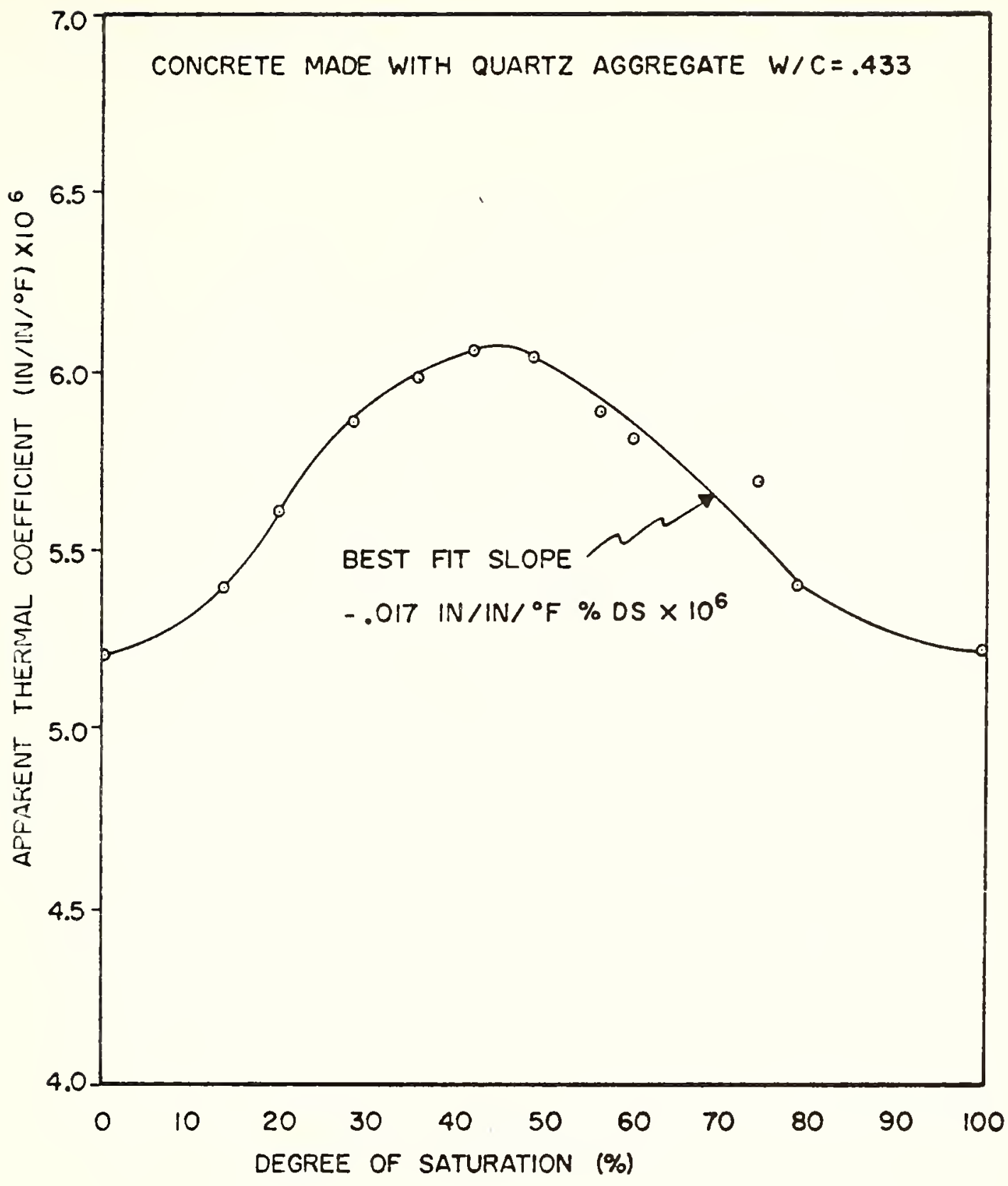

FIGURE 41. APPARENT THERMAL COEFFICIENT VERSUS DEGREE OF SATURATION 
the overlayed pavement was 67.3 percent, the coefficient would always decrease with increasing degree of saturation. The experimental slope, $-0.018 \times 10^{-6} /{ }^{\circ} \mathrm{F} \% \mathrm{DS}$, can be used to predict the maximum and minimum coefficients of thermal expansion to be expected over the possible range of degree of saturation. A maximum coefficient of thermal expansion of $4.47 \times 10^{-6} /{ }^{\circ} \mathrm{F}$ would occur' at a degree of saturation of 50 percent and a minimum value of $3.55 \times 10^{-6} /{ }^{\circ}$ at 100 percent degrees of saturation.

Expected degree of saturation can be determined using the experimental slope and a measured value of coefficient of thermal expansion. The predicted average degrees of saturation for the bare pavement and the overlayed pavement are 70 percent and 66 percent, respectlvely, for the 1973 testing period. Considering the amount of precipitation before and after the pavement was overlayed, the season of the testing period, and the time period after being overlayed, these values seem reasonable. These values also imply that an extended period of time is required for an overlayed pavement to increase its degree of saturation. To date, the overlayed pavement has a 13 percent higher degree of saturation than the bare pavement.

In conclusion it seems that overlaying a pavement increases its degree of saturation and concomitantly decreases its coefficient of thermal expansion. The time required for a significant change in the moisture state 
of the overlayed pavement is a function of precipitation and, to date, is still increasing after two years, having a 13 percent higher degree of saturation to date than the bare pavement. This corresponds to a decrease in the coefficient of thermal expansion of about 6 percent.

Summarizing the overlayed pavement reached a level of critical saturation when freezing temperatures were prevalent. The increase of moisture due to overlaying a pavement caused an expansion equal to the same effect as a ten degree temperature rise. The horizontal moisture gradient was 5 percent per foot. Except during periods of high precipitation, the degree of saturation increased from the pavement's side to the middle portion of the pavement. The middle portion of the pavement always had a higher degree of saturation. The slope of the thermal coefficient of expansion and degree of saturation curve over the normal range of moisture encountered in the field was $-0.018 \times 10^{-6} / \mathrm{F}^{\circ} / \% \mathrm{D}$.S. The occurrence of critical saturation of overlayed pavements would lead one to expect more deterioration in freezing and thawing in the colder portion of the state. This was found to be true. However, it also could be caused by infiltration or deflections caused by heavier traffic. In all probability, all three factors contribute to the demise of quality concrete adjacent to cracks and joints under overlays.

The quality of the aggregate in freeze-thaw exposure is of considerable concern. A marginally D-cracking aggregate, for instance, would become more saturated and undergo more distress after overlaying than when it was bare. 


\section{LABORATORY TESTING}

\section{Coring Scheme}

The first objective of this study was to collect information concerning the blow-up performance of overlayed rigid payements under the authorlty of the Indiana State Highway Commission. Information was compiled on more than 3400 miles of rural highway. These data included the blow-up distress, as categorized during the 1971 fleld survey, and construction data for each test section. These data were extensively analyzed as reported by Foxworthy (10).

Previous work of Woods, Sweet and Shelburne (2) Implies that the source and type of the coarse aggregate have a high correlation with blow-up performance for bare concrete pavements. The field survey data were statist1cally analyzed to see if such a correlation also exists for overlayed pavements. The analysis concluded, on the average, that pavements made with gravel aggregates showed poorer blow-up performance than those made with crushed stone and, unlike the original work of Woods, Sweet and Shelburne, that little significance could be placed on the Individual source of aggregate. The first conclusion seems reasonable if significant emphasis is placed on the coefficient of thermal expansion, since concrete made of gravel 
would be expected to have a higher coefficient of thermal expansion. Statistical insignificance of source also seems reasonable in light of the wide spread blow-up performance of overlayed concrete pavements.

Although the field survey did not show a significant difference among the various sources of aggregate analyzed, the possibility of such a relation could not be ignored in the method of core selection.

A generalized correlation between blow-up distress and composition of aggregate, if reliable, would be beneflcial in determining the method of core selection. Such correlations were determined by relating blow-up distress to chemical composition and rock type composition. The compositional data compiled by the Indiana Geological Soclety and the Indiana Limestone Producers Association were determined from samples obtained in the general vicinity of the aggregate sources used in the pavement test sections. Correlation regression $R^{2}$ values of 0.30 and 0.06 were found for the limestone and gravel sources, respectively. Unfortunately these correlation equations were not capable of relating blow-up performance to aggregate type w1th any rellability, and were not used as a basis of core selection. This does not imply that a reliable correlation does not exist, because in order to accomplish this analys1s 1t was necessary to assume the test sections were constructed with aggregate of the same composition and type as the samples 
taken from the general area of the aggregate sources.

In the absence of any known relation of blow-up distress it was decided to select the sections to be cored by observing the information complled in the state blow-up survey (10). Concrete age, blow-up distress, route number, number of overlays, age of last overlay and source of coarse aggregate were given consideration in selecting the test sections to be cored.

Bare pavements were also included in the coring sections in addition to the overlayed sections considered in the state survey of blow-ups. Special emphasis was given to the location of those sections which were partially overlayed, as this would glve a valuable indication of the effect of overlaying a pavement. Test sections of bare concrete pavement which had been overlayed with portland cement concrete were also selected to evaluate the effect of a non-asphalt overlay. Unfortunately every section had also been overlayed at least one additional time with asphalt; in fact, one section on U.S. 20 had a total thickness in excess of 24 inches and could not be sampled with conventional coring equipment.

V1sual observations were made of the selected sections, and the specific locations to be cored were determined. The basis of determining the position of coring within each section was to core in the vicinity of a blow-up distressed area, and also within an area of zero blow-up distress. The 
locations cored on those sections without blow-ups were determined primarily on a basis of traffic safety.

The effect of infiltration was also investigated during the coring process for certain selected sections by taking cores over joints and cracks.

A total of 176 test cores were obtained from selected test sections throughout the six districts of the state. Appendix $G$ gives detailed information for each test core. The Indiana State Division of Materials and Testing of the Indlana State Highway Commission kindly supplied the coring rigs and personnel to obtain the test cores.

\section{Test Core Analysis}

The test cores were given an identification number and were then stored until tested. The first digit of the identIfication number corresponds to the Indiana state Highway District in which the test section was located. The districts, labeled one through six, are: LaPorte, Fort Wayne, Crawfordsville, Greenfleld, Vincennes and Seymour, respectively. The remaining digits in the identification number chronologically numbers the test cores in the order in which they were taken.

Physical measurements were taken and recorded on each test core as 1 t was recelved in the laboratory. These include number and thickness of overlays, concrete thickness, aggregate types, and presence of freeze-thaw cracks and scaling cracks. In addition to physical measurement, 
each test core was photographed.

Polished sections were examined for composition, General physical condition, and infiltration. Surfaces were prepared by cutting a slab from the center of each test core and then polishing one side of the slab. The polished sections were approximately four inches wide and as long as the original test core was high. A technique was developed to repair those samples that broke during the coring or cutting processes. This worked well on clean breaks and maximized the polished areas on friable, weak samples.

\section{Composition}

Compositional analysis was determined on selected test cores in accordance with the modified point count method of C457 (29). These data are presented in Table 5. With the exception of air content, they are approximately equal. This is as expected, since all test cores were from pavements that have approximately equal specified compositions. The average percentages for paste, coarse aggregate and fine aggregates were 22.4 percent, 46.5 percent and 27.9 percent, respectively. Test cores 3-49, 3-51, 3-52 and 3-54 were the test cores obtained in preparing the Cherry Lane test site for moisture probes BPI, BP3, OPI and OP3, respectively. The average values of air, paste, coarse aggregate and fine aggregate for the bare test pavement were $4.4,23.7$, 49.3 and $22.8 \%$ respectively, and for the overlayed test 
TABLE 5

COMPOSITTONAL ANALYSIS OF TEST CORES

SAMPLE

NUMBER

AIR

PASTE

COARSE

FINE

$1-1$

1.1

26.4

41.5

31.0

$3-6$

1.7

20.8

53.3

24.2

$3-21$

1.0

23.9

45.6

29.4

3-22

1.1

23.4

41.8

33.6

3-25

1.7

20.1

43.1

35.1

3-27

0.9

20.1

51.2

27.8

3-28

4.5

19.9

38.8

36.8

3-30

5.4

21.7

41.4

32.4

3-32

2.4

20.5

47.9

29.2

3-35

3.0

21.1

49.1

26.8

3-36

3.7

28.0

38.6

29.8

3-40

3.5

26.3

49.7

20.6

3-41

2.7

24.1

51.1

22.1

3-45

6.8

26.3

43.0

23.9

3-46

5.6

25.2

32.0

37.2

3-47

5.4

22.4

46.6

25.5

3-48

4.7

20.1

48.3

26.9

$3-49$

5.6

23.8

48.1

22.5

3-51

3.1

23.5

50.4

23.0

3-52

4.5

18.2

52.5

24.8

3-54

4.3

22.9

46.8

26.0

5-19

2.4

16.1

63.3

18.2 
TABIE 5, CONT.

\begin{tabular}{llccc} 
SAMPIE & & & \multicolumn{2}{c}{ AGGREGATE } \\
NUMBER & AIR & PASTE & COARSE & FINE \\
\hline $6-3$ & 0.7 & 17.3 & 59.7 & 18.2 \\
$6-17$ & 1.7 & 24.8 & 32.6 & 40.9
\end{tabular}


pavement $4.4,20.6,49.7$ and $25.4 \%$, respectively.

These data were statistically analyzed to determine if significant difference exist among the concrete composition components as related to blow-up distress. The air content variable $F$-ratio versus F-test statistic was 2.46 versus 2.95 at the 0.10 level of significance. Although this analysis did not show a significant difference among the variables, it gives an indication of the relative significance of the varlables. The regressional analysis of these data shows the effect of air content to be a negative correlation with blow-up distress. This implies that as percent of entrained air increases, the level of blow-up alstress decreases.

\section{Physical Condition}

Polished sections of selected test cores were visually examined under a microscope to determine their physical conditions. The presences of air entrainment, lime deposits In volds and cracks, aggregate type, presences of freezethaw cracks, aggregate cracks, the overall intensity of cracks in the concrete and scaling cracks were noted for each tested polished section. These data with source of coarse aggregate, if known, along with any comments are presented in Table 6. The last digit of the aggregate source 1dentification number, 1, 2, or 3, represents aggregates composed of gravel, crushed limestone or slag, respectively. The remaining numbers correspond to a 


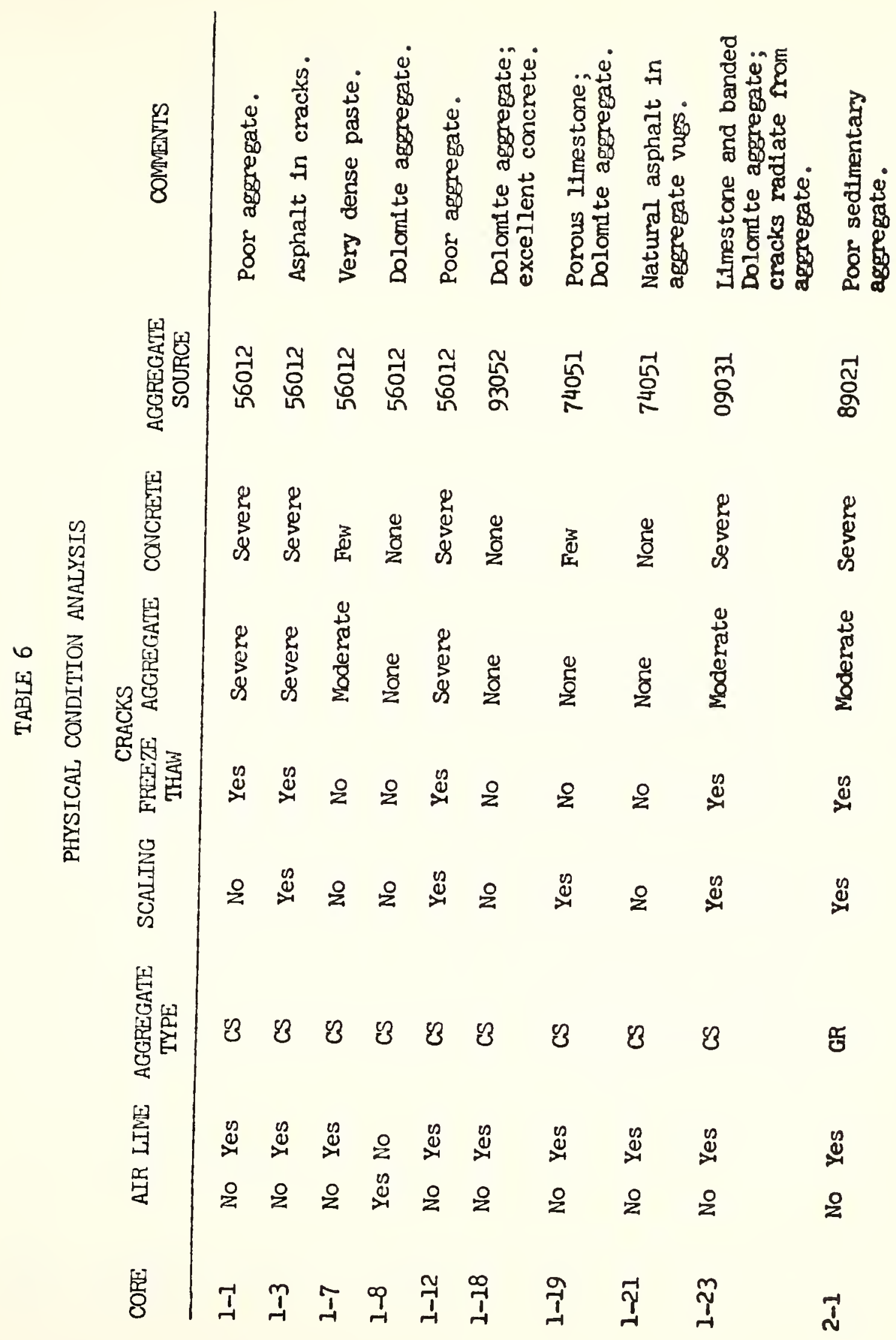




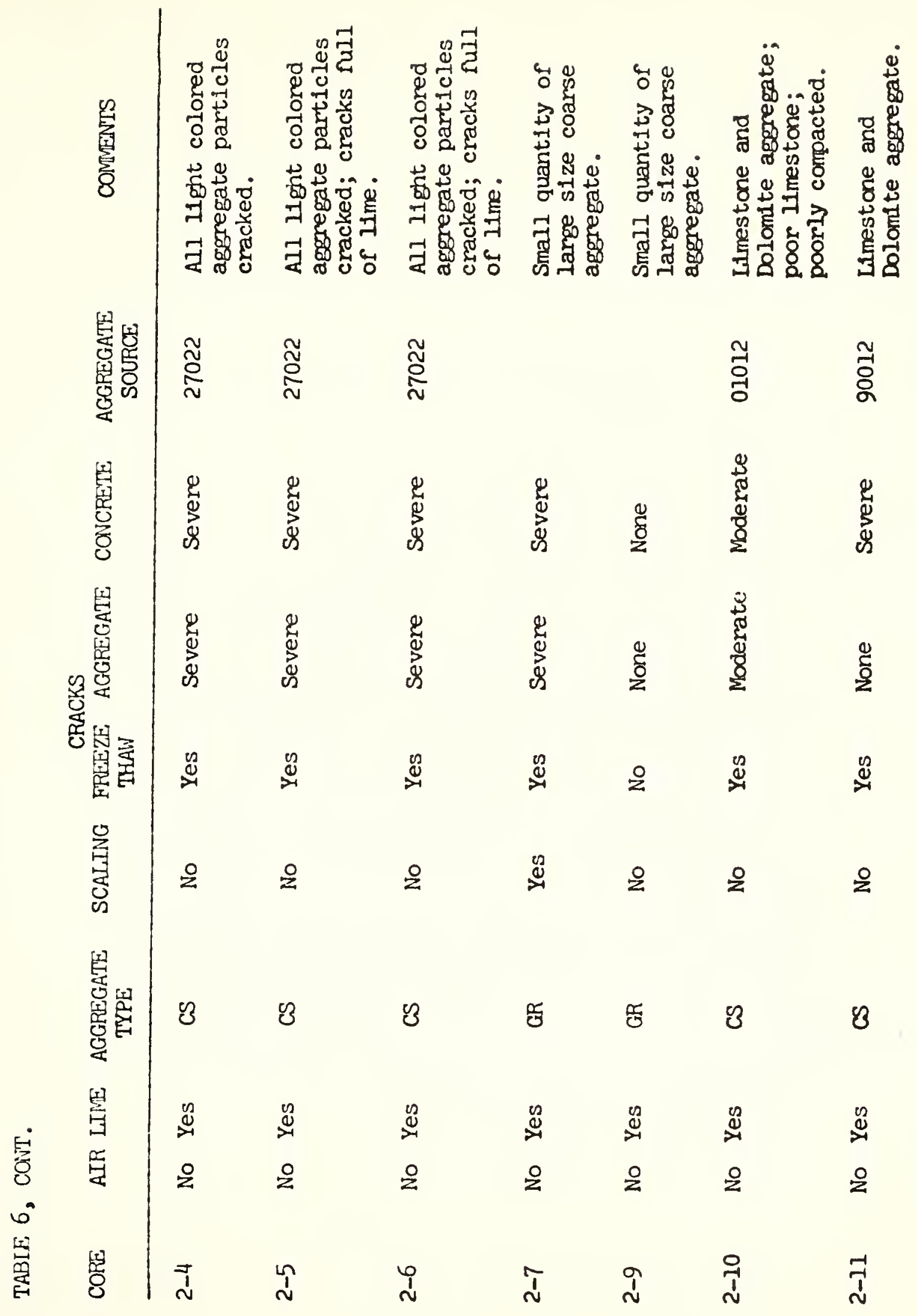




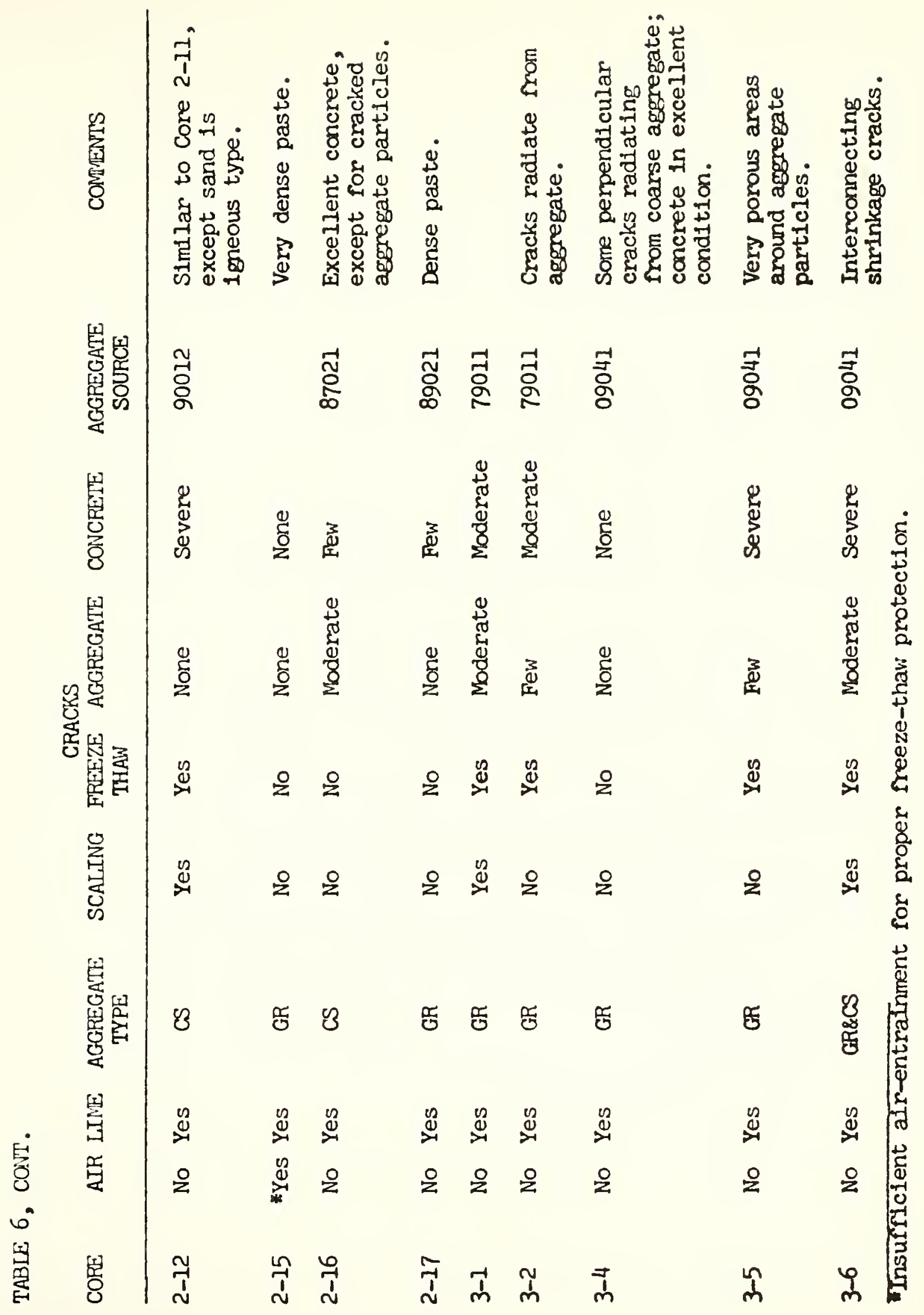




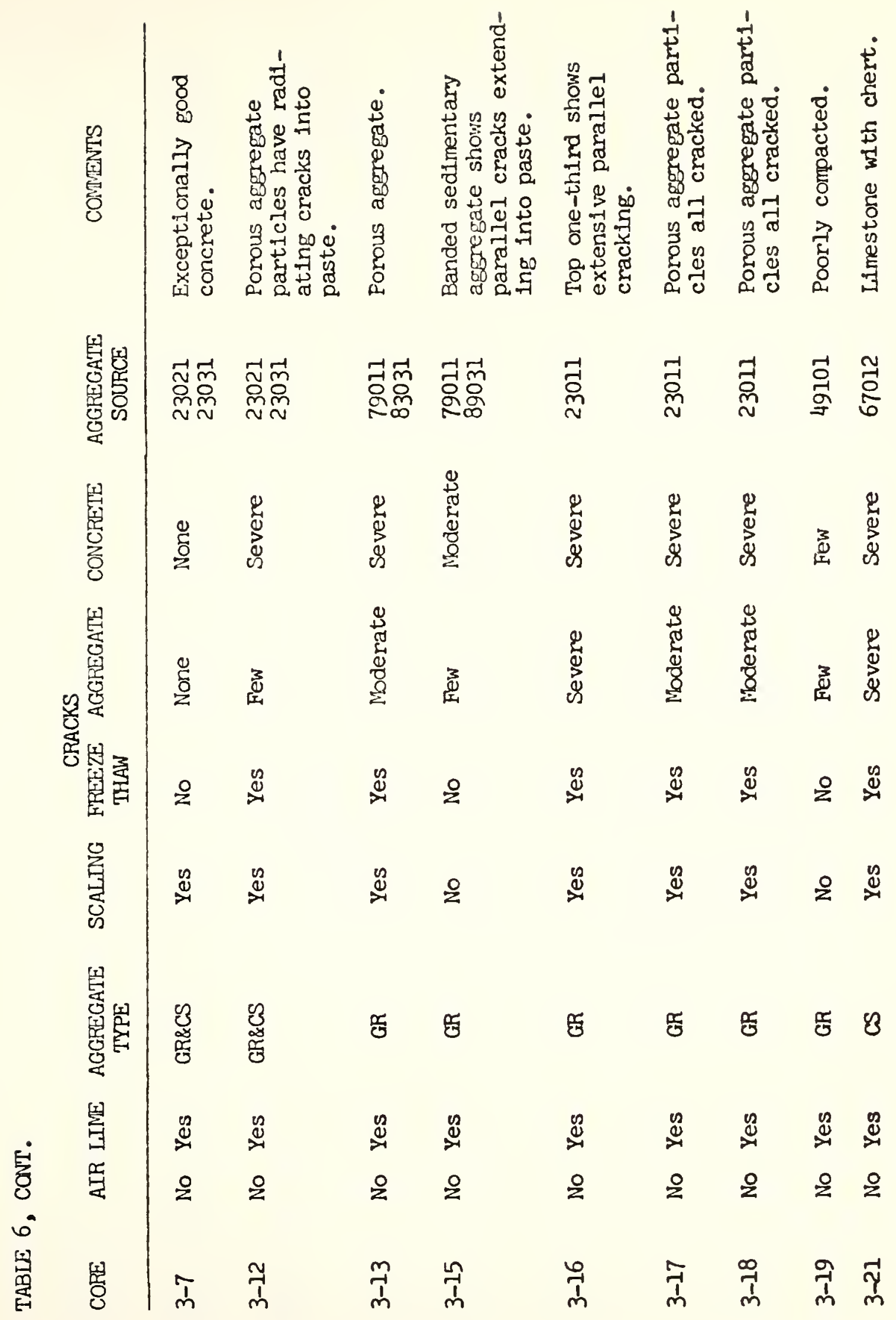




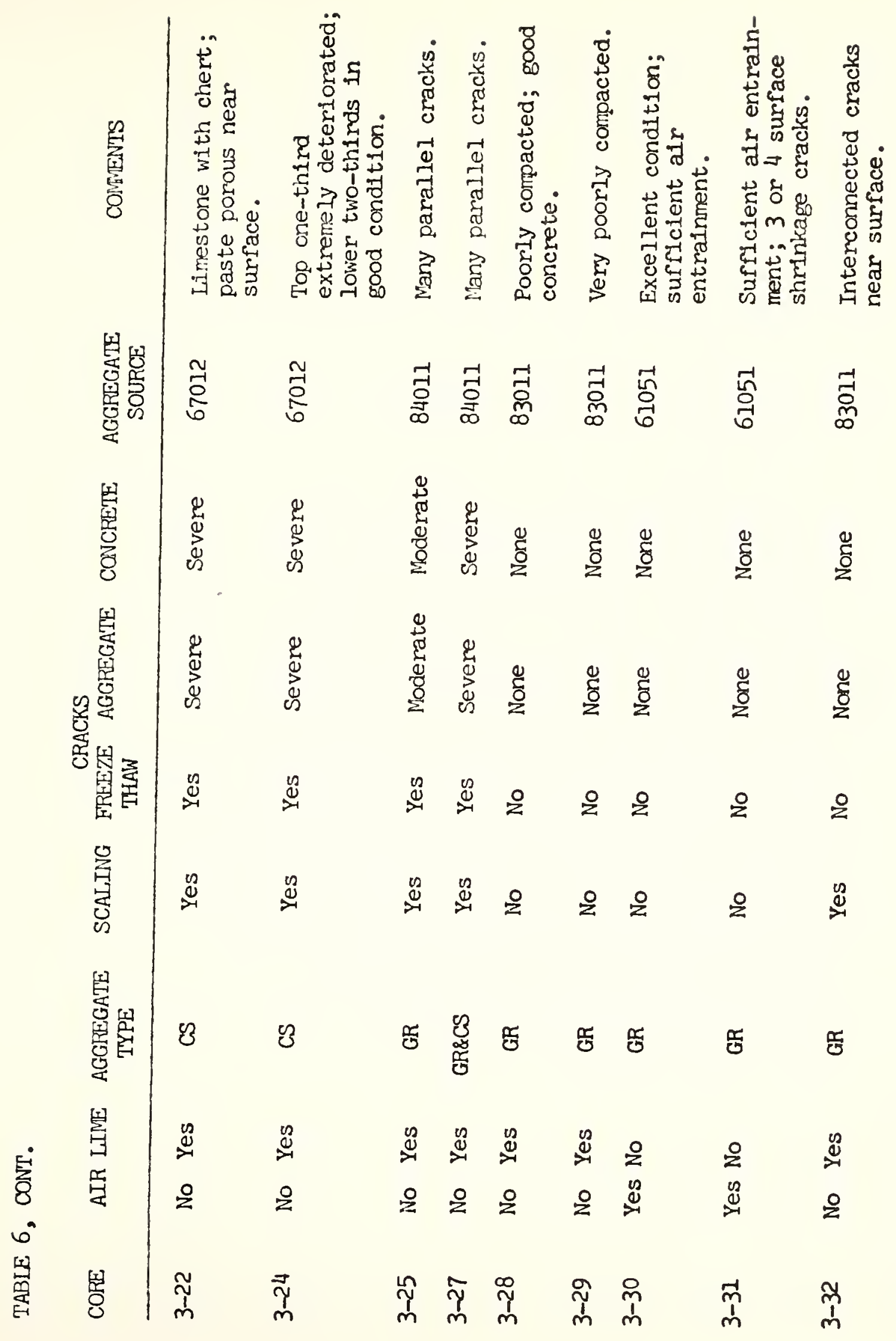




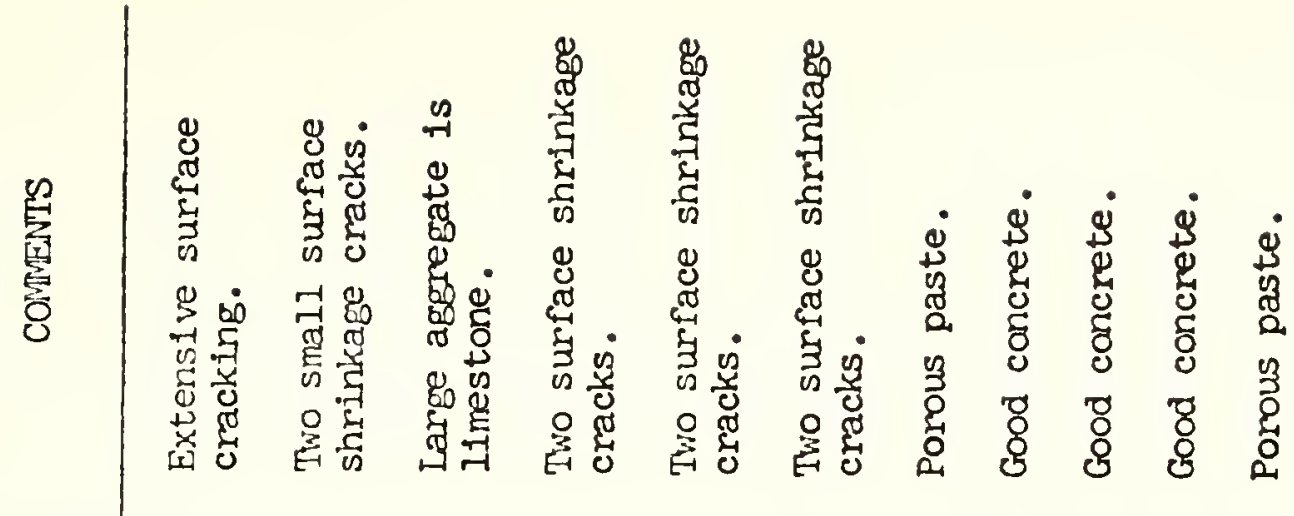

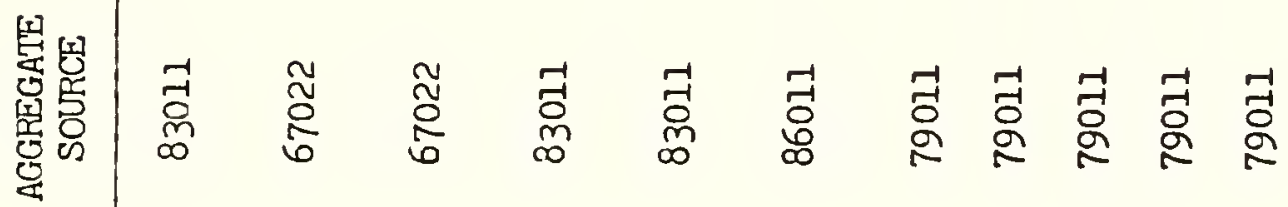

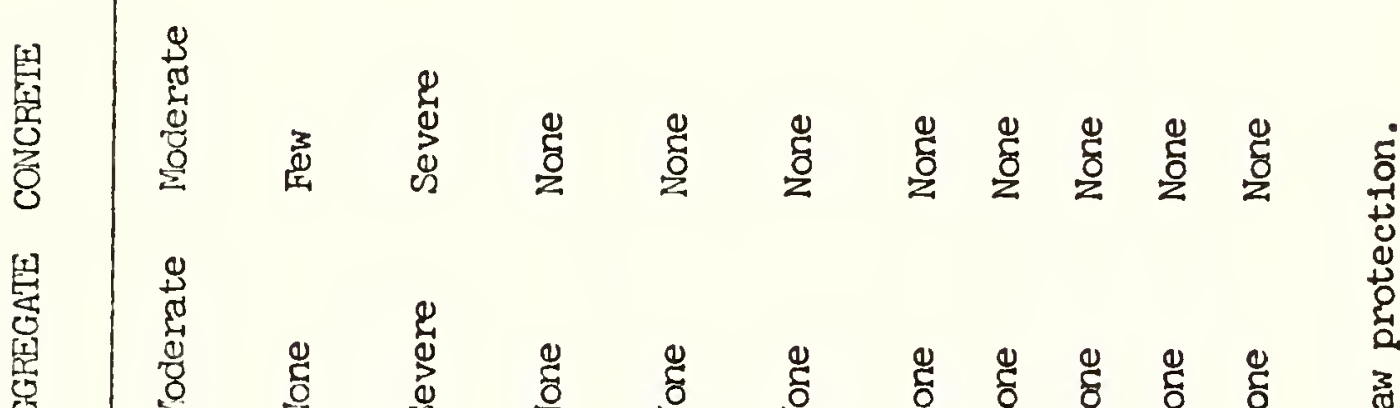

है

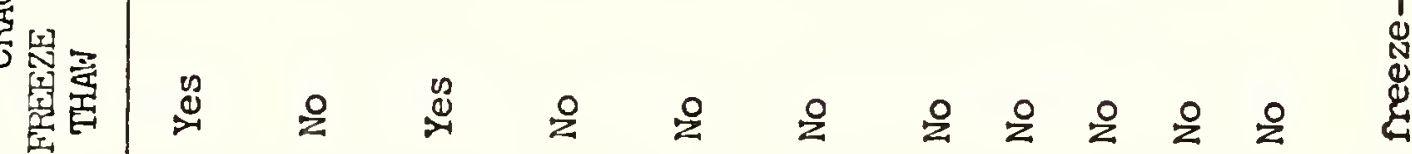

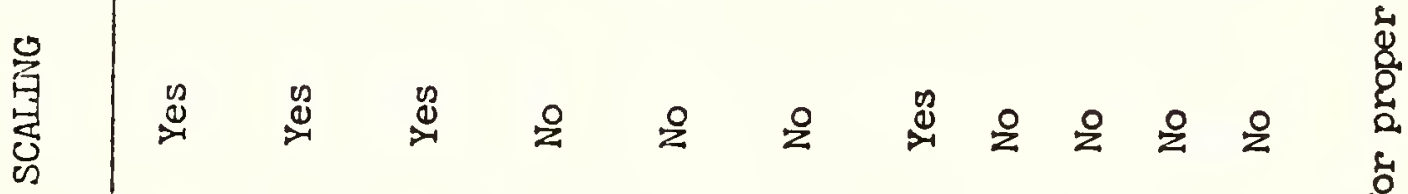

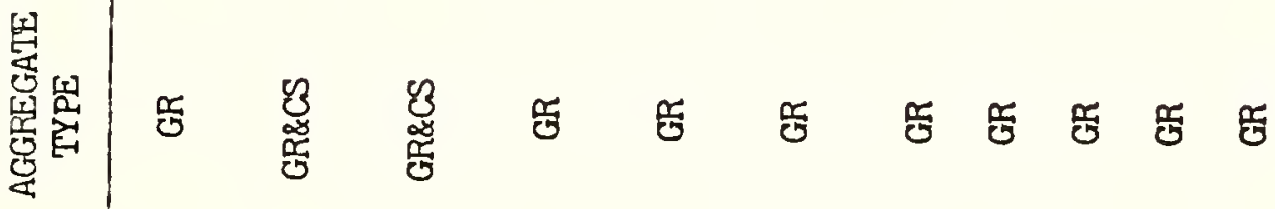

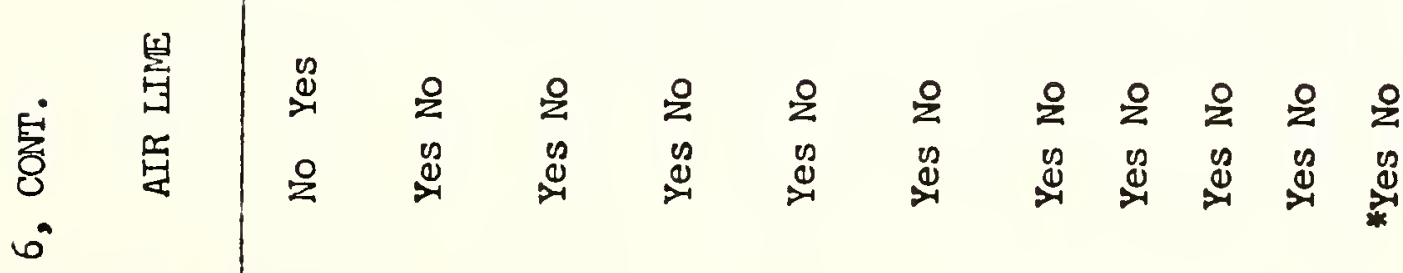

舀 


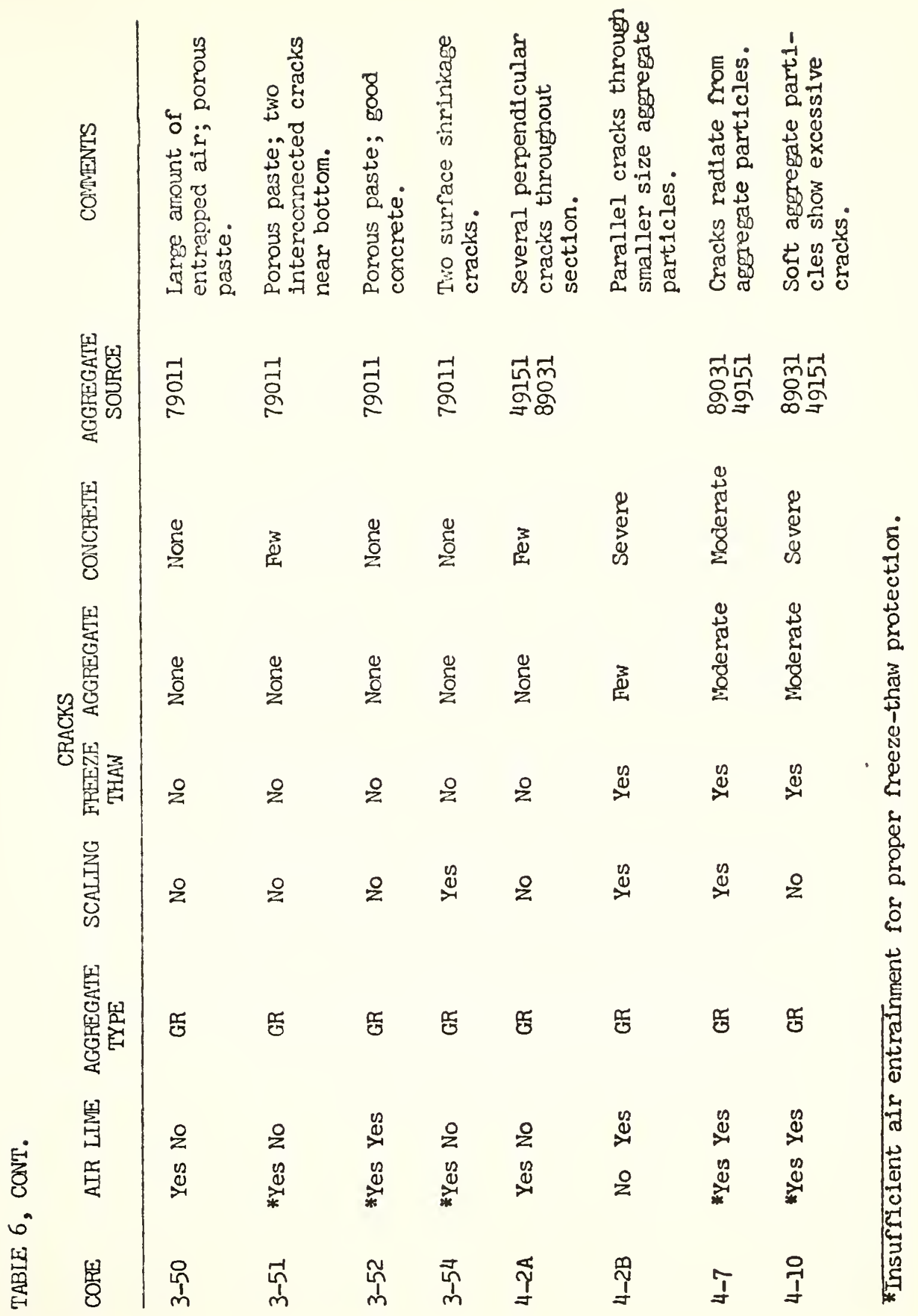




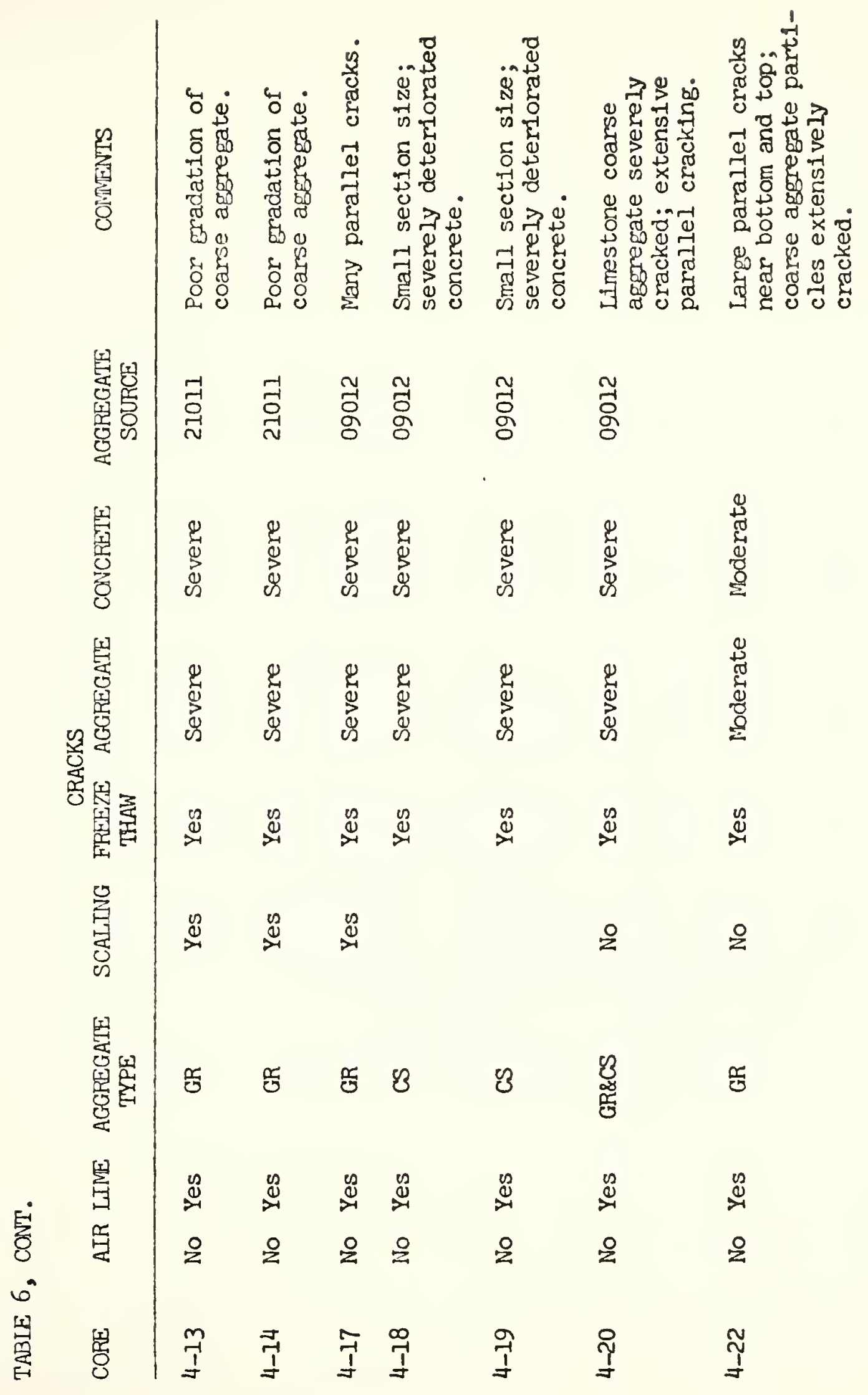




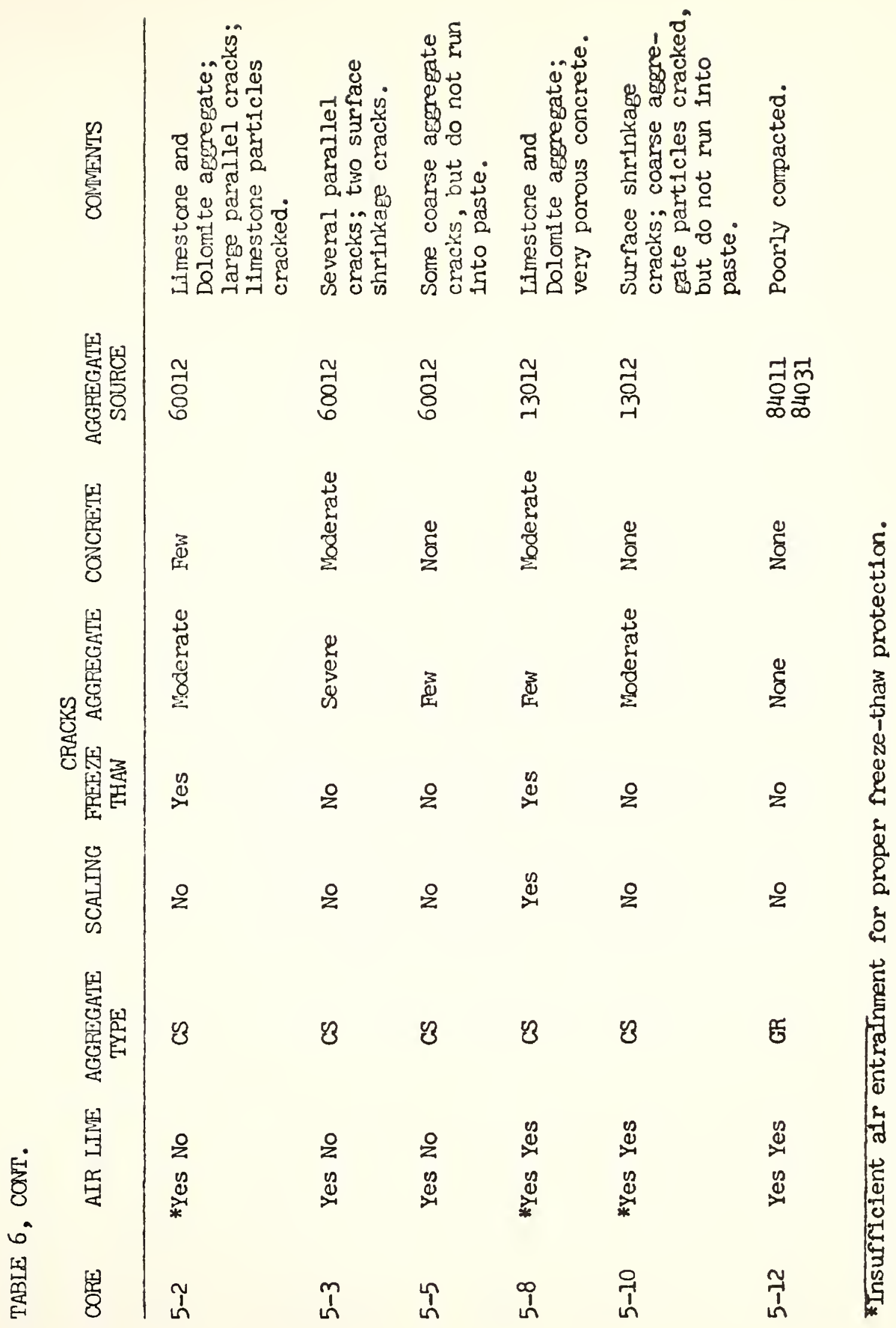




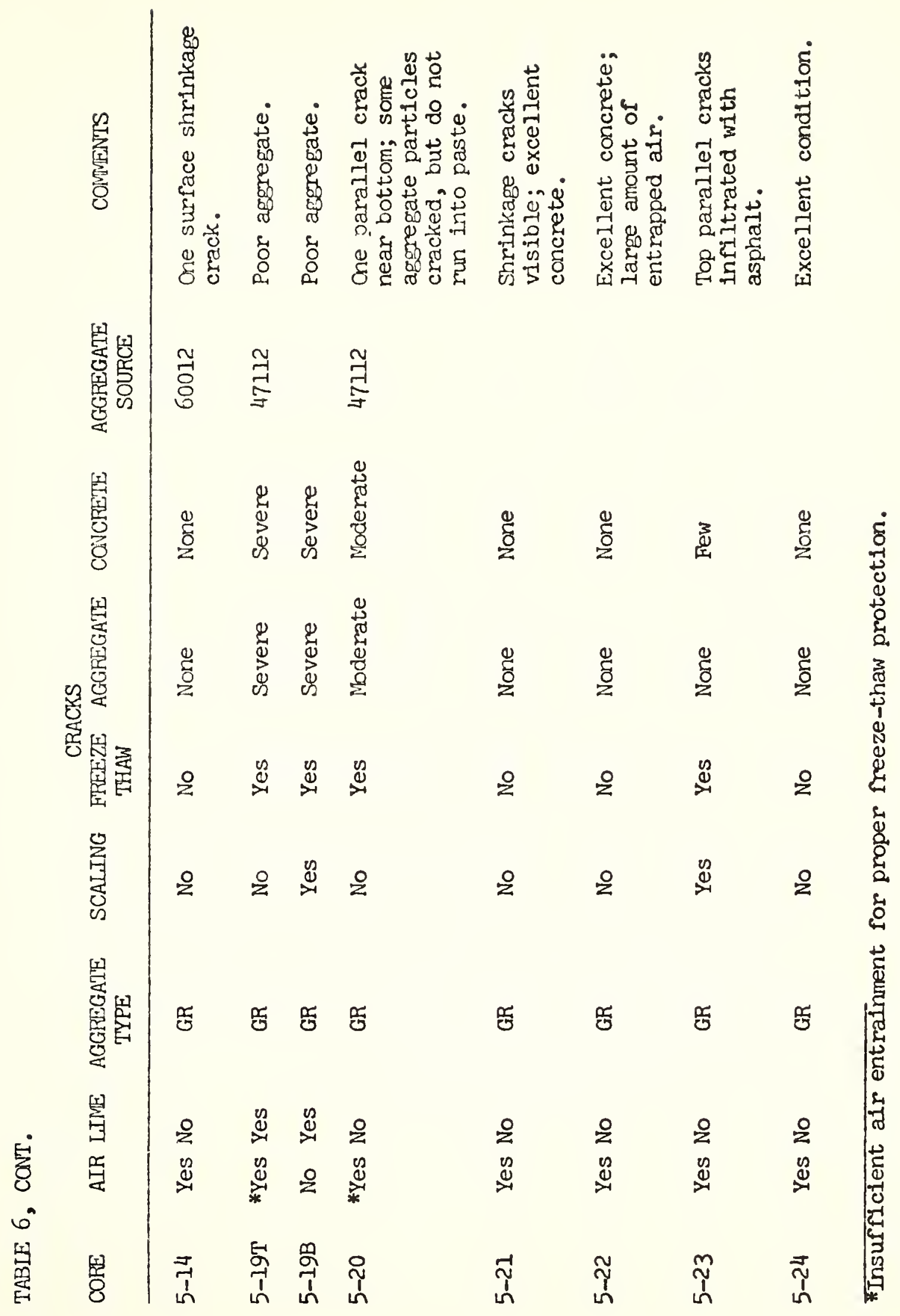




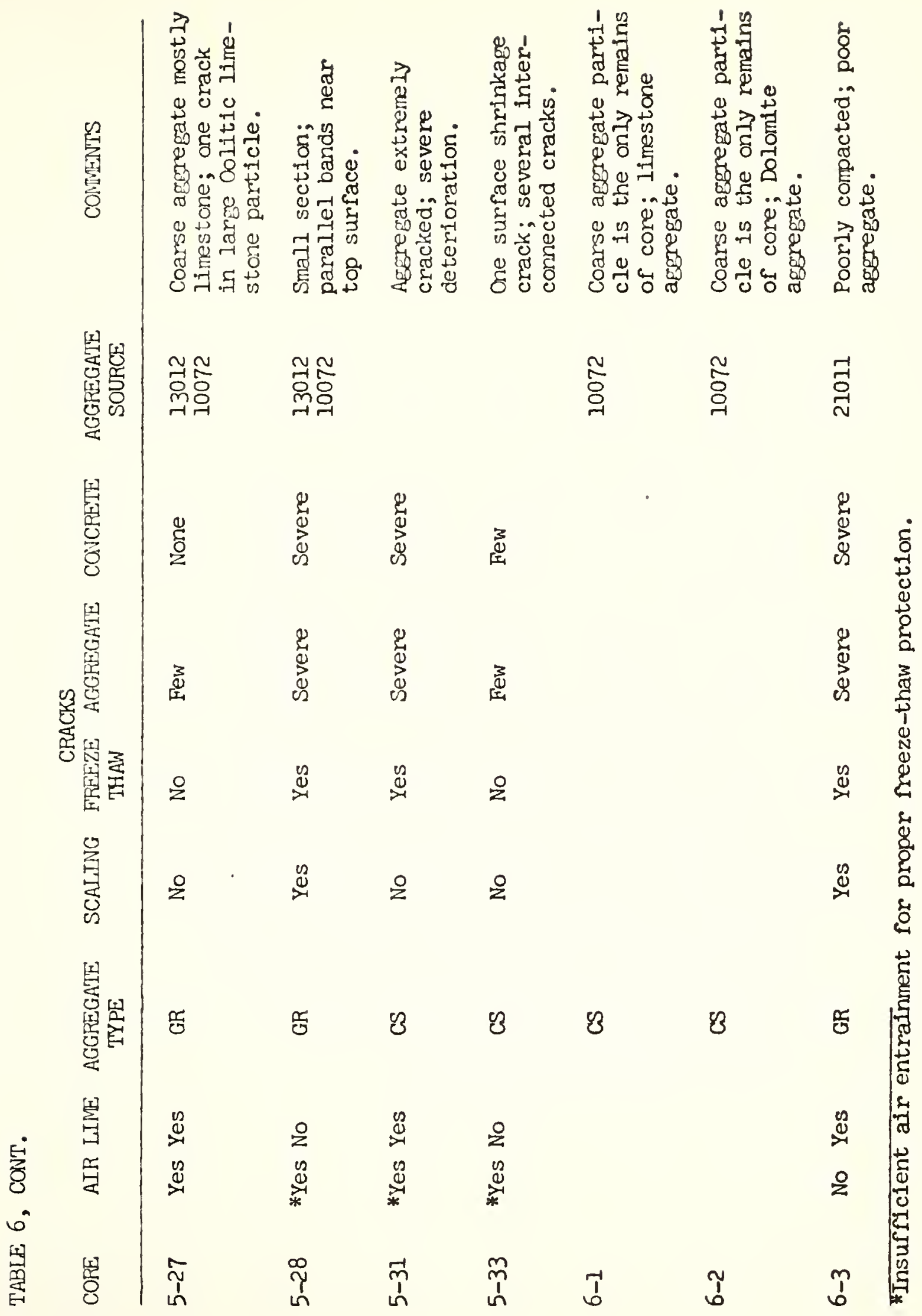




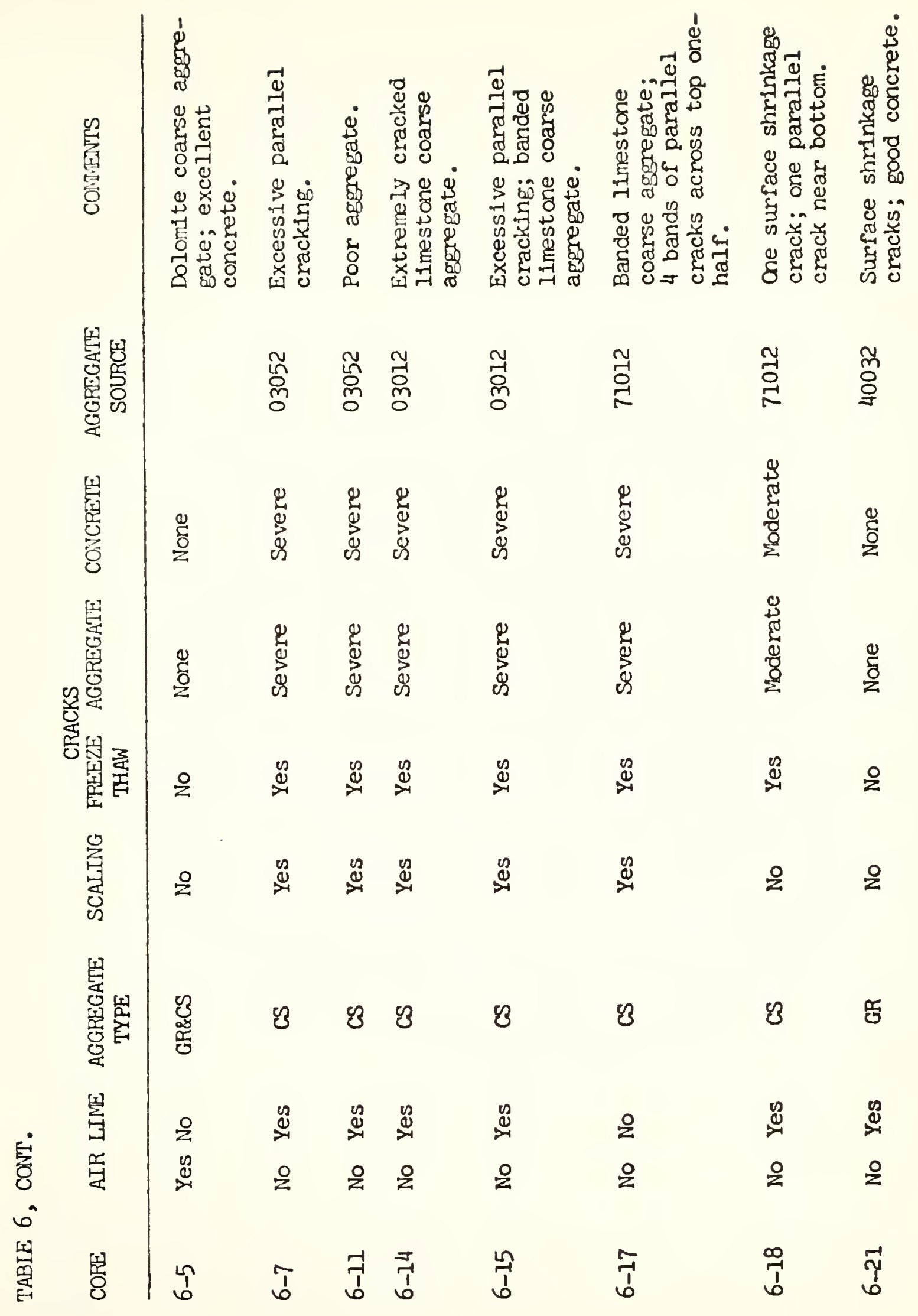




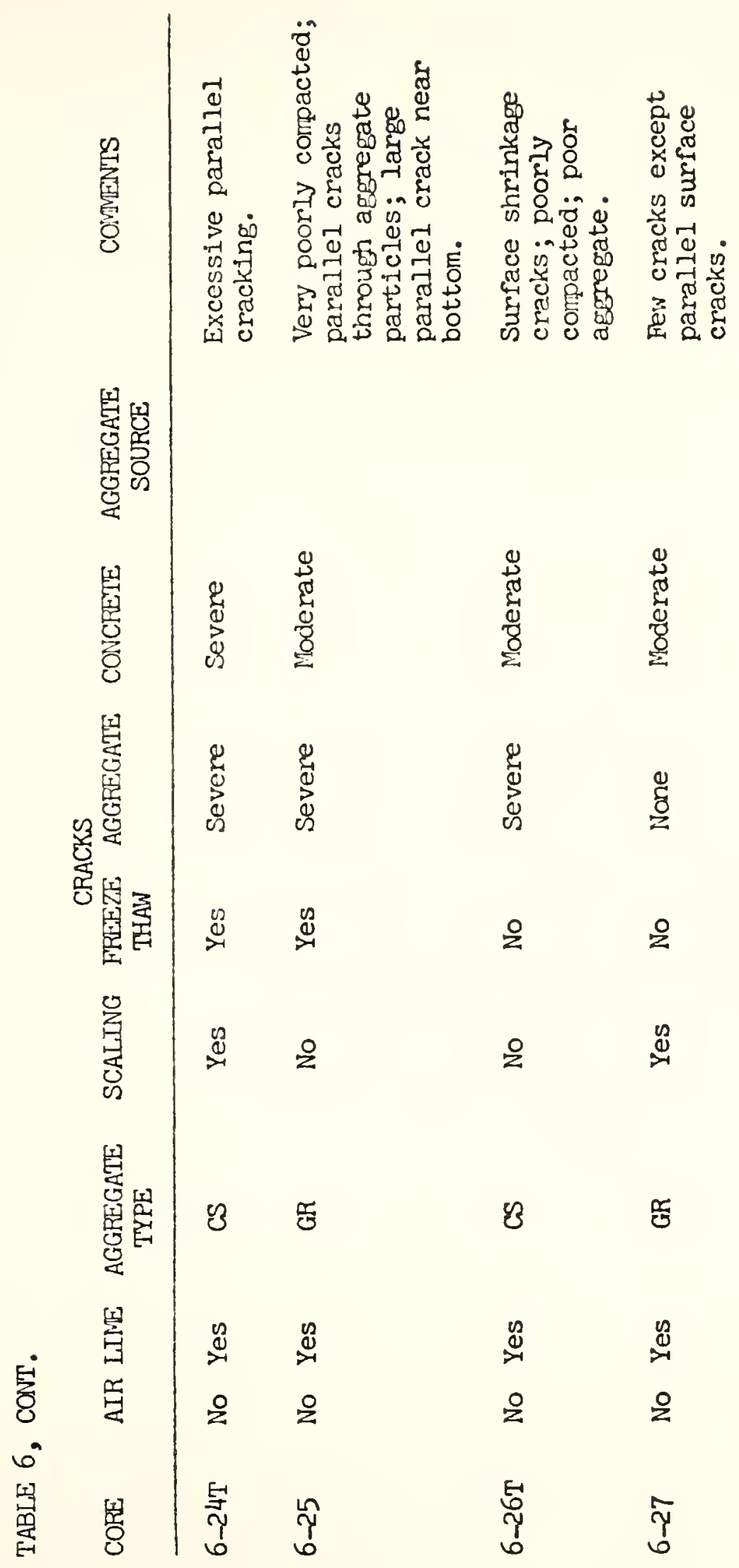


filing system identifiying aggregate suppliers and their locations.

Analysis of varlance was run on the test core physical condition microscope data to determine which variables significantly affect the blow-up distress of a concrete pavement. The analysis technique was individually to analyze the effect of two or three factors, each factor with two levels. Extreme values were selected for the levels of each factor. An unequal cell size two-way and three-way factorial analysis of variance was run on selected factor combinations.

Table 7 shows the factors and the factor levels analyzed for the test cores physical condition microscopic data. Concrete age, overlay thickness and source of coarse aggregate were also analyzed and are included in Table 7. Table 8 shows a typical analysis of variance table for the statistical analysis of surface and aggregate type. This shows the type surface to be signiflcantly different at the 0.01 level and no difference in aggregate type or the interaction of both factors. The cell means of the surface factor imply that overlaying a pavement increases the blowup distress. The analysis of varlance summary of all those factor combinations analyzed is shown in Table 9. Surface is the only factor which shows a signiflcant difference. All cell means of the surface factor show overlaying a pavement increases the blow-up distress. 


\section{TABLE 7 \\ FACTOR LEVELS OF THE \\ TEST CORES PHYSICAL CONDITION}

FACTOR

Surface

Air Entrainment

Lime Deposits

Aggregate Type

Freeze-Thaw Cracks

Aggregate Cracks

Concrete Cracks

Concrete Condition

Age

Total Overlay Thickness
LEVEL ONE

Bare

Yes

Yes

Gravel

Yes

Yes

Yes

Excellent

$<21$ years

$<2$ inches
LEVEL TWO

Overlayed

No

No

Crushed Stone

No

No

No

Poor

$>21$ years

$>2$ inches

TABLE 8

STATISTICAL ANALYSIS OF SURFACE AND AGGREGATE TYPE

SOURCE

$$
\begin{aligned}
& \text { DEGREES } \\
& \text { OF FREEDOM }
\end{aligned}
$$

Surface

Aggregate Type

Interaction

Residual

88

Total

$$
\begin{aligned}
& \text { SUMS OF } \\
& \text { SQUARES }
\end{aligned}
$$

$$
822.60
$$

9.09

13.72

4759.65

5605.08

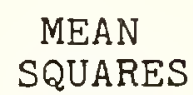

822.62

$\$ 15.21$

9.086

0.17

13.72

0.25

54.09 

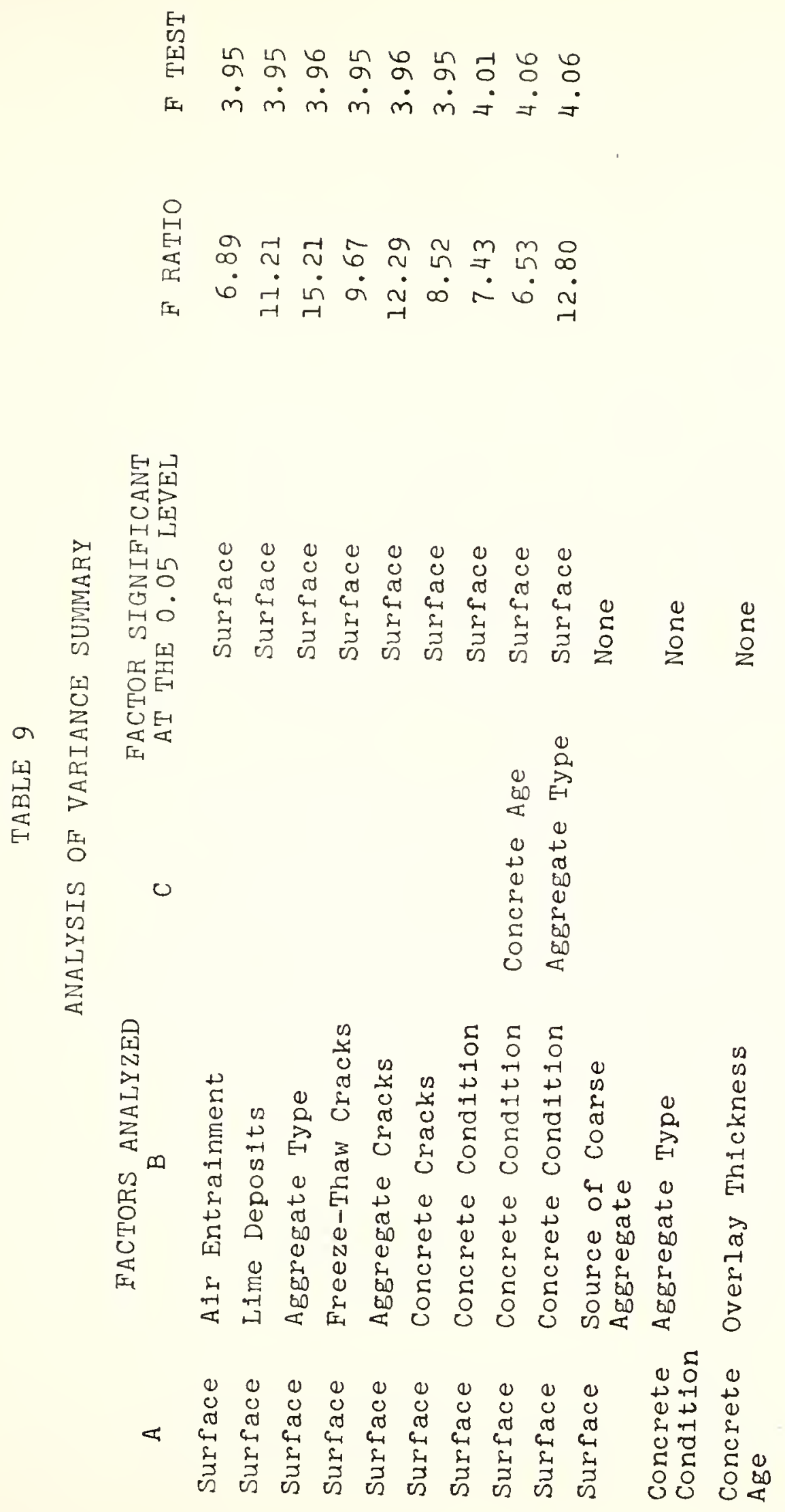
Infiltration

Infiltration is suspected to be the main factor of the blow-up mechanism by some people. Th1s hypothesis was investigated by coring joints and cracks. The general vicinity of a joint or crack, especially in a deteriorated pavement, is commonly more deteriorated than any other location, and difficulty in obtaining a good core was encountered. Many cores were taken at the location of a joint or crack only to find that the concrete was in such a deteriorated state that only rubble was obtained. The walls of the core hole crumbled and made it impossible to determine if infiltration was present except for the cases where it was excessive.

A reliable technique in obtaining a core over a joint or crack was to core through the top of a dowel bar. The dowel bar supplied rigidity to hold the concrete together while it was cored and removed. Special care must be taken during coring, because if the concrete semicircle crosssections slip and turn, the drill core will be destroyed. The cores were removed from the pavement, and the two sections were Immediately taped together so that they would remain intact without loss of infiltration material unt 11 tested in the laboratory.

The cores were allowed to air dry in the laboratory before being opened and processed for testing. A technique was developed to determine quantitatively the amount of 
infiltration present at a joint or crack. The procedure was to carefully separate the two sections of each core, apply a very thin coat of a wetting epoxy, carefully place the two pieces together exactly as they were orlginally and apply pressure to cause the excess epoxy to excrete before setting. Once hardened, sections were cut perpendicular to the joint or crack. These sections were then carefully polished and visually investigated under the microscope. This technlque worked well and can be used to detect and quantitatively measure infiltration. Amount of infiltration was determined to 0.5 milimeters through the microscope by placing a scale near the area to be measured. The average values of infiltration determined by this method along with comments and test section information are given in Table 10. Based on the infiltration analysis of the test cores, It is apparent that the top portion of a pavement is infiltrated by sand particles. This seems reasonable since it Is common practice to apply a mixture of sand and de-icing compounds for snow and ice removal during the winter months when the joints are open.

Unlike the top portion, the lower portions of jolnts are commonly infiltrated by fine-grained solls. Pumping through joints and cracks is a common occurrence when subgrades and bases are composed of fine-grained soils and are wet. The presence of lime deposits was a common finding for most of the test cores visually analyzed under the 


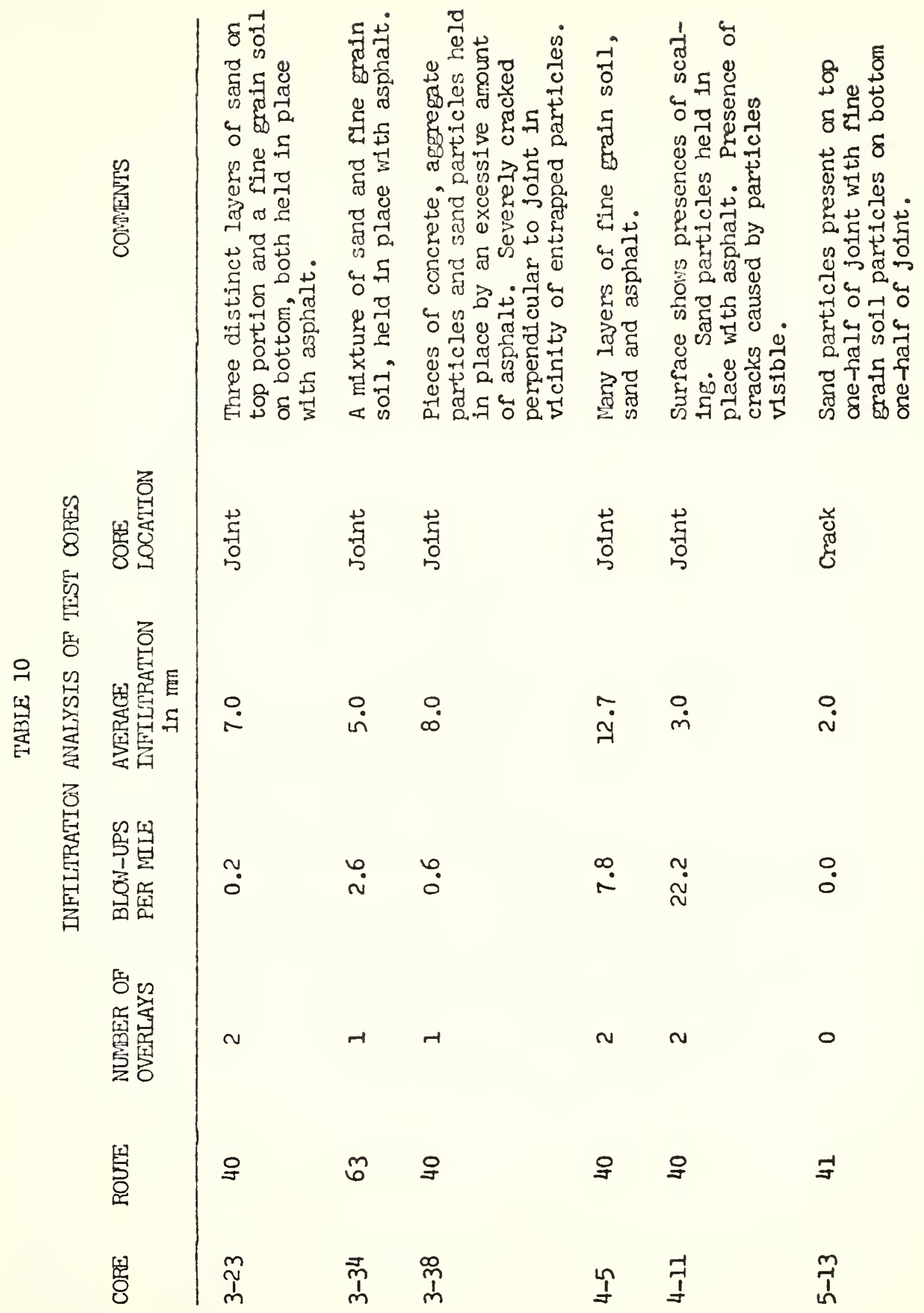




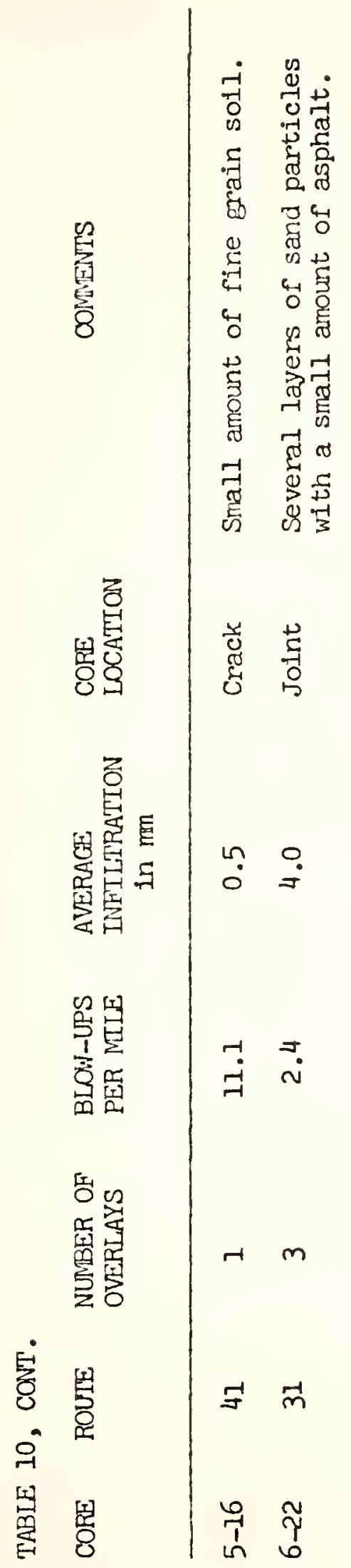


microscope as previously presented in Table 6. This implies that pavements are at one time or another in the presence of water since lime can be transported in solution only. Therefore the presence of fine-grained soll in the lower portion of the joints is due to pumping of subgrade and base fine-grained particles.

Both sand and fine-grained particles generally show a layered structure, which 1mplies time dependence. This gives an indication of continuous infiltration growth which could explain the time dependence of blow-up distress as presented in the state blow-up survey (10).

Infiltration is compounded by the presence of asphalt. Although compounds, usually asphalt based, are applied to protect and seal joints from water and infiltration, it is obvious that their presence adds to the infiltration problem by trapping particles which possibly could be removed by traffic or pumping.

The data of Table 10 were statistically analyzed to determine if a correlation exists between blow-up distress and inflitration. $A R^{2}$ value of 0.05 was found for the relationship, which indicates hardly any correlation.

The joint of a typical forty foot pavement must go through a range of contraction and expansion over the seasons of approximately 6 milimeters. If the pavement placement temperature was $70^{\circ} \mathrm{F}$ and 1 ts shrinkage was $200 \times 10^{-6}$ at $100^{\circ} \mathrm{F}$, every jolnt would be open by 0.6 
millimeters. Assuming Euler's column buckling theory and the above conditions apply, the total amount of incompressible infiltration required to cause a blow-up is 4 millimeters. Therefore any pavement with infiltration in excess of 4 millimeters would be expected to fail by buckling. This value is not in agreement with the test data. The heavily infiltrated test samples do not show the highest blow-up disturbance, and two of the least infiltrated test samples show the highest blow-up performance. This is in contradiction with what might be expected, but consideration must be given to the data analyzed. The blow-up distress was categorized by visual observation of the pavement's surface condition; past blow-up distress could have been repaired or covered by an overlay. The joint samples were difficult to obtain and no replicas exist for a given road. Therefore it was necessary to assume uniformity of infiltration within a section which most probably did not occur.

The number of samples in joints was insufficient to reach definite conclusions. Several points, however, do warrant comment. Many of the cores which were taken showed concrete was so badly deteriorated as to be essentially rubble. This condition invalidated the core for evaluating infiltration but provided valid input as to the condition of the concrete at the location of the blow-up. 
Further overall inference as to the problem of infiltration can be made when considering the finding of the Statewide Survey of Blow-ups in Resurfaced Concrete Pavements, (10). Reduced infiltration from the bottom would be expected when granular bases were used. This may be one, but probably not the only reason, that such bases reduce blow-ups. Other reasons are better drainage and better pavement support hence reduced deflections under load. Surface infiltration is attributed largely to winter maintenance activities hence the greater occurrence of blow-ups in the northern districts is in agreement with the concept of infiltration stresses.

Infiltration most assuredly is not the only cause of blowups, but its occurrence can only aggravate the problem.

\section{Thermal Expansion}

A conclusion of the State blow-up survey (10) was that blow-up distress of overlayed concrete pavements made of gravel aggregate is higher than pavements made of crushed limestone aggregate. This implies that the coefficient of thermal expansion may be a significant factor in the blow-up mechanism because silicious materials have generally a higher coefficient of thermal expansion than carbonate 
materlals. To test this hypothesis, the coefficients of thermal expansion of selected test cores with known blow-up performance were determined.

A typlcal blow-up occurs between one and three o'clock In the afternoon on a hot day that was preceded by one or two days of heavy rainfall (1). This implies high temperature and molsture states are necessary for a blow-up to occur. The coefficient of thermal expansion is a function of moisture content, so consideration must be given to it as well as temperature in establishing the method of testing. The fleld data given in Appendix $D$ show the average da1ly temperature range within a pavement is $70^{\circ} \mathrm{F}$ to $100^{\circ} \mathrm{F}$ during the time a blow-up is most likely to occur. This was established as the temperature range to be used in determining the coefficlent of thermal expansion of the test cores and laboratory prepared samples.

A $30^{\circ} \mathrm{F}$ temperature change corresponds to a length change of approximately 0.00060 inches for a sample length of 4 inches and a coefficlent of thermal expansion of $5.0 \times 10^{-6} /{ }^{\circ} \mathrm{F}$. The length change measuring device must be capable of measuring, with sufficient accuracy and sensitivity, to 0.00003 inches or better in order to determine the coefficient of thermal expansion to 5 percent accuracy. 
Linear Variable Differential Transformer

A Inear varlable different1al transformer, hereafter referred to as an LVDT, was selected as the length change measuring device for the coefficlent of thermal expansion apparatus. A Schaevitz type 050-HR S/N602-M LVDT was f1tted with a teflon liner and meticulously honed to obtaln a near perfect core fit. Two stainless steel counterwelghts, one aboye the LVDT and one below the LVDT, were used to obtain core balance. The core was indexed so that 1ts radial pos1tion, relative to the LVDT, would remain constant during calibration and testing.

The primary coil of the LVDT was supplied an Input of 3.0000 volts at 2500 hertz by an Exact Model M 7230 function generator. The output of the secondary coll was measured, unamplifled, to the nearest 0.00001 volt with a digltal voltmeter.

Sensit1vity, accuracy and repeatibility were increased several orders of magnitude by the LVDT modifications and input-output techniques described above compared with conventional LVDT operational methods.

The LVDT was calibrated with a large barrel calibration m1crometer capable of measuring to the nearest .00005 1nches. The slope of deformation and voltage change was found to be 0.056 IN/VOLT. Th1s corresponded to a sensitivity of $5.6 \times 10^{-7}$ inches which was two orders of magnitude greater than required to confine the error to 5 percent. 


\section{Heating Chamber}

The function of the heating chamber was to vary the temperature of the test sample. The heating chamber was designed so its dimensional changes would be independent of the test samples measured dimensional change.

The heating chamber is shown in Figure 42, and consists of a series of different sized cylinders mounted on a base of brass and plexiglas. The inner brass cylinder with inside diameter of $6 \frac{1}{4}$ Inches and $1 / 8$ inch wall was welded to the $3 / 8$ inch brass base plate which was attached to the bottom $3 / 4$ inch plexiglas base by a series of screws. Two o-rings located between the two base plates assured against leakage when the chamber was full of water. The middle pyrex glass cylinder with outside diameter of 180 millimeters and 4 millimeters wall, wrapped with flat strip nichrome heater wire and overlayed with insulation tape to assure contact, rested atop an 0-ring that was contained in a grooved slot in the base plate. The outer cylinder with outside diameter of $8 \frac{1}{2}$ inches and $1 / 8$ inch wall was also welded to the brass base plate to assure rigidity. The space between the middle and outer cylinder was filled with perlite to help minimize heat loss across the outer cylinder. A plexiglas $1 \frac{1}{4}$ inch thick cap plate with three grooves, each containing O-rings, was held in place by a threaded plexiglas ring which screwed on to the threaded outer brass cylinder. Flve holes through the cap plate provided access 


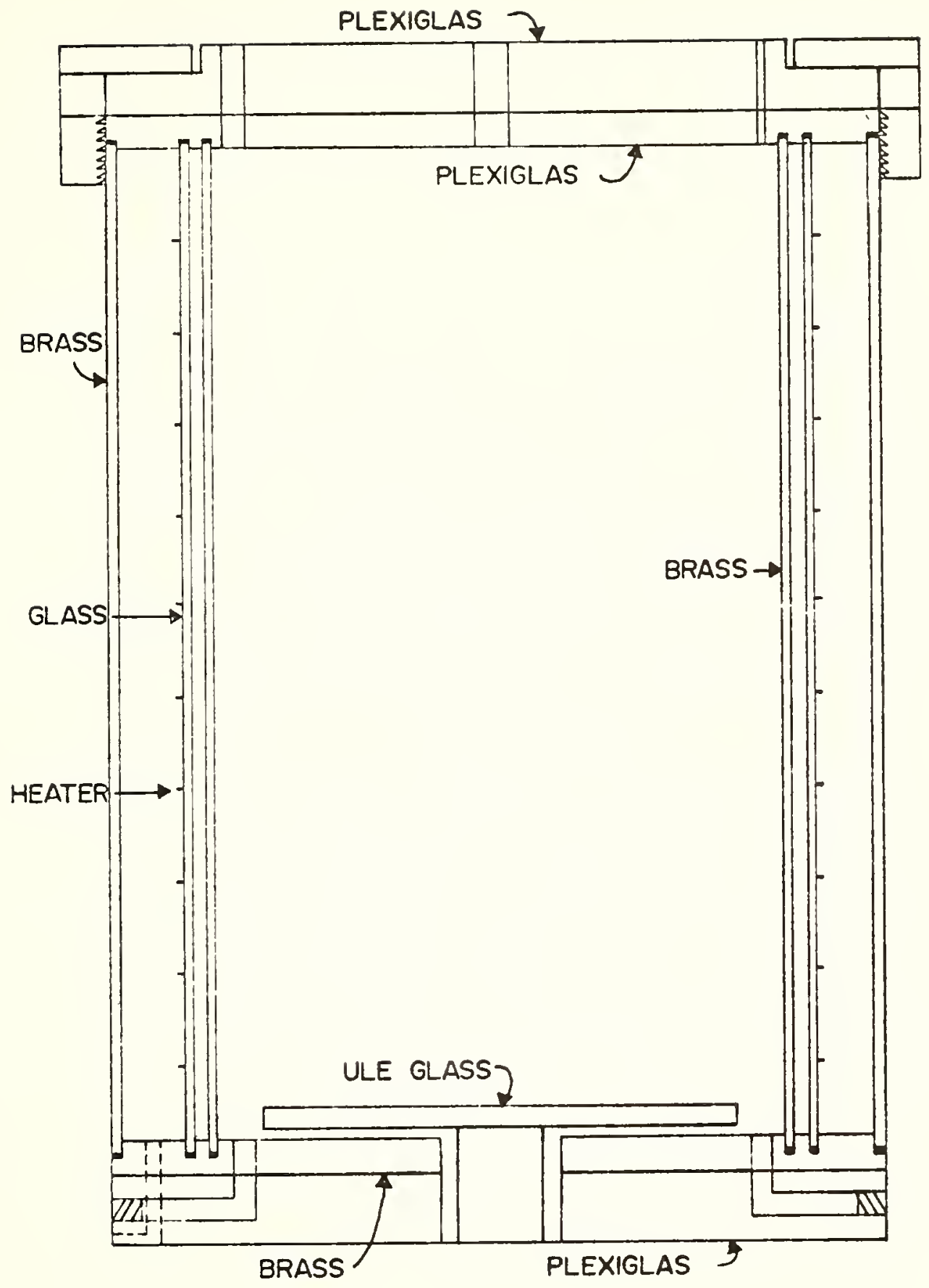

FIGURE 42. DETAILS OF HEATING CHAMBER 
for temperature sensors, a cooling coll and sample extension rod. The plexiglas base had two horlzontally tapped holes which connected to a sertes of holes in the brass base plate. This allowed fllling and draining of the heating chamber. The heater wire leads were routed through the brass base plate and out the side of the plexiglas base. Temperature regulation was obtalned by a Cole-Palmer Model 2157 temperature controller. The sensing probe was Inserted through the top cap next to the wall of the Inner brass cylinder. A variable voltage controller wired in series with the temperature controller supplied voltage to the heater coil and was therefore a means of varying the rate of temperature change within the heating chamber.

\section{Tripod}

The LVDT was suspended above the heating chamber by a special fused quartz tripod. Fused quartz tubing was precisely ground and epoxied together to form a tripod 14 inches high. The LVDT fitted inside the center fused quartz tube and was vertically aligned by three adjusting set screws which were held in place by three nuts epoxied at the midale of the tube.

Fused quartz was selected over other materials for construction of the LVDT tripod support because of its low coefficient of thermal expansion, $2.7 \times 10^{-7} /{ }^{\circ} \mathrm{F}$. It was Imperative for the support to remain dimensionally stable during the testing perlod. A dimension change would be 
erroneously recorded as a change in sample length. Special emphasis was placed on insulating the test chamber to minimize temperature change in the support tripod. The test chamber was completely enclosed by a one inch layer of Armstrong Armarlex foam insulation to minimize heat loss. Likewise, an additional precaution was taken to assure temperature stability, a small fan was placed near the test apparatus to maintain constant temperature. The temperature of the support tripod was therefore maintained at room temperature during the testing period. Although the room temperature of the laboratory is not controlled, it did not vary by more than five degrees during the testing time period. A temperature change of this magnitude, over the 14 inch high tripod, causes a dimensional change of 0.000019 inches which is readily measured by the LVDT system. Obviously the accuracy of the testing apparatus was limited by temperature stability and not by electronic sensitivity or stability. Nevertheless, the error involved by temperature stability was within the limits previously mentioned.

\section{Sample Support and Extension Rod}

Special consideration was given to the method of supporting the test sample because every change in dimension from the support base through the LVDT supporting tripod was measured by the LVDT. A spectal glass called ULE, and supplied by the Corning Glass Company, with a zero coefficlent of thermal expansion within the temperature testing 
range was used to prevent dimensional change caused by the method of specimen mounting. The centrally located base plate hole of the heating chamber was oversized to provide ample clearance for a one inch diameter ULE glass cylinder of variable helght (dependent upon specimen height), to rest upon the support base. A ULE glass plate was placed atop the ULE glass cylinder and the test specimen atop this. Another ULE one inch diameter cylinder was placed on top of the test specimen with a fused quartz extension rod bonded to it by a thin layer of Eastman 910 contact cement. The ends of the ULE glass cylinders and the fused quartz extension rods were ground parallel to within 0.001 inches to assure vertical alignment. The only measurement error possible in the mounting was due to the dimensional change of the short extension rod. The length of this sample extension rod was always minimized by using an optimum combination of varlous lengths of ULE glass. The length was kept to three inches or less. Th1s length over a $30^{\circ} \mathrm{F}$ temperature change glves a dimensional change of 0.00002 inches. This is a conservative value because the temperature change was not uniform throughout the three inch length and only the portion within the heating chamber would undergo the $30^{\circ} \mathrm{F}$ temperature change.

The total temperature stability error of calculating a coefficient of thermal expansion is a summation of the dimensional changes caused by a temperature change in the 
LVDT supporting tripod and the sample extension rod. Th1s summation is a maximum of 0.00004 1nches wh1ch for a short sample of 4 inches represents an error of 5 percent. The error of measuring the temperature change as previously discussed in the field section and the error of the LVDT are both much less than the temperature stability error and do not significantly affect the total error.

The only other sources of error involved in this method of measuring the coefficient of thermal expansion is caused by the support base. The heating chamber, sample and LVDT supporting tripod were independently supported by the support base. Several materials were evaluated for the common support base. The optimum base was found to be the concrete floor of the laboratory. The error caused by the support base could not be quantitatively evaluated but is not expected to be significant. The low conductivities of the plexiglas and ULE glass along with the high mass of the concrete floor are in favor of little or no temperature change in the concrete floor. The effect of the support base was therefore not expected to have any influence on the total error of measurement. Therefore the maximum error possible by the testing apparatus was always smaller than 5 percent.

\section{Test1ng Technique}

Specimen preparation consisted of cutting the ends of a test core perpendicular to its longitudal axis and 
polishing each end until parallel within 0.01 inches, as measured by rotating the sample under an independently mounted dial gauge. The test specimen was then oven dried to constant weight at $105^{\circ} \mathrm{C}$, brought to room temperature, and three thermocouples were attached to its side by a double layer of masking tape, one at its mid helght and one one-half inch from each end.

The sample was then placed in the heating chamber, and the LVDT was vertically aligned. Upon temperature equilibrlum among the three sample thermocouples and the LVDT input and output, the three temperatures were recorded, and the temperature controlier was turned on. When the temperature of the test core sample was stabilized at approximately $100^{\circ} \mathrm{F}$, the temperature controller was turned off, and a set of data points were recorded.

The time of test for the dry and wet tests varied from two to flve hours, depending upon the size of the test specimen. The total time of heating was a function of the temperature variation as measured on the surface of the specimen. Temperature was maintained unt1l a variation of $2.0^{\circ} \mathrm{F}$ or less between the top and bottom thermocouples was obtained. The heater was then turned off and the cooling perlod started. The temperature chamber was so efficiently insulated 1t was necessary to draw alr through the test apparatus by means of an aspirator to cool the sample. When room temperature was obtained the aspirator was turned off, 
and upon equilibrium of temperature, another complete set of data points were recorded. To assure repeatibility the above sequence was repeated so an average value of coefficlent of thermal expansion could be calculated. One cycle of heating and cooling was completed in an average of eight hours.

The testing technique for the saturated case was to saturate the oven dried cores for twenty-four hours and then test them submerged under water in the heating chamber in the same manner as the dry testing technique. A copper cooling coil was placed inside the heating chamber and temperature was controlled by pumping ethylene glycol from a constant temperature bath. Occasionally the heating chamber was used as an auxillary heater to expedite the rate of heating.

\section{Test Cores}

The coefficient of thermal expansion was determined for the dry and wet moisture states for selected test cores in accordance with the previously outlined techniques. The data are shown in Table 11. Except for those coefficlents noted, all are an average of two to five cycles of heating and cooling. These data are separated into heating and cooling temperature cycles to show the variation encountered In the coefficients of thermal expansion. The dry molsture state coefficients calculated from the positive and negative temperature changes were all Individually within the 5 
出至

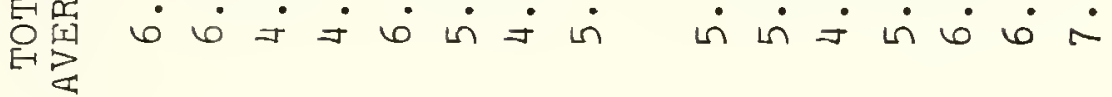

$\underset{P=1}{E-1}$

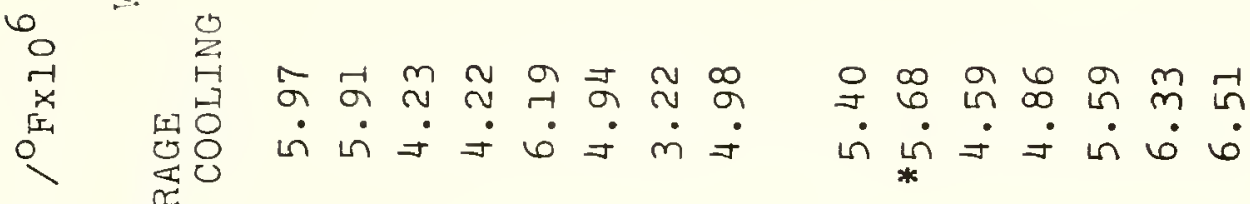

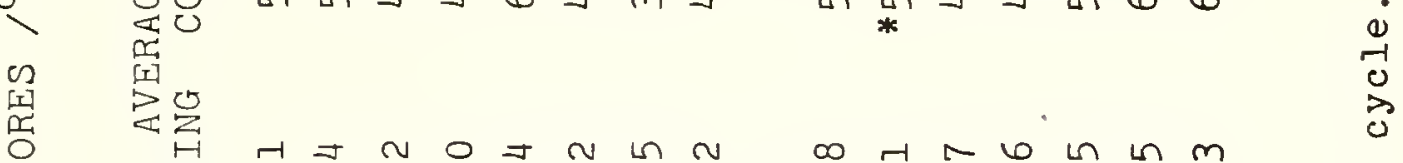

U E

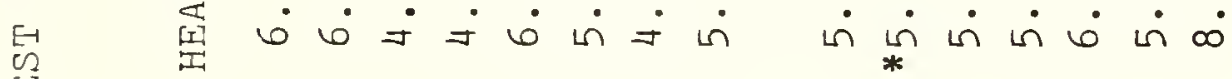

0
0
0
0
0
0
0
0
0
0
0

II

还足

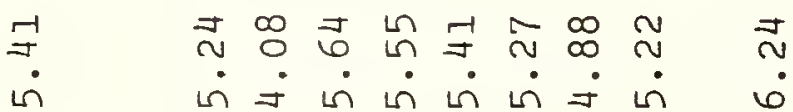

ธิ

焉

D-1

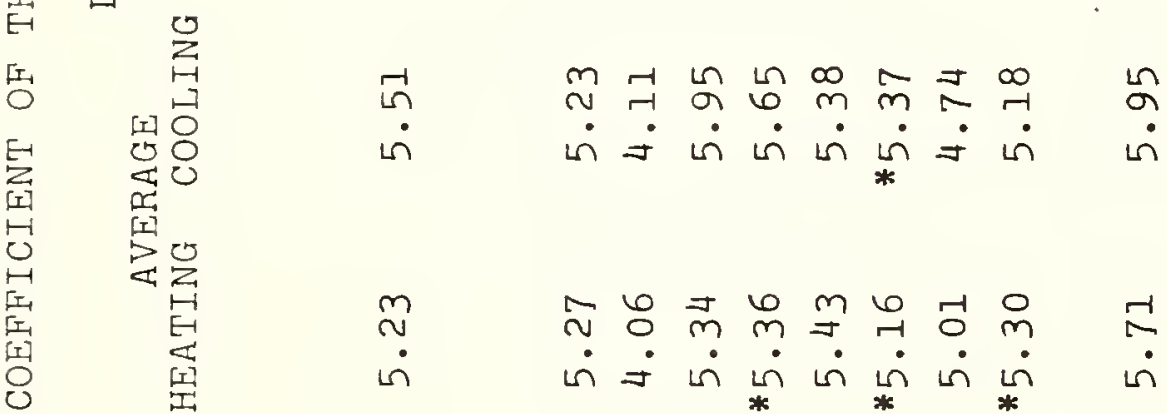

$\sum_{\text {II }}^{E-1}$

[I]

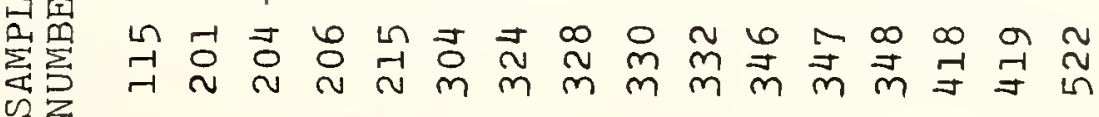


percent accuracy range previously discussed. The wet coefficients however show a difference between the heating and cooling cycles in excess of the 5 percent maximum error. The general trend is for the coefficlent calculated from the heating cycle to be larger than the coefficient calculated from the cooling cycle.

The variation in the wet coefficients can be explained in terms of hygrothermal shrinkage and swelling as defined by Powers (27) and Helmuth (20). When the temperature of a paste is increased the free energy of the water in capiliary pores decreases more than that of the water in the gel pores. This energy difference, caused by increasing the temperature, is eliminated by diffusion of gel water into the capillary pores. Removal of gel water causes a shrinkage. Decreasing the temperature causes a swelling by diffusion of capillary water into the gel pores.

This hygrothermal effect was shown to be time dependent. When the temperature change takes place slowly a state of equilibrium is maintained in the transfer of capillary and gel water and the hygrothermal effect is eliminated. Increased rates of temperature change induce a lag in the transfer of water and cause a portion of the total length change to be time dependent. Given sufficient time at constant temperature this portion of the length change is eliminated. Since insufficient time was allowed for equilibrium in the testing procedure the effect of 
hygrothermal shrinkage and swelling was compounded in the apparent coefficient of thermal expansion. The end result would appear as an increase in the coefficient of thermal expansion for a positive temperature change and a decrease in the coeffictent of thermal expansion for a negative temperature change thus explaining the differences.

The data of Table 11 were statistically analyzed to evaluate the effect of coefficient of thermal expansion on blow-up distress. The analysis showed coefficlent of thermal expansion was not related to the blow-up distress of the pavements from which the test cores were obtalned.

\section{Mo1sture Expansion}

Concrete placed in the presence of molsture or air at a higher relative humidity will expand or swell. The maximum swelling is approximately two-thirds of the original shrinkage the concrete has undergone (30). For the usual range of concretes the irreversible part of the shrinkage represents between 0.3 and 0.6 of the drying shrinkage, the lower value being more common. The magnitude of swelling and shrinkage vary with the range of molsture or humidity and composition of the concrete. The irreversible portion can be explained in terms of increased bonding between solids and a collapsing of the gel structure.

Dimensional changes caused by changes in molsture content are often referred to as "mo1sture movement" but will be considered here as molsture expansion. The possibility 
of this dimensional change being highly related to the blowup mechanism is apparent when consideration is given to the moisture state that must exist for a blow-up to occur. The total magnitude of moisture expansion obviously could be an important factor. The rate at which moisture expansion can occur could also be significant. To examine these hypotheses, a test was devised to obtain molsture expansion data on selected test cores with known blow-up distress.

\section{Test Cores}

The technique was similar to that of the test for coefficient of thermal expansion except that temperature was held constant and moisture content was varied. Moisture expansion was monitored as a function of time. The test set-up was similar to the coefficlent of thermal expansion testing apparatus. Water was added to the test chamber after initial LVDT readings were recorded on the oven dried test cores. When the water level reached the base of the test sample the time was recorded. Temperatures were recorded from three thermocouples mounted in the water next to the test core. The initial temperature was recorded when the water reached the top of the test core. Data were taken at various time intervals over a period of at least twenty-four hours.

The moisture expansions occurring after twenty-four hours and forty-eight hours of submersion in water were selected for correlation with blow-up distress. These time 
periods were selected because blow-ups occur during periods of high precipitation when pavements molsture contents are already high.

The data were corrected for temperature varlation by using the "wet" coefficients of thermal expansions. The best fit power curve equation,

$$
y=a x^{b}
$$

where $\mathrm{y}$ is the moisture expansion in micro-strains, $\mathrm{x}$ is the time in hours and $\mathrm{a}$ and $\mathrm{b}$ are constants, was determined over the range of the twenty-four to forty-eight hour expansion data. The power curve equation was found to reliably describe the data. The regression coefficients and predicted moisture expansions of twenty-four hours and fortyeight hours are given in Table 12. The difference in these moisture expansions gives an indication of the amount of expansion which might occur per day after one day of saturation.

Stepwise regression was run on the wet coefficient of thermal expansion data and the moisture expansion data to determine the relation with blow-up distress. The most significant variable, explaining 32 percent of the variation, was the twenty-four hour moisture expansion. The second most significant variable was the "wet" coefficient of thermal expansion determined over a heating cycle. The $\mathrm{R}^{2}$ value for these two variables was 0.48 . The third most significant variable was the forty-eight hour moisture 
TABLE 12

MOISTURE EXPANSION OF TEST CORES

\begin{tabular}{|c|c|c|c|c|c|}
\hline TEST & REGRESSION & COEFFICIENTS & $R^{2}$ & \multirow{2}{*}{\multicolumn{2}{|c|}{$\begin{array}{c}\text { MOISTURE EXPANSION } \\
\begin{array}{c}\mathrm{y}=a \mathrm{x}^{\mathrm{b}} \\
\text { MICRO-STRAINS }\end{array}\end{array}$}} \\
\hline CORE & $\mathrm{a}$ & $\mathrm{b}$ & & & \\
\hline & & & & $x=24$ hrs. & $x=48$ hrs. \\
\hline 115 & 219.5 & 0.12 & 1.00 & 325.3 & 354.5 \\
\hline 201 & 199.6 & 0.21 & 0.98 & 394.4 & 457.5 \\
\hline 204 & 116.0 & 0.26 & 0.96 & 265.1 & 317.4 \\
\hline 206 & 98.4 & 0.23 & 1.00 & 203.6 & 238.5 \\
\hline 215 & 162.1 & 0.22 & 0.93 & 328.9 & 383.7 \\
\hline 304 & 74.7 & 0.31 & 0.96 & 199.2 & 246.7 \\
\hline 324 & 36.5 & 0.48 & 1.00 & 160.3 & 234.9 \\
\hline 328 & 94.8 & 0.16 & 0.99 & 155.3 & 172.9 \\
\hline 330 & 103.3 & 0.19 & 1.00 & 189.3 & 216.1 \\
\hline 332 & 72.4 & 0.23 & 0.99 & 148.2 & 173.2 \\
\hline 346 & 105.3 & 0.20 & 1.00 & 201.5 & 232.2 \\
\hline 347 & 127.6 & 0.19 & 0.98 & 236.8 & 270.9 \\
\hline 348 & 18.3 & 0.42 & 0.97 & 69.5 & 92.9 \\
\hline 418 & 428.1 & 0.03 & 1.00 & 469.9 & 479.5 \\
\hline 419 & 280.2 & 0.07 & 1.00 & 351.0 & 368.7 \\
\hline
\end{tabular}


expansion with a combined $\mathrm{R}^{2}$ value of 0.58 . The difference between the forty-elght hour and twenty-four hour moisture expansion and the coefficlent of thermal expansion based on the negative temperature change were not found to be significant. Analysis of variance of the data showed the twentyfour hour molsture expansion, wet coefficient of thermal expansion determined over a heating cycle, and forty-eight hour moisture expansion to be significantly related to a pavement's blow-up distress at the 0.05 level. 


\section{SUMMARY}

This research was conducted with two primary objectives, first to determine if overlaying a concrete pavement significantly influences blow-up performance, and second, to isolate those variables that affect blow-up distress.

The findings of this study are based upon the results of the field testing of a bare pavement and an overlayed pavement and the laboratory testing of pavement cores taken from various Indiana highway pavements.

The following summarize the findings of this report.

\section{Field Testing}

1. Moisture gauges were successfully developed and used to evaluate the moisture contents of a bare pavement and an overlayed pavement.

2. The overlayed pavement, for any given vertical position, always had a higher degree of saturation than that of the bare pavement.

3. The overlayed pavement holds moisture and did not dry out as readily as the bare pavement and therefore showed a smaller variation of degree of saturation with time. 
4. Vertical moisture gradients were always present in the overlayed pavement. In general the degree of saturation increased from the top to the bottom of the pavement. Except for the winter season the bare pavement had an approximately constant degree of saturation throughout its depth.

5. Both pavements surpassed the level of critical saturation for freezing and thawing damage during the test period. The overlayed pavement obtained this critical level during the winter months whereas the bare pavement did not obtain this level until late spring when freezing temperatures were no longer present.

6. Horizontal moisture gradients were a function of the season. Through late winter the overlayed pavement's average degree of saturation increased horizontally from its side to its middle at the rate of approximately 5 percent per foot. During the spring the average degrees of saturation of the pavement's side and middle were approximately equal and higher than the intermediate area between them. This horizontal moisture gradient was also about 5 percent per foot.

7. The time required for a significant change in the moisture state of the overlayed pavement was a function of precipitation. The overlayed pavement had a degree of saturation approximately 13 percent higher than the bare pavement to date.

8. The ball system was capable of measuring horizontal and vertical pavement deformations. 
9. The overall seasonal trend of deformation, based on the original lengths, was for the overlayed pavement to always show an expansion while the bare pavement tends to show a slight contraction. The maximum difference in deformation between the two pavements corresponded to a temperature change of about 10 degrees and occurred during the summer months when blow-ups are prevalent.

10. The average degree of saturation of the pavements and their deformations responded directly with extended dry periods and precipitation in excess of one inch.

11. Overlaying a pavement increased its degree of saturation and decreased its coefficient of thermal expansion.

12. The slope of the thermal coefficient of thermal expansion and degree of saturation curve over the normal range of moisture encountered in the field was about $-0.018 /{ }^{\circ} \mathrm{F} / \%$ degree of saturation.

\section{Laboratory Testing of Pavement Cores}

1. Laboratory equipment were devised to determine the coefficient of thermal expansion of test cores within an accuracy of 5 percent.

2. Analysis of variance showed a significant difference in the blow-up performance for the type of iurface the overlayed pavements showing the greater blow up occurrence 
3. Twenty-four hour moisture expansion, wet coefficient of thermal expansion and forty-eight hour expansion analyzed together were shown to be significantly related to a pavement's blow-up distress at the 0.05 level. It is interesting to note that coefficient of thermal expansion when analyzed alone was not significantly related to blow-up distress. This showed the complex interaction that must exist between temperature and moisture. Although such an interaction exists, regression analysis did not show a high correlation $\left(R^{2}=0.58\right)$.

4. Infiltration did not relate highly to blow-up distress, for the tested joint cores.

5. The "wet" coefficient of thermal expansion determined over a heating cycle were significantly larger than the coefficients of thermal expansion determined over a cooling cycle. 


\section{CONCLUSIONS}

The following conclusions seem reasonable and are based on the results of the field test pavement and the laboratory testing of test cores.

1. Overlaying a concrete pavement causes its degree of saturation to increase and a corresponding moisture expansion occurs.

2. An overlayed concrete pavement becomes critically saturated with respect to freezing and thawing durability during the winter season.

3. Seasonal variation of moisture content is reduced by overlaying a concrete pavement.

4. Vertical moisture gradients always exist in the overlayed pavement. In general the degree of saturation increases from the top to the bottom of the pavement. Except for the winter season the bare pavement shows an approximately constant degree of saturation throughout its deptin.

5. The coefficient of thermal expansion is reduced slightly, but probably not significantly, by overlaying a concrete pavement. 
6. The blow-up distress of an overlayed pavement is significantly greater than the blow-up distress of a bare pavement.

7. Blow-up distress is related to moisture expansion and coefficient of thermal expansion by some complex interaction.

8. Infiltration commoniy found in pavement joints consists of sand particles on the top and fine grained soll particles on the bottom held in place by asphalt sealants.

9. Infiltration cannot be demonstrated to be signif1cantly related to blow-up distress. 


\section{CONCLUDING COMMENTARY}

Blow-ups in bituminous overlaid rigid pavements were found to increase with the age of the pavements. Several reasons for this have been previously elaborated upon but little has been said concerning ways of alleviating the problem.

Obviously forces develop within the pavement causing the pavement to fault or crush. The latter is more probable in older pavements which includes most overlays. The result is a hump but it is generally not nearly as abrupt as that caused in newer pavements by faulting or even fracturing (crushing) of quality concrete.

When crushing, (fracturing) occurs the bulk volume of the concrete increases and horizontal stress relief is accomplished by further displacement of the material. The result is the formation of a hump beneath a pavement. This could occur slowly over a period of months or years. If the volume of crushed material is small the height of the bump may be larger as well as more abrupt because all of the horizontal relief is accommodated within the relative small distance of the blow-up. If a larger area were broken the height and abruptness of the bump would presumably be less.

It follows then that relief regions could be provided. This is done in many instances by removing portions of the pavement and replacing with bituminous material. An alternative 
which would perhaps insure better continuity in the pavement, especially if it is a reinforced pavement would be to break up, but leave in place, portions of the rigid pavement in transverse section across the pavements. Resurfacing or patching would then cover the section.

To the knowledge of the principal investigators, this approach has not been intentionally done on a pavement. It is suggested that when blow-ups are occurring beneath an overlay, or when the bare concrete pavement shows evidence of concrete deterioration adjacent to joints or transverse cracks, the following be tried on an experimental basis:

By means of mechanical hammer break up concrete for at least three feet on each side of the joint or crack, resulting in a broken pavement section at least six feet in length. The break up should be most severe in the center of the six feet section. All material should be left in place. Patching or resurfacing should then be done to restore a smooth surface.

Such sections should be located at a frequency depending upon judgement of the severity of the pavement deterioration or possible future deterioration. For an old deteriorated pavement the spacing might be every 40 feet, while in a relative new pavement, 100 feet or more might suffice. 
LIST OF REFERENCES 


\section{LIST OF REFERENCES}

1. "Repair of Concrete Blowups in Delaware", Engineering News-Record V. 95, V. II, p. 432, September 1925.

2. Woods, K. B., Sweet, H. S., and Shelburne, T. E., "Pavement Blowups Correlated with Source of Coarse Aggregate", Proceedings, Highway Research Board, Vol. 25, 1945.

3. Graham, M. D., Chamberlin, W. P., "Summary of 1966 Rigid Pavement Blowup Survey", Unpublished Report, Engineering Research and Development Bureau, New York State Department of Transportation.

4. Hensley, M. J., "The Study of Pavement Blowups", Research Project 10, Arkansas State Higliway Department, January, 1966.

5. Illinois Division of Highways, "A Study of Blowups in Rigid Pavements in Illinois", Research and Development Report 18.

6. Stott, J.P. and Brook, K. M., "Report of a Visit to U. S. A. to Study Blowups in Concrete Roads", RRL Report LR 128, British Ministry of Transport, 1968.

3. Moyer, R. A., "An Eleven-year Study of the Expansion and Contraction of a Section of Concrete Pavement", Proceedings, Highway Research Boara, Vol. 25, p. 7i, 1945.

8. Regel, F. V. and Gotham, "Field Observation on Effects of Joints on Cracking and Other Deterioration in Concrete Pavements", Proceedings, Highway Research Board, Vol. 21, p. 179, 1941.

9. Spancler, M. G., "Stresscs; in the Corner Region of Concrete Pavements", Iowa Engineering Experiment Station Bulletin 157, 1942.

10. Foxworthy, P. T., "Statewide Survey of Blow-ups in Resurfaced. Concrete Pavements", Master Thesis, Purdue University, May, 1973. (Also Interim Report, JHRP-73-3, February 1973). 
11. Lu, N. Y., "Comparison of the Thermal and Moisture Expansion of Concrete", Master Thesis, Purdue University, February, 1948.

12. Meyers, S. L., "Thermal Expansion Characteristics of Hardened Cement Paste and of Concrete", Proceedings, Highway Research Board, Vol. 30, pp. 193-203, 1950.

13. Mitchell, L. J., "Thermal Expansion Tests on Aggregate, Neat Cements and Concretes", Proceedings, American Society of Testing and Materials, Vol. 53, p. 963, 1950 .

14. Teller, L. W., and Sutherland, E. C., "Observed Effects of Variations in Temperature and Moisture on the Size, Shape, and Stress Resistance of Concrete Pavement Slabs", Public Roads, Vol. 16, No. 9, November, 1935.

15. Hatt, W. K., "The Effect of Moisture on Concrete", Transactions, American Society of Civil Engineers, 89:270, 1926.

16. Scholer, C. H., "Factors Affecting Volume Changes in Concrete and Their Significance in Desigin", Proceedings, Highway Research Board, Vol. 11, pp. 240-261, 1932.

17. Myers, B., "Volume Changes in Concrete Slabs in the Field", Proceedings, Highway Research Board, Vol. II, 1932, pp. 262-270.

18. Davis, R. E., "A Summary of Investigations of Volume Changes in Cements Mortars and Concretes Produced by Causes other than Stress", Proceedings, American Society of Testing Materials, 668-85, 1930.

19. Dawley, E. R., "Volume Changes of an Early-Strength Concrete", Proceedings, American Society of Testing and Materials, Vol. 32, p. 642, 1932.

20. Helmuth, R. A., "Dimensional Changes of Hardened Portland Cement Pastes Caused by Temperature Changes", Proceedings, Highway Research Board, Vol. 40, 315-336, 1961.

21. Gordinier, D. E. and Chamberlin, W. P., "Pressure Relief Joints for Rigid Pavements", Research Report 68-12, Engineering Research and Development Bureau, New York State Department of Transportation.

22. Lewis, D. W., "The Performance of Concrete Resurfacing in Indiana", Proceedings, Highway Research Board, Vol. 50, December, 1950 . 
23. Gotham, D. E. and Lord, G. W., "Concrete Resurfacing of Concrete Pavement in Various Stages of Deterioration", Bulletin No: 87, Highway Research Board, 1954.

24. Ballard, L. F., "Instrumentation for Moisture Measurement", NCHRP Project 21-1, July, 1971.

25. Lentz, A. E. and Monfore, G. E.", Thermal Conductivity of Concrete at Very Low Temperatures", Bulletin No. 182, Research and Development Laboratories of the Portland Cement Association, May, 1965.

26. Klieger, P., Monfore, G., Stark, D., and Feske, W., "D-Cracking of Concrete Pavements in Ohio", Portland Cement Association, October, 1974.

27. Powers, T. C., "The Physical Structure and Engineering Properties of Concrete", Bulletin No. 90, Research and Development Laboratories of the Portland Cement Association, July, 1958.

28. Powers, T. C. and Brownyard, T. L., "Studies of the Physical Properties of Hardened Portland Cement Paste", Bulletin No. 22, Research and Development Laboratorles of the Portiand Cement Association, March, 1948.

29. American Society of Testing Materials Standard Specifications C457, 1967.

30. Neville, A. M., Properties of Concrete, John Wiley and Sons, Second Edition, 1973.

31. Kingery, W. D., Introduction to Ceramics, Wiley. 


\section{NOTICE}

The following Appendices listed in the Table of Contents of this Report have not been included in this copy of the Report.

Appendix No.

A

B

C

D

E

$\mathbf{F}$

G
Title

Field Testing Error of Measurement

Molsture Gauge Design

Molsture Probe Calfbration Data and Regression Analysis

Field Data

Cherry Lane Moisture Data

Dafly Precipitation

Test Core Information
Pages

$128-139$

$140-153$

$154-159$

$160-166$

$167-173$

$174-176$

$177-181$

A recipient of the Report may secure a copy of the Appendix or Appendices desired upon request to:

Joint Highway Research Project

Civil Engineering Building

Purdue University

W. Lafayette, Indfana 47907 

